Paulo Yun Cha

An integrated quantitative framework propose for sustainability assessment in geographical indication production systems

São Paulo

2020 
Prof. Dr. Vahan Agopyan

Reitor da Universidade de São Paulo

Prof. Dr. Fábio Frezatti

Diretor da Faculdade de Economia, Administração e Contabilidade

Prof. Dr. Moacir de Miranda Oliveira Junior

Chefe do Departamento de Administração

Prof. Dr. Eduardo Kazuo Kayo

Coordenador do Programa de Pós-Graduação em Administração 

Paulo Yun Cha

\section{An integrated quantitative framework propose for sustainability assessment in geographical indication production systems}

Tese apresentada ao Programa de PósGraduação em Administração do Departamento de Administração da Faculdade de Economia, Administração e Contabilidade da Universidade de São Paulo, como requisito parcial para a obtenção do título de Doutor em Ciências

Orientador:Prof.a Dr Adriana Marotti de Mello

Versão Corrigida

São Paulo

2020 

Autorizo a reprodução e divulgação total ou parcial deste trabalho, por qualquer meio convencional ou eletrônico, para fins de estudo e pesquisa, desde que citada a fonte.

\section{CATALOGAÇÃO NA PUBLICAÇÃO}

Universidade de São Paulo, Faculdade de Economia e Administração

Cha,Paulo Yun

An integrated quantitative framework propose for sustainability assessment in geographical indication production systems/ Paulo Yun Cha. - São Paulo - Brazil, 2020-

136 p. : il. (algumas color.) ; $30 \mathrm{~cm}$.

Orientador: Prof Dra Adriana Marotti de Mello

Tese (Doutorado) - Universidade de São Paulo - USP

Faculdade de Economia e Administração - Fea

Programa de Pós-Graduação em Administração. Versão original

1. Sustainability 2. Multi-objective 3. Data envelopment 4. Evolutionary Algorithm 5. Canastra Cheese I. Moretti, Adriana

CDD 22.ed.-338.52 
Para minha querida avó Kim Sa-Nyo 


\section{Agradecimentos}

Tenho muitos agradecimentos a serem feitos nessa longa jornada que passei. Primeiramente, a minha orientadora, Professora Adriana Marotti, pelo seu apoio total, orientação, palavras de estímulo(inúmeras) e disponibilidade em trabalharmos juntos. Eternamente grato pela sua compreensão e igualmente inúmeras puxadas de orelha. Ao professor Biaggio pelo seu grande acolhimento, palavras de sabedoria e ensinamento igualmente.

Aos meus pais, Sung Ki Cha e Hae Suk Cha Yun, que sempre me apoiaram nessa empreitada intelectual, emocional e física. São dois heróis que sempre me espelho. Para minhas irmãs Fabiana e Catarina Yun Cha por serem sempre companheiras e transmitirem otimismo mesmo nas situações mais difíceis. Para Ana Beatriz, minha companheira que enfrentou situação similar com a defesa da tese, e sempre me apoiou na mesma direção incondicionalmente.

Preciso agradecer também para todos os responsáveis que me ajudaram na coleta de dados em São Roque de Minas, Minas Gerais. Especialmente pelo zelo dado pelos profissionais da Aprocan, especialmente ao Higor - nosso guia 24/7 que nos conduziu por todos os cantos da Canastra e fez a ponte direta entre mim e os produtores. Todos os produtores com que tive contato me ensinaram grandes lições e espero retribuir com os resultados desse trabalho, ao menos um pouco. Por fim, agradeço a todas as amizades que fiz na pós-graduação, professores e professoras que me inspiraram a tentar ser uma pessoa melhor e ao corpo administrativo da faculdade que sempre prestou um exemplar serviço com total solicitude e esmero. 

"Nothing in life is to be feared, it is only to be understood. Now is the time to understand more, so that we may fear less.

(Marie Curie) 



\section{List of figures}

Figura 1 - Canastra Valley Region Map (CRUZ; HESPANHOL et al., 2018) . . 36

Figura 2 - 5Sensu conceptual framework (GIANNETTI et al., 2019) . . . . . . . 37

Figura 3 - Network of countries ...................... 51

Figura 4 - Network of institutes . . . . . . . . . . . . . 52

Figura $5-$ Network of keywords . . . . . . . . . . . . . 53

Figura 6 - Optimization Curve Frontier . . . . . . . . . . . . . 69

Figura 7 - Histogram of the variables . . . . . . . . . . . . . 81

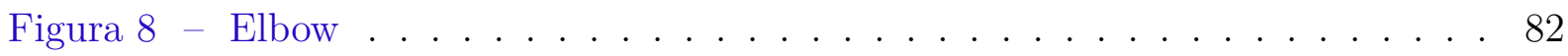

Figura 9 - Silhouete . . . . . . . . . . . . . . 83

Figura 10 -Variance explained by the PCA . . . . . . . . . . . . . . . 84

Figura 11 -K-means representation . . . . . . . . . . . . . . . 84

Figura 12 -Histogram of the variables . . . . . . . . . . . . . . 97

Figura 13 -Pareto optimum demonstration using 2 objective functions . . . . . . . 99 



\section{List of tables}

Tabela 1 - Variable selection . . . . . . . . . . . . . . . . . 39

Tabela 2 - Emergy literature performance . . . . . . . . . . . . . 48

Tabela 3 - Top 5 subject categories . . . . . . . . . . . . . . . . 49

Tabela 4 - Top 15 journals . . . . . . . . . . . . . . . . . . 49

Tabela 5 - Top 10 countries . . . . . . . . . . . . . 50

Tabela 6 - Top 10 institutes and universities . . . . . . . . . . . . . 51

Tabela 7 - Keyword frequency table . . . . . . . . . . . . . . . 52

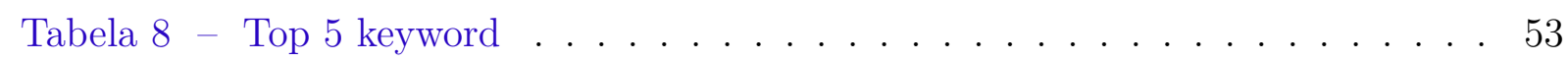

Tabela $9-$ Technologies levels . . . . . . . . . . . . . . 63

Tabela 10 -Technologies levels . . . . . . . . . . . . . . 67

Tabela 11 -Matrix of inputation values . . . . . . . . . . . . . 68

Tabela 12 -Sustainability level and machinery level for the producers . . . . . . 68

Tabela 13 -Summary table of the variables . . . . . . . . . . . . . . 81

Tabela 14 -Number of farms included in each of the 3 main groupings defined by cluster analysis . . . . . . . . . . . . . . . . . 82

Tabela 15 -Data envelopment analysis summary . . . . . . . . . . . 85

Tabela 16 -Summary table of the variables . . . . . . . . . . . . . . 97

Tabela 17 -The set of optimized solutions . . . . . . . . . . . . . . . 99 



\section{Summary}

1 General introduction $\ldots \ldots \ldots \ldots \ldots \ldots$

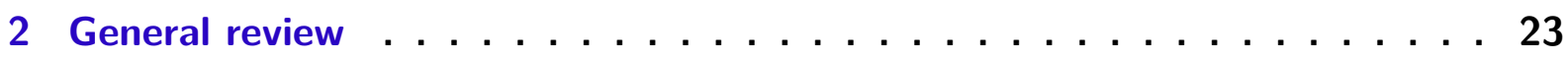

2.1 Sustainability assessment . . . . . . . . . . . . . . . . . . 23

2.1.1 limitations of the present status of the studies . . . . . . . 27

2.2 Geographical Indication $\ldots \ldots \ldots \ldots \ldots \ldots$

2.2 .1 Food and Place . . . . . . . . . . . . . . . . . 27

2.2.2 Degrees of Origin and Authenticity: Terroir from Countries to Specific Regions . . . . . . . . . . . . . . . . . . 28

2.2.3 The Fundamental Dimensions of Terroir _ . . . . . . . . . . . . 29

2.2.4 Consumer Perception of Terroir Products . . . . . . . . . . . . 30

2.2 .5 Terroir Products in Brazil . . . . . . . . . . . . . . . . . 30

2.2.6 Artisanal cheese as Terroir Products in Brazil . . . . . . . . . . . 32

3 General method . . . . . . . . . . . . . . . . . 35

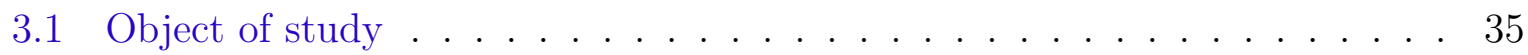

3.2 Theoretical framework . . . . . . . . . . . . . . . . . 37

3.2.0.1 Theoretical framework for integrated sustainability assessment and variable selection . . . . . . . . . . . . 37

3.3 Establishing indicators, goals and weight values to feed the 5 sensu . . . . . 38

3.3.0.1 Sector 1 - environment as a donor . . . . . . . . . . . 39

3.3.0.2 Sector 2 - environment as a receiver . . . . . . . . . . 39

3.3.0.3 Sector 3 - production unit . . . . . . . . . . . . 40

3.3.0.4 Sector 4 - society as provider . . . . . . . . . . 40

3.3.0.5 Sector 5 - society as receiver . . . . . . . . . . . . 40

3.4 Functional Unit . . . . . . . . . . . . . . . . . . . . . . . . . . . 41

3.5 Data collection process . . . . . . . . . . . . . . . 41

4 A bibliometric study of Emergy . . . . . . . . . . . . . . . . 43

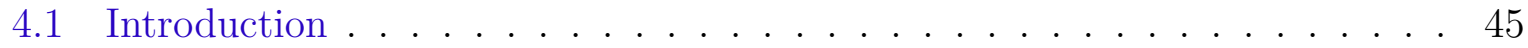

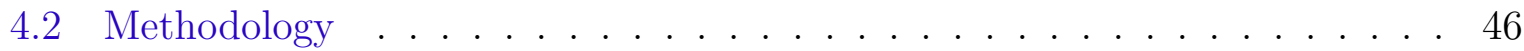

4.2.1 Network theory and bibliometric analysis . . . . . . . . . 46

4.2 .2 Data sample and tools . . . . . . . . . . . . . . . 47

4.3 Results . . . . . . . . . . . . . . . . . . . . . . . . . 47

4.3.0.1 General trend of the field . . . . . . . . . . . . 47

4.3.0.2 Distribution of subject categories and journals . . . . . . 48 
4.3.0.3 Contribution of Countries and Institutions . . . . . . . . 50

4.3.0.4 Main research fields . . . . . . . . . . . . . . . . 52

4.4 Conclusion . . . . . . . . . . . . . . . . . . . . . . 54

5 Sustainability assessment propose in a micro farm level perspective for geographical indication regions ................. 57

5.1 Introduction . . . . . . . . . . . . . . . . . . . 59

5.2 Methodology .......................... 62

5.2.0.1 Theoretical framework for technology adoption assessment 62

5.2.0.2 Data envelopment analysis - a multi-criteria algorithm for relative optimization . . . . . . . . . . . 63

5.2 .1 Functional Unit . . . . . . . . . . . . . . . . . . . 65

5.3 Results . . . . . . . . . . . . . . . . . . . 66

5.3 .1 Assessing technification level . . . . . . . . . . . 66

5.3.2 Performance on sustainability for the Canastra producers: intervals, hierarchy and policy implications . . . . . . . . . . . . 67

5.4 Conclusion . . . . . . . . . . . . . . . . . . . 70

6 Sustainability assessment in a macro farm level perspective in geographical indication regions . . . . . . . . . . . . . . . . . . 73

6.1 Introduction . . . . . . . . . . . . . . . . . . . 75

6.2 Materials and Methods . . . . . . . . . . . . . . . 77

6.2.1 Grouping farms in clusters . . . . . . . . . . . . . . 77

6.2.2 Assessing sustainability of each cluster . . . . . . . . . . . . . . 79

6.3 Results . . . . . . . . . . . . . . . . . . . . . 80

6.3 .1 Descriptive statistical analysis . . . . . . . . . . . . 80

6.3.2 Definition of the farms grouping . . . . . . . . . . . . . . . . 82

6.3.3 Assessing sustainability of the formed groups . . . . . . . . . . . . . 84

6.4 Conclusion . . . . . . . . . . . . . . . . . . . . 87

7 Sustainability assessment in a micro farm level perspective using genetic algorithm for global optimization in a geographical indication regions . . . . 89

7.1 Introduction . . . . . . . . . . . . . . . . . . . . . . . . . 91

7.2 Materials and Methods . . . . . . . . . . . . . . . . . . . . 93

7.2.1 Multi-objective genetic algorithm . . . . . . . . . . . . . 93

7.3 Results . . . . . . . . . . . . . . . . . . . 96

7.3.1 Descriptive statistical analysis . . . . . . . . . . . . 96

7.3.2 Optimization results using MOGA . . . . . . . . . . . . 98

7.4 Conclusion . . . . . . . . . . . . . . . . . . . . 102

8 General conclusions . . . . . . . . . . . . . . . . . . . . . 105 


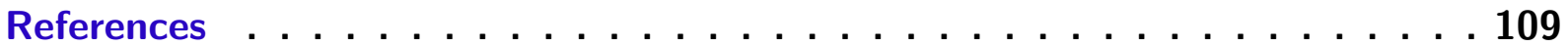





\section{Abstract}

This research aims to propose a comprehensive sustainability quantitative evaluation method capable of dealing within a vast range of dimensions at the same time in geographical indication(GI) production systems.

While past studies taken account sociological or environmental aspects, setting aside economic content, the present study takes account production efficiency and profitability, an elementary condition for regional development. The previous work struggled even, by turning such evaluations into actionable information in a micro and macro context of production units, and to tackle the difficult tasks of disseminating findings outside the scientific community.

In order to deal with these problems, four papers were written aimed at bringing different viewpoints into the discipline.

The first study categorized emergy as a solid conceptual framework for sustainability assessment and because of its technical robustness, it developed studies for determining sustainability in several sectors abroad. Some scholars, however, point out that it is difficult to disseminate findings outside the scientific community and convert such analyses into actionable information from the micro and macro viewpoint of the producers and decision makers.

The second study major finding was that technology adoption is an important driving factor to elevate GI producers competitiveness. The best ranked producers among the studied set were surprisingly the highest technified and the lowest technified producer, where the the second one is highly leveraged out in intangible assets such as public awareness of his roots, tradition and society contribution. Everything materialized in large revenue by per kilo. However, when taking off social variables of the assessment model, this producer ranks in the lowest rank by considering only economic and environmental efficiency and not taking account social variable such as tradition and owner's age, crucial for a long term sustainability development of Gi's.

The investigation of the third study has shown that the clustering process indicated a high homogeneity of the farms within the three clusters. The main differences between the clusters were the tradition, whey produced, total cheese output, gross revenue and paid tax. These variables have a strong impact in the design of farm level strategies, affecting directly the choice of the farms inputs in terms of an integrated and broad concept of long term sustainability. The ability to handle similar herd and maximize production was shown to be related to labour and mechanization. Different farm types in each cluster utilized the same proportions of the available land to cultivate vegetable crops and husbandry.

The investigation of the third study has shown a macro perspective of sustainability assessment through clustering process of the production units. The results indicated a high homogeneity of the farms within the three clusters. Different farm types in each formed cluster can be benefited by adequate strategies of development and assessment.

Lastly, the fourth study through multi-objective genetic algorithm optimization expose a high potential and feasible interval for improvement. In general, the average output of environment discharge is kept lower than the average of the region. Information asymmetry reduction through digital channels communication, produc- 
tion efficiency increment and addition of value by service disposition are emerged general strategies provided by the genetic algorithm model.

Finally, the study certainly adds to our understanding of the sustainability assessment in GI's by providing a robust quantitative framework for assessment, classification and communication of the results much abroad to the academy space, leading to easy communication for managers to achieve better sustainability by changing impactful leverages such as technification, maintenance of clusters proportions or following competitive strategies for each farm.

Key-words: sustainability, data envelopment, multi-criteria, evolutionary algorithm, Canastra Cheese 


\section{General introduction}

This study aims to contribute to this growing area of research of sustainability assessment in geographical indication (GI) regions. The importance and originality of this study are that it explores a holistic approach of GI aiming long-term sustainability while understanding of micro, macro and global perspective and helping managers to achieve better results through assertive interpretation of the results. The findings should make an important contribution to the field of sustainability assessment and to the object of study by itself, helping other prospective labels achieve better results. This thesis was conceived during my time working for Sebrae. Sebrae is a federal agency for small and medium-sized enterprises(MELO et al., 2008). As an extensionist and researcher, i witnessed artisan cheese producers routine located in GI regions and selected it as object of study in order to contribute to this relevant and crescent sector.

Shortly, geographical indication is a label designed to products, primarily rural products, which conform to a delimited geographical location (ALLAIRE; CASABIANCA; THÉVENOD-MOTTET, 2011). GI's have emerged as powerful platforms for regional development in rural areas(BRAMLEY, 2011). Thus, the concepts of assessment of GI's sustainability are central to achieve a durable and robust cycle of development.

Traditionally, GI subject have subscribed to the belief that was exclusive matter of developed countries such as France and Italy (BRAMLEY; BIENABE, 2012). More recently, a dozen of developing countries have made a continuous effort towards consolidation of GI policy strategies(COOMBE; IVES; HUIZENGA, 2014).

In recent years, there has been an considerable increasing of interest in GI's affairs due to several trends(GROTE, 2009). For instance, China is the fifth biggest purchaser of certified french wine from GI regions in the world for a number of decades, thanks for a middle class in rapid expansion. A market segment which already operates tens of billions of dollars yearly(XIAOBING; KIREEVA, 2007).

As explained earlier, GI is a growing public policy concern extending worldwide(BELLETTI; MARESCOTTI; TOUZARD, 2017). Several countries have established federal agencies and dedicated secretaries committed to development of GI regions as highly strategic (WILKINSON; CERDAN; DORIGON, 2017; RAMOS et al., 2012). Existing research recognizes the critical role played by sustainability assessment in GI food production systems long term development(BRUNORI et al., 2016).

According to Barjolle, Paus e Perret (2009), prior to the 21th century, a large portion of the GI market was self-contained in Europe and North America, transportation of those goods could require months in the coming calendar and appetite of the market 
were steady. Those rural cities strives due to the positive rate of fertility, large subsidized agriculture credit lines, profit growth of the resident companies and an quasi-monopoly positions in the GI market. Past studies reflected the GI's sustainability guidelines of that moment. Those studies of sustainability highlighted the importance of production efficiency and environment discharge reduction practices of the daily basis operation(MARIEVIVIEN; BIÉNABE, 2017).

Notwithstanding this, the present scenario have rapidly evolved from it. To list a few them: the leveraging private investment around the world in GI's (i.e: Chinese capital investing in french wineries and Brazilian cheese making areas)(BUCKLEY et al., 2010), rapid and cheap transportation system able to deliver goods in just a short time (i.e: Wagyu beef been transported everyday to the United States, resulting in vertiginous price increase in rural lands)(AUGUSTIN-JEAN; SEKINE, 2012), easy access to information, growth of a voracious and huge middle class (LOUREIRO; MCCLUSKEY, 2000) and an increasingly concerned and engaged part of the society with child labour, slavery, fair and just working conditions to small producers(SCHRAGE; EWING, 2005; BERLAN, 2013; MORRIS; EVANS, 2001); have challenged policy makers, managers and academics to give a proper and accountable method of sustainability analysis in GI's.

The Food and Agriculture Organization of the United Nations add to that claiming that one of the main obstacles reported in GI sustainability is to convey not only production efficiency and economic gain, but consider simultaneously an environmental perspective and social benefit as well(ACKER, 1999; CROWDER et al., 1998; PEREIRA, 2017).

Indeed, most studies in the field have only focused on economic gain or efficiency frontier maximization(MOSCHINI; MENAPACE; PICK, 2008). Such expositions are unsatisfactory due to the cited challenges. The potential outcome of those guidelines are several in the long run. Several studies have presented several cases concerning that such as loss of identity(FERRARI, 2014), reduction of local biodiversity(GARCIA et al., 2007), standardization of taste, massive bankruptcy of small producers and customer perception of illegitimacy around the world (BOWEN, 2010). Up to now, far too little attention has been paid to GI's sustainability studies which considers multiple-criteria concurrently (HÁK; JANOUŠKOVÁ; MOLDAN, 2016).

A search of the literature of multiple-criteria decision analysis revealed a vast tradition in engineering and operation research (ODU; CHARLES-OWABA, 2013). While engineering and operation research are frequently subjects where multiple-criteria optimization functions results have reported several improvements, so far, very little attention has been paid to the role of multiple-criteria in GI's sustainability assessment (WOODHOUSE; HOWLETT; RIGBY, 2000; DIAZ-BALTEIRO; GONZÁLEZ-PACHÓN; ROMERO, 2017). 
Moreover, very little attention has been paid to the role of micro-macro perspective in the studies of GI sustainability assessment(TREGEAR; GIRAUD et al., 2011). Despite the importance of critical mass of producers to legally sustain a competitive GI label, much of the research up to now has been limited in small samples. This characteristic is a major source of uncertainty in the previous published studies. With a small sample size, caution must be applied, as the findings might not be able infer and support strategic decisionmaking and management of the production system. In general, those studies consider only a micro farm-level perspective, putting aside macro perspectives directly related to GI's regional development.

This thesis examines the emerging role of sustainability assessment in GI's in the context of multiple criteria perspective, aiming to provide a robust quantitative framework for sustainability assessment able to delivery actionable insights in the micro, macro and global perspective. Those results may enable to guide managers and decision makers to improve sustainability in a series of gradual efforts.

Turning now to the overall structure of the thesis, it takes the form of general review, general method and 4 articles. The general review forms a review of the sustainable assessment and geographical indication literature. The general method comprises the main components of the methodology shared commonly by 3 articles presented in this series of works. Regarding the articles, the first paper is a literature bibliometric of the concept of Emergy, reporting most recent trends of the framework and the reasons of been postponed in this thesis. The last three studies use a holistic approach, by integrating a theoretical framework for sustainability assessment named 5sensu instead of Emergy, quantitative methods for optimization and/or classification and data visualization. The data collection which is the main input to the quantitative tools was conducted is a mixed methodology based on the form of a survey, with data being gathered via third parties and personal interview. Therefore, the second paper examines the relationship of technification level and sustainability in a study case using a micro perspective of farm level which the owner can manage. The third paper examines the clustering according to their attributes and using those clusters, we analyze each cluster sustainability on the macro perspective which the public policy manager can observe. The last paper output a set of optimized not existent producers using multi genetic algorithms in order to create global optimums as guideline to the farmers.

Finally, the general conclusion wrap up all the study restating the aims of the study, summarizing main research findings, recognizing the limitations of the study and making recommendations for further research work. 



\section{General review}

\subsection{Sustainability assessment}

Sustainable development concept has been assimilated into many degrees of society and evolved over time (DIXON; FALLON, 1989; PURVIS; MAO; ROBINSON, 2019). Early presentation of the term is in the World Charter for Nature (WOOD, 1985). This first definition is provided by the Brundtland Commission, summarizing sustainability concept in the respective sentence: "to make development sustainable - to ensure that it meets the needs of the present without compromising the ability of future generations to meet their own needs" (BURTON, 1987). Those initial concepts opposes Stockholm Commission guidelines for development which set apart environment and society developmentment spheres (MITCHAM, 1995).

Those initial guidelines were elaborated in 40 Chapters of Agenda 21 of the Earth Summit in 1992, Rio de Janeiro (QUARRIE, 1992). Further, The United States National Research Council (COUNCIL et al., 1999) postulate that there are three fundamental components of sustainable development, (1) what is to be supported or sustained, (2) what is to be advanced or developed and (3) the temporal component or inter generational.

Three areas to be supported are determine: environment, life-support systems and culture. In addition, the group brings three parts to be supported: people or individual, society or community and economy. Finally, the inter generational or temporal component as the scale of time needs to be expressed explicitly and relevant to humanity.

Kasemir et al. (1999) describe this research area as a combination of different fields of science in order to better comprehend the complex dynamic interactions between environmental, social and economic topics.

Though all over the literature the 'three pillars' have become ubiquitous, they are not prevalent. Some works consider additional components such as institutional (SPANGENBERG, 2011), cultural (SOINI; BIRKELAND, 2014), and technical (KAATZ et al., 2006). Other frameworks completely bypass sustainable silos. For instance, Milbrath (2002) provides a vision of a 'sustainable society' based on a collection of universal values, and the conceptualization of Giddings, Hopwood e O'brien (2002) when incorporating equity and wealth distribution concepts (GIDDINGS; HOPWOOD; O'BRIEN, 2002).

Nonetheless, priorities and targets have to be set for sustainable development (CLARK; DICKSON, 2003). For example, the UN-developed sustainable development goals have evolved a 'integrated' approach, adopting 17 broad objectives over a smaller number of categorizations (SACHS, 2012). 
This has provided the scientific community with major challenges in the provision of appropriate yet reliable tools and frameworks (ROBERT; PARRIS; LEISEROWITZ, 2005). Sustainability assessment has become a rapidly developing area as an answer to these challenges (MEADOWCROFT, 2007; JANSEN, 2003).

EU Sustainability Impact Assessment argue that the aim of the Sustainability Assessment is to provide decision-makers with short and long-term scenarios (CLAEYS, 2007), global evaluation of local interconnected environment (BALLABRIGA; MARTINEZMONGAY et al., 2005), decision making support processes to help them decide what measures should or should not be taken in an attempt to sustainable society (AKADIRI et al., 2019).

According to Berke e Manta (1999), methods for sustainability evaluation can be used to predict and evaluate conditions and patterns, and provide early warning information to avoid or mitigate harm to the economy, society and climate (BERKE; CONROY, 2000). Eventually, devise plans and strategies and convey ideas for the community (HASSAN; LEE, 2015).

In the last few years, the number of instruments that say they can be used to determine sustainability has grown(CIEGIS; RAMANAUSKIENE; STARTIENE, 2009); all of the methods have been established concurrently, offering clearer guidance for implementation, data and case study experiences (ROBÈRT et al., 2002).

Earlier overviews of evaluation methods / tools / indicators showed that approaches can be categorized according to numerous factors or dimensions (HURLEY; HORNE, 2006; REED et al., 2009; GLAVIČ; LUKMAN, 2007).

For instance, Sharifi e Murayama (2013) proposes a framework for tool categorization by breaking down over seven components as cited bellow:

1. Sustainability coverage: What are the main themes in the tools and how effective they are in the systematic and integrated assessment of neighborhood performance?

2. Inclusion of pre-requisites: What techniques exist to ensure that a certain degree of efficiency is achieved.

3. Adaptation to locality: The instruments in their assessments must took into account contextual background.

4. Scoring and weighting: What techniques are used by tools to measure and weigh different criteria and how robust and rigorous is this process?

5. Participation: What processes are used in the production and operational stages of the tools by the various stakeholders? 
6. Presentation of results: How the tools evaluate the results of the evaluation and to what degree they are useful as decision support systems?

7. Applicability: How realistic and practical are the methods and techniques that can be used to improve their applicability?

(GIDDINGS; HOPWOOD; O'BRIEN, 2002) developed a comprehensive framework able to categorize tools composed of 5 factors emphasizing equity in the interaction:

1. futurity-inter and generational equity;

2. social justice-intra-generational equity;

3. Beyond frontier responsibility for geographical and equity aspects;

4. procedural equity-people treated openly and fairly

5. inter-species equity-importance of biodiversity.

Lastly, Ness et al. (2007) developed a comprehensive Sustainability Assessment Framework system composed of:

1. Temporary component: the instrument measures historical growth (ex-post or descriptive), or if it is designed to forecast potential results (ex-ante or progressoriented) such as a regulatory transition or increase in the production method. Guinee et al. (2011), Guinée (2016), Finnveden et al. (2009). Life cycle assessment practitioners and researchers designed such aspect as attributory and consequential assessment. Attributional is defined by its focus on definition of specific physical motions and subsystems to and from a life cycle. In response to future decisions, consequential is described by its goal to explain how environmentally related flows will alter.

2. The focus (coverage areas), for example, if their focus is on the level of the product or the proposed policy change.

3. Convergence of processes in nature/society. For instance, the extent to which the mechanism fuses natural, social and/or economic facets.

From those frameworks, (NESS et al., 2007) elaborates three umbrellas or general categorization areas:

1. metrics and indexes further broken down into non-integrated and integrated indicators 
2. product-related measurement methods based on the content and/or energy flows of a product or service from a life-cycle perspective

3. integrated evaluation methods which is a set of resources typically focused on heterogeneity

The first umbrella of methods for sustainability evaluation is consisting of metrics and indices. Indicators are basic, most often quantitative, indicators that reflect a condition of economic, social, and/or environmental growth or recession in a given region often the national and regional level. The resultant calculation is an index, if the measures are aggregated in any way.

The main global assessment of countries' progress towards Sustainable Development Goals (SDGs) was underpinned by an indicator-based approach (BIERMANN; KANIE; KIM, 2017).The history materials presently contain 17 goals, 3169 goals and 303 indicators (FUKUDA-PARR, 2016).

The second umbrella consists of product-related instruments that concentrate on input and output flows in relation to products and services. Building on a similar flow perspective, they are closely linked with regional flow indicators (POFF et al., 2010). But the methods in this area concentrate on analyzing various flows in relation to specific goods or resources, rather than regions(JENNICHES, 2018).

They evaluate the utilization of energy and the environmental effects in the supply chain or over a product's life cycle (from cradle to grave)(ZAMAGNI; PESONEN; SWARR, 2013). The aims to recognize clear risks and inefficiencies to help decisionmaking are similar to the geographic flow metrics, but in this case relevant to product design and manufacturing processes (STERN; DIETZ, 2008; NILSSON; DALKMANN, 2001).

Integrated evaluation instruments are tools under the third umbrella; they are used to support policy or mission decisions in a specific area. Project-related instruments are used for reviews on a local basis, while policy-related resources rely on tests on a local and global scale (SARTORI; WITJES; CAMPOS, 2017). Integrated assessment methods have an ex-ante orientation in the field of sustainability assessment, and are frequently carried out in the form of scenarios(ALBERTÍ et al., 2017). Many of these standardized evaluation methods are focused on approaches to structure design that incorporate elements of nature and culture. Integrated evaluation consists of a broad variety of methods for coping with dynamic challenges (POPE et al., 2017; KENNY, 2018). 


\subsection{1 limitations of the present status of the studies}

There are drawbacks about certain instruments that can be incorporated into their particular dimensions of measurement, reflecting only a minority of strategies that exist today (NESS et al., 2007; KLÖPFFER, 2006; GUINÉE, 2016).

There is still a strong emphasis on environmental criteria, particularly among the product-related assessment tools, where the tools, with the exception of life cost cycle assessment, mostly neglect social and/or economic aspects(WEIDEMA, 2006). Even though tools have made a transition to more integrated approaches in some categories, these are not commonly used. Efforts have been made to expand the scope of research by integrating two or three separate methods (O'ROURKE, 2014).

Examples of this pattern are the simultaneous study of a product or service feature using Life Cycle Assessment, Life Cycle Costing and/or Social Life Cycle Assessment, Footprint Study and Emergy studies, which attempt to cope with product-related assessment and an integrated evaluation perspective (CHANG; LEE; CHEN, 2014; HELLWEG; CANALS, 2014; SALADINI et al., 2016; SICHE et al., 2010). A shortcoming of such approach is, therefore, that the study's overall results are not currently integrated (GUINÉE, 2002).

Morrison-Saunders e Therivel (2006), Hallstedt et al. (2010) assumed that attempts to combine integrative and product-related tools should be viewed as techniques and decision analysis methods rather than an integrated framework capable of managing multiple variables, but the modeling and selection of variables is arbitrary. Nevertheless, the same sustainability assessment reports that use integration-related evaluation have different interpretations from different academics and practitioners, indicating lack of testability and results reproducibility (GIANNETTI; ALMEIDA; BONILLA, 2010).

\subsection{Geographical Indication}

\subsubsection{Food and Place}

Food are often connected to places where they are of land-based and geographical origin, and over time food production and consumption patterns have been established in a place based on their natural resources and socio-cultural factors (TREGEAR et al., 2007). For this normal relationship between food and place, when evaluating the consistency of food goods, place comparisons can be used by customers as an acquired indicator (SIMS, 2009) and can distinguish the commodity both for its practical benefits and for brand identity (TRICHOPOULOU; SOUKARA; VASILOPOULOU, 2007; SIDALI; KASTENHOLZ; BIANCHI, 2015).

In today's market, many food enterprises use local partnerships to position the 
brand to stay competitive and to achieve a sustainable competitive edge (LIN; PEARSON; CAI, 2011). Food companies express this point of reference through names, official labels, unofficial markings, etc. Images in various ways: by means of a sticker, a stamp, a logo or some other plain and noticeable symbol on the box, on the social media banner or at the point of sale (OHE; KURIHARA, 2013).

This differentiation strategy is increasing also because of the demand side: consumers are increasingly asking for authenticity, reliable origin and traceable products. This consumers' demand is also due to food security and safety issues (BAUER; HEINRICH; SCHÄFER, 2013).

This distinction approach is also on the demand side: customers are constantly looking for quality, reputable sources and traceable goods, because they want to learn exactly what they buy (IQBAL et al., 2016). The desire by goods is also attributed to food quality, safety and health concerns (ZANDER; STOLZ; HAMM, 2013).

\subsubsection{Degrees of Origin and Authenticity: Terroir from Countries to Specific Regions}

In the field of origin of food products, the most common approach and perhaps the most examined in literature is the country of origin (COO) technique (CHARTERS; SPIELMANN; BABIN, 2017). In the case of a commodity, the COO is an signal reflecting to the price and the brand name may have a significant effect on the consumer's probability of purchasing the product (SPIELMANN, 2014; LOPES; LEITÃO; RENGIFO-GALLEGO, 2018).

For Melewar e Skinner (2018), this influence heavily depends on the involvement of consumers in the product category, on their knowledge of the country, on their experience in previous purchasing decisions and on patriotism.

Although certain brands of COO can be an advantage to their promotional policy, others tend to disassociate their logo from their COO either because the identity of the nation is not important or because it is not compatible with the standard principles in the product category (SPIELMANN; MAGUIRE; CHARTERS, 2018; GUROVA, 2019).

Another geographical attribution used to control the price perception of food products is the Region of Origin (ROO) reference (SPIELMANN; WILLIAMS, 2016), which is less studied than the COO, but widely used, particularly by small and medium-sized local enterprises (SMEs) (SPIELMANN, 2014). The ROO strategy is similar to the COO strategy, with two advantages: it will result in a more coherent segment or proposedvalue, since smaller regional areas are more homogeneous than countries, and it offers an incentive to distinguish the brand from other domestic goods as well. 


\subsubsection{The Fundamental Dimensions of Terroir}

According to Charters, Spielmann e Babin (2017), 'Terroir goods derive from one region, with the characteristics committed by the specific geographical location and its special and unreproducible characteristics. Terroir is a multi-dimensional concept (SPIELMANN, 2014, 2014). As Iqbal et al. (2016) stated, terroir is not only a 'normal' environment, as it is the aggregate of (1) physical, (2) human and (3) philosophic factors that determine the significance of the place. Those 3 components can be defined as a structure that derives from encounters and contact flows between various types of stakeholders (LOPES; LEITÃO; RENGIFO-GALLEGO, 2018).

Firstly, the physical dimension of the terroir is based on the geographical and geological characteristics of the site (LACOEUILHE; LOUIS; LOMBART, 2017) Aspects such as climate, geomorphology, as these elements influence the soil, fertility, flora and fauna and therefore determine the local raw material (WILSON, 1998; BARHAM, 2003). Essentially, this factor is all the physical aspects that affects the quality of the raw materials that will later be used for the product (LEEUWEN; SEGUIN, 2006).

However, the ecosystem itself does not generate terroir products. As a result, human interference is essential, because humans are responsible for shaping the value and quality of terroir goods (MORAN, 2001; BREVIK et al., 2019). In addition, the terroir integrates the concept of signature, which is the connection between people and the place (BARHAM, 2003). Fundamentally, the human aspect is the direct link between knowledge and the place being processed and crafted in different recipes, goods and special cooking methods (GOODMAN; DUPUIS; GOODMAN, 2012). It is basically a matter of expertise and human know-how in relation to the manufacturing cycle required to produce food that is either learned or passed on to generations of families and craftsmen (FEAGAN, 2007; MARTINEZ, 2010)

Finally, the terroir also has a philosophic aspect, which deals with the semiotic and symbolic characteristics of a substance that appears because of its unique nature (CHARTERS; SPIELMANN; BABIN, 2017). This dimension is a historical view of the terroir and is about the strong relationship that food can have with culture: local food can communicate and symbolize the cultural identity of the place, developing local heritage (BARHAM, 2003; SPIELMANN; CHARTERS, 2013). This refers to the characteristic and style of the terroir object, which is an elusive and unreproducible feature (COULON; PRIOLO, 2002; COULON et al., 2000).

In short, this dimension refers to heritage and characteristic, to the constitutive element of food, as demonstrated by Hassan e Mohamed (2014), Spielmann e Charters (2013). Therefore, terroir may be used to support agricultural items. Terroir's products also have the power to promote geographical areas and straight local development (HAR- 
VEY; WHITE; FROST, 2014; BESKY, 2014).

\subsubsection{Consumer Perception of Terroir Products}

The definition of terroir food items has evolved substantially and has met with renewed scientific interest for the past 30 years, especially in Europe (LENGLET, 2014; BERNUES et al., 2014). Terroir products are from specific origin, made from raw materials with limited supply(BERNUÉS et al., 2015) and they are produced using traditional artisanal techniques, resulting in restricted production and higher costs (LORENZ; HARTMANN; SIMONS, 2015; MARTINEZ, 2010; FEAGAN, 2007).

Consumers often consider terroir goods as more natural, conventional and authentic (SPIELMANN; CHARTERS, 2013). In fact, foods that rely on their place of origin branding is perceived as authentic by consumers when it comes to small-scale and familyowner business (CHARTERS; SPIELMANN; BABIN, 2017). The style of usage is broad and small in size, the form of processing is artisanal and represents the local trend (SPIELMANN, 2014).

In addition, the perception of terroir as a quality indicator depends on the knowledge and involvement of consumers (SPIELMANN, 2014; SPIELMANN; CHARTERS, 2013; MOULARD; BABIN; GRIFFIN, 2015). Although some work has shown that both beginner and heavy consumers use origin as a criterion for product evaluation, broader representations of locations such as COO, particularly for low-profile goods, are more important, although very clear origins such as terroir may not be fully understood (LORENZ; HARTMANN; SIMONS, 2015; MOULARD; BABIN; GRIFFIN, 2015; LENGLET, 2014).

\subsubsection{Terroir Products in Brazil}

Given the high potential of Brazil for geographical indication products (the nation is the biggest producer in the world of coffee, sugar cane and one of the biggest suppliers of soya bean products, orange juice, cocoa, beef, tobacco and cotton) little is known and discussed nearby (RAMOS et al., 2012). The country have only eight national GIs issued (SILVA et al., 2013; DRUZIAN; NUNES, 2012).

The amount of certificates of GI in Brazil is well below that of most European Union countries as well as developing countries like India, Mexico and China, which have been improving the legal framework in order to protect and enhance important traditional goods. The country, for example, after signing a technical cooperation agreement with France, introduced more than 300 GIs for traditional goods (RUIZ et al., 2018; BRAMLEY; BIÉNABE; KIRSTEN, 2009).

The importance of using GIs as a method in Brazil mechanism to support local development are followed by another argument: registration of a GI is a means of enabling 
participation for small producers, both the regional and exterior sectors of production is able to differentiate their products and segments (FAGUNDES et al., 2012; SILVA et al., 2013).

This is an important aspect, as the family farming market, comprising of small and medium-sized farmers, is the large proportion of producers. The plurality of rural farmers in Brazil plays an important part and a crucial role in the economies of small towns (FENSTERSEIFER, 2007).

Strategies to promote the protection of their products and uncover awareness can be a way through GIs receive stimulus and strengthen the social organization of these groups (WILKINSON; CERDAN; DORIGON, 2017). Registration of GIs requires detailed information discussions on problems relevant to the notion of land Identity and description of existing territoriality, in a geographical setting, interactions dictated by socio-cultural affinities, capable of ensuring a specific identity (YAMAGUCHI et al., 2015).

The country follows international treaties and Agreements: the Paris Convention for the Protection of Industrial Property, the Madrid Agreement for the Protection of Industrial Property and the TRIPs Agreement (NIEDERLE; GELAIN, 2013).

The Industrial Property Policy (LPI - 9.279 of 14 May 1996) is intended to put a national law aligned with the TRIPs, which governs the rights and duties relating to the manufacturing sector of agricultural products, including GIs from Brazil (ULLRICH, 1995; SELL, 2002).

The LPI does not set out the concept of GI, but establish two forms of protection that are given Characterized as GI: Source Indication (IP) and Appellation of Origin (DO) (PARASECOLI, 2017; FERRARI, 2014).

There are certain peculiarities with respect to the IP and DO concepts. The IP shall not guarantee specific and different quality, characteristics or means of use, it only makes sure that the product comes in from a city or a well-known locality (CONRAD, 1996; KIREEVA; O'CONNOR, 2010). The DO, as well as In comparison with the IP, it is more restrictive as a result of its enhanced specifications (BRAMLEY; BIÉNABE; KIRSTEN, 2009; DESELNICU et al., 2013).

The National Institute of Industrial Property (INPI) surveyed, covering the period from 1997 (when the LPI came into force) to February 2011, identified 55 applications for registration of GIs (17 foreign and 38 national) (MELLO, 2015). From 2011 to 2019, 4 other registers were established, 59 of which 1 is a service, or Porto Digital em Pernambuco. It is noted that of the 59 current IGs, 49 fall as IP and 10 fall as DO (MENDONÇA; PROCÓPIO; CORRÊA, 2019; SANTOS; VALENTE; MEDEIROS, 2019).

According to Niederle e Gelain (2013), one of the explanations that explains the predominance of PIs in relation to DOs is due to the inaccurate perception of scaling 
(levels) that includes the design and operation of IGs in Brazil. In this way, IPs are seen as more versatile than DOs. The author points out, however, that the IP and the DO cover unique aspects of immaterial property. Although IP favors popularity, DO is based on the particular nature of the product or service, that is to say, on reputation.

With regard to the agrifood sector, the most outstanding product was coffee with five (05) IPs and one DO. The artisanal cheese sector, which is part of this research, has three ( 03) registered products: Queijo Serro and Canastra, both MG and Witmarsum Colony's Cheese in Paraná (PR) (PINTO; PAIXÃO, 2018).

As regards the distribution of GIs across national territories, it should be noted that of the 59 national GIs registered with the INPI, $42(69.4 \%)$ are concentrated in the Center South Region, 13 (24.48 \%) in the North East Region and just 04 (6.12 \%) in the Amazon. It appears from the data that there is a predominance of GIs in the Center South Region and, secondarily, in the Northeast Region (PINTO; PAIXÃO, 2018).

The concentration of IGs in these three states is linked to the pioneering nature of their initiatives, the institutional arrangements for these initiatives and the way in which the productive sector has been structured and organized, which has seen in these devices a way of distinguishing their products in an increasingly competitive market, as was the case with Association of Canastra Cheese Producers (APROCAN)and Association of Vine Valley Producers (APROVALE), cheese and wine producers, respectively (WILKINSON; CERDAN; DORIGON, 2017).

\subsubsection{Artisanal cheese as Terroir Products in Brazil}

The artisanal cheese segment from raw milk has 16 production areas already identified in Brazil, representing a considerable number of rural establishments, in addition to an important Brazilian gastronomic heritage, as each of these cheeses carries the story of a know-how, coalescing product-producer-production space (BOTTELLI, 2020).

The category of artisanal cheeses already described, only three of IGs: Minas Artesanal Cheese from the Serro Region, Minas Artesanal Cheese from the Serra da Canastra, both in MG and Colônia Witmarsum Cheese in PR. The remainder of the ventures are: Marajó Cheese (PA), Serrano Cheese (RS / SC), Coalho Cheese from Agreste (PE), Seridó $(\mathrm{RN})$, Jaguaribe (CE) and Serra do Salitre and Araxá Cheese (MG). Each of these projects provided financial funding from minister of agriculture, livestock and supply (MAPA) for the planning of their IG projects in 2019 (KAMIMURA et al., 2019).

The three IGs already approved by the INPI, the closest to becoming a reality is the Canastra Cheese at the final stage of the test control and use of the casein label, a product that will be used in the manufacture of the seal to be placed on cheeses with t information. The pause in the enforcement of this IG relates to the use of this mark, 
which was not regulated in Brazil, and to the checks carried out by the Regulatory Council (MARGALHO et al., 2020).

In addition, the law is very restrictive, because there is no culture of valuation of IGs for such goods and the lack of articulation between IG and other products and services within the framework of the sub-area (region) specified for IG, it can build synergies and differentiated interactions, as an illustration of what has happened in Vale dos Vinhedos (RS) where there has been a strong appreciation (DAROLT et al., 2016).

In relation to the distribution, the municipality shall have an inspection seal (SIM) in the case of a product with GI, and the state shall cover the region if it is a State Inspection Seal (SIE), and the state can circulate on the whole of the territory if it is a Federal Inspection Seal (SIF) (KAMIMURA et al., 2019).

However, this process (SISBI-POA registration) can only be carried out if the Province, the Municipality and/or the Coalition of Municipalities in which the cheese factory is situated have an equivalent health inspection service and are approved by MAPA (NACEF et al., 2019). However, this is already a very incipient fact in Brazil, which greatly restricts the formalization of artisan cheese producers. Thus, even though it has introduced more flexible rules compared to the SIF, it is still a very complex and costly inspection system for rural family production (MEDEIROS; HORODYSKI; PASSADOR, 2017).

However, SISBI-POA certification tends to significantly diminish registration due to the entry of Law 13.680/2018 establishing the Selo Arte (Art Seal) and releasing the sale of artisanal cheeses throughout the national territory (PINTO et al., 2020), 



\section{General method}

\subsection{Object of study}

Ranked as fourth greatest milk producer worldwide, Brazil is still a minor player and consumer of cheese if contrasted to other economically similar countries (NIEDERLE; GELAIN, 2013). However, Brazil has experienced an increase demand for cheese in the last decade with positive prognostic to the next 20 years(WILKINSON; CERDAN; DORIGON, 2017). Artisan cheese, a product based on raw milk and manufactured normally by small scale dairy farmers, have gained large attention of the national and international market. Hence, International prizes have already been awards to Brazilian producers (WILKINSON; CERDAN; DORIGON, 2017).

Thus, several policy efforts have been made towards valorization of small farms and dairy producers for two strategic reasons. Firstly, as a long term plan of fixation in the rural areas given Brazil's enormous territory and avoiding massive rural exodus phenomenon(DASKALOPOULOU; PETROU, 2002). Fostering artisan cheese development, those products become differentiated from generic offering, thereby enhancing their commercial appeal and competitiveness (TREGEAR; KUZNESOF; MOXEY, 1998). Secondly, if such actions can be focused towards mainly small scale rural producers, direct social advantage such as improvement of skilled workers' employment rates, increases in regional and international trade networks and conservation of local traditions and cultural heritage may be leveraged (BÉRARD; MARCHESNAY, 1998).

With this in regard, the State of Minas Gerais located in the southeast of Brazil delivery half of Brazil's cheese production where farming for the domestic market created by gold mining developed as early as the 18th century (MEDEIROS; HORODYSKI; PASSADOR, 2017).

The research was carry out in this state and it has an area total of $586522,122 \mathrm{~km}$, representing $6.8 \%$ of the national total, but with a population of more than 21 million, it is the second most populated zone in the country. Over 31.4\% (148 471 thousands tons) of the cheese national manufacture (471 thousands tons) were produced in Minas Gerais (NOGUEIRA; LUBACHEVSKY; RANKIN, 2005).

From there, the region of Canastra comprises seven municipalities: Delfinópolis, São Roque de Minas, Medeiros, Tapiraí, Bambuí, Piumhi and Vargem Bonita. Those areas are highlighted in the respective map 1. Those municipalities composed the Canastra's Valley which is the unique region allowed to produce and use Canastra's Cheese as a brand (INHAN; ROVERE, 2016). Moreover, this product is officially recognized as a cultural 
asset making it a Brazilian intangible patrimony (MENESES, 2007).

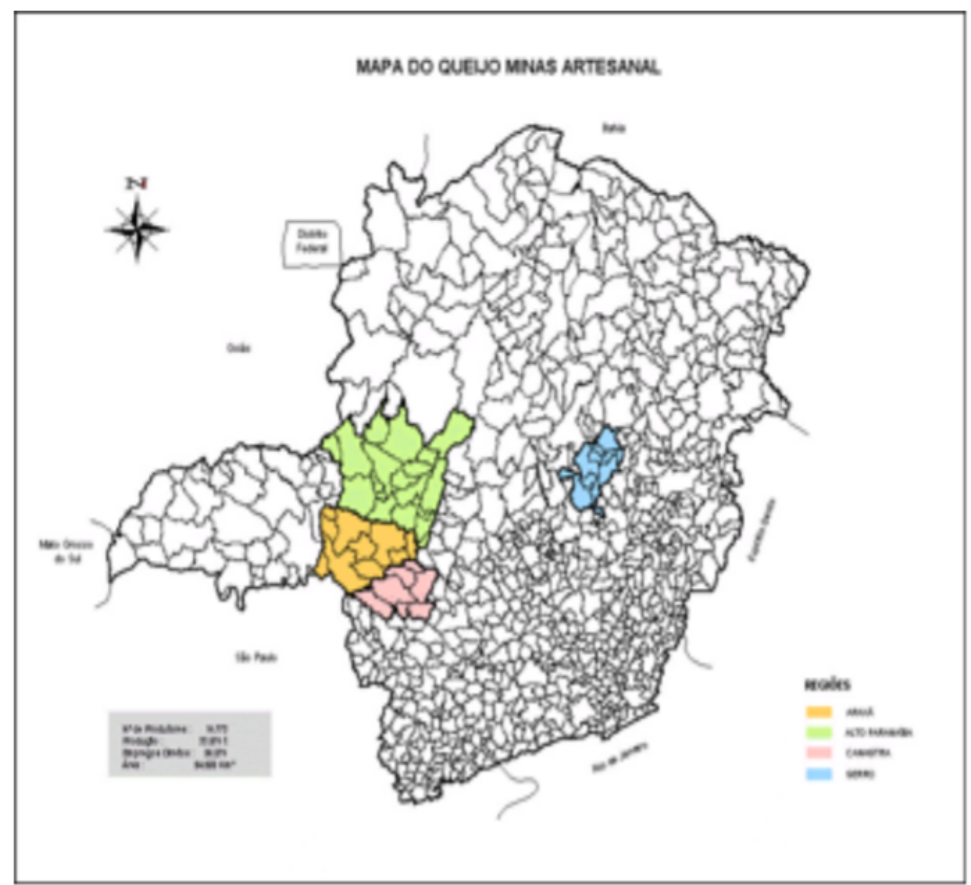

Figura 1 - Canastra Valley Region Map (CRUZ; HESPANHOL et al., 2018)

Such area have about 1,500 farmers and produces some 6,000 tons of cheese per year. Farmers who have been registered to use the GI are authorized to sell their cheese in any State of the domestic market but unable to export (KAMIMURA et al., 2019). According to the President of the Canastra Cheese Producers' Association farm-gate prices have tripled and retail prices can fetch double farm-gate prices. On the other hand, by 2014 , more than a decade later, only some 30 farmers had managed to get their farms registered (MEDEIROS et al., 2017).

Indeed, Canastra Valley (Serra da Canastra) plays a major vanguard role in the economic development of artisan cheese and the recognition as a national heritage as well, influencing potential clusters of production and further development of public policies in Brazil towards geographical indication products (CRUZ; HESPANHOL et al., 2018).

Important prizes were brought by local producers supported by Aprocan competing in recognized and international affairs. Public policies towards agricultural small producers as label art and a more appropriate sanitary regulatory to small producers and not big producers. Moreover, institutional partnership with national and international agencies and academies for exchange of knowledge and support were achieved in the last years (WILKINSON; CERDAN; DORIGON, 2017).

Saying this, the object of this study is the artisan cheese producers based on the region of Canastra Valley (Serra da Canastra) located in Minas Gerais, a southeast state of Brazil plays a major vanguard role in the economic development of artisan cheese and the 
recognition as a national heritage as well, influencing potential clusters of production and further development of public policies in Brazil towards geographical indication products (MOTA, 2017).

\subsection{Theoretical framework}

\subsubsection{Theoretical framework for integrated sustainability assessment and variable selection}

Different perspective exist in the literature regarding sustainability. Much of the current literature pays particular attention to economic quality (MACDONALD et al., 2017) and production efficiency (SALA et al., 2017; NOTARNICOLA et al., 2017). Regarding environmental sector, several methods to estimate environmental impacts of dairy livestock production chains(MOLDAN; JANOUŠKOVÁ; HÁK, 2012) have been deployed. Only in the past 10 years have studies of sustainability directly addressed how social and environmental characteristic impacts to long-term sustainability (TEDDLIE; YU, 2007; BENOÎT et al., 2010)

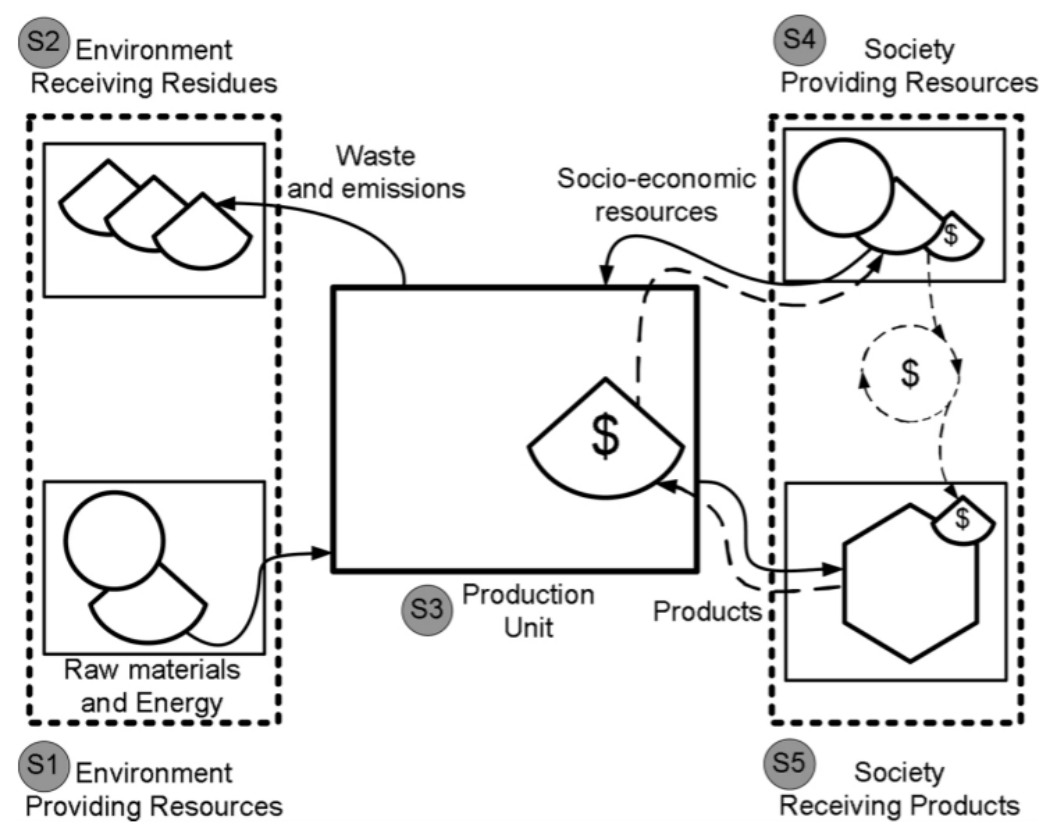

Figura 2 - 5Sensu conceptual framework (GIANNETTI et al., 2019)

According to Lebacq, Baret e Stilmant (2013), most theoretical frameworks concern mostly one dimension disregarding other feature development. The present studies are applications centered on life cycle analysis, ecological footprint and material flow. Other more wide frameworks such as emergy and bio capacity are able to consider a wide spectrum but they are relative difficulty to transform in action insights.

Moreover, there is a relatively small body of literature that is concerned with sociological and cultural aspects derived from dairy activity but not product or efficiency 
oriented either (ESPINOZA-ORTEGA et al., 2007; SOLANO et al., 2000).

Saying so, a comprehensive literature review shows that although several innovative environmental assessment tools and techniques have been developed, there are still very few comprehensive, practical frameworks to address all sustainability aspects simultaneously, conflictuous and heavily based on human judgment (HOSSAINI et al., 2015; SOLTANI et al., 2015; LU; HANANDEH; GILBERT, 2017). Indeed, the same sustainability assessment report can have diverse interpretations according to the reader (GIANNETTI et al., 2019). The presence of subjectivity of the reader makes the present assessment frameworks results confused and inconsistent (KLÖPFFER; CIROTH, 2011).

With this in regard, the theoretical framework used in this study is proposed by Giannetti et al. (2019). The author proposed a model named 5Sensu which is a holistic model that comprises multi-characteristics overcoming previous studies limitations of single metric methods. The conceptual framework of the model can be see in the figure 2 . First, the multi-dimension is an important characteristic since it embraces social, environmental and economic dimensions. Second, it can be understood as a multi-view model that may assume the point of view from the natural environment, society as well as from the production unit.

Also, those multi-dimensions are considered as both donors and receivers of energy, materials, and information flows. Which means they impact each other simultaneously somehow. An important characteristics where much frameworks are stationary and not very clearly associated(ESMAIL; GENELETTI, 2018; KIKER et al., 2005).

Third, the indicators applied to the model are usually multi-metric, including energy, volume, mass, money, labor force, etc. Fourth, its multi-criteria approach can be seen as an important feature of the tools considered within the 5SEnSU model, since an unlimited combination of indicators with several weights and goals can be applied. Those features may overcome variables selection limitation and unique point of view. Such characteristics are important for such problem given multi-criteria problem which will be used.

\subsection{Establishing indicators, goals and weight values to feed the 5sensu}

The indicators and goals selection were following geografical indication social and economic purpose of regional development (TREGEAR; KUZNESOF; MOXEY, 1998; CAENEGEM; CLEARY, 2017). Also, the variable selection were chosen according to data availabity. Two indicators per sector were chosen to feed the 5SEnSU theoretical framework model for variable selection, totalizing ten indicators. The time window consi- 
dered for all indicators is one year. With this in regard, the variable used in this study are briefly introduced in the table 1 attending recommendation of the author's model 5sensu (GIANNETTI et al., 2019):

Tabela 1 - Variable selection

\begin{tabular}{cccc}
\hline Sector & Indicators & Metric & Objective \\
\hline \multirow{2}{*}{ K1 - Environment as provider } & Electricity & KVA & Max \\
& Area & Hect & Max \\
\hline \multirow{2}{*}{ K2 - Environment as receiver } & $\mathrm{CH}_{4}$ & $\mathrm{Kg}$ & Min \\
& Whey & $\mathrm{Kg}$ & Min \\
\hline \multirow{2}{*}{ K3 - Production unit } & Revenue & $\mathrm{R} \$$ & Max \\
& Size Herd & Head & Max \\
\hline \multirow{2}{*}{ K4 - Society as provider } & Work Force & Person & Max \\
& Tradition & Year & Max \\
\hline \multirow{2}{*}{ K5 - Society as receiver } & Tax & $\mathrm{R} \$$ & Max \\
& Population Age & Age & Min \\
\hline
\end{tabular}

\subsubsection{Sector 1 - environment as a donor}

The main input are electricity and territory in small dairy producers. Land use used by agriculture, forestry, mining, house-building or industry leads to substantial impacts, particularly on biodiversity and on soil quality as a supplier of life support functions. Electricity is the main source of energy to utilities function and operation. Thus, both indicators should be maximized since the higher those values, the more real wealth the producers hold. Other authors have used those indicators to assess (LABUSCHAGNE; BRENT; ERCK, 2005; YIGITCANLAR; DUR, 2010; GOGLIO; OWENDE, 2009).

\subsubsection{Sector 2 - environment as a receiver}

Cheese whey and methane $\left(\mathrm{CH}_{4}\right)$ are the main pollutant generated from the cheese production (PRAZERES; CARVALHO; RIVAS, 2012). The dairy industry is associated with the production of waste waters, effluents and air population that could have a significant environmental impact because of their characteristics.

Whey can cause several environmental impacts (GANNOUN et al., 2008) and cannot be directly discharged to the environment without an appropriate treatment. The polluting power of whey has led countries such as United States, Canada, Australia, New Zealand, and the European Union, to introduce strict environment protection legislation (SMITHERS, 2008). 
On top of that, ruminant systems are a significant contributor to total GHG emissions with the main sources being $\mathrm{CH}_{4}$ emissions from enteric fermentation, reports that methane is more than twenty times as effective as $\mathrm{CO}_{2}$ at trapping heat in the atmosphere

Both indicators should be minimized given their negative impact in the environment and has been used by several authors to measure dairy cattle impact Palmieri, Forleo e Salimei (2017). For this study, we use a default value used by Food and Agriculture Organization.

\subsubsection{Sector 3 - production unit}

Enterprise revenue and Herd size are the variables selected to this sector. Both indicators are fully controlled by unit production and they are important proxy for production system management health. Despite their high correlation, revenue extra marginal gain can come from other activities apart cheese production. Addition value from marketing, new products development and adequate strategy of communication are built-in in revenue. The same occur with herd size milk productivity with the adoption of technology, a variable controlled by the unit production. Both indicators should be maximized and they are used by (PETERS, 2005; XU; FLAPPER; KRAMER, 2009) in previous studies.

\subsubsection{Sector 4 - society as provider}

The variables are total number of hired workforce and tradition. The first indicator represents the number of employees hired in the farm, thus it should be maximized.

Tradition constitute an important element of culture, identity and heritage for GI regions as it provides entailing substantial product differentiation. This indicator embodies knowledge and a life style which supports the producer's region. The unit production owner's number of years spent to learn and produce cheese in the region is the proxy for this indicator. This proxy measure owner link to the region culture and ethos. Thus, it should be maximized and they are used by (PAPADATOS et al., 2002; BIELECKA; POKONIECZNY; KAMIŃSKI, 2014). Tradition is represented in number of years comprised in training and/or production experience.

\subsubsection{Sector 5 - society as receiver}

The variables are tax collect and GI's population age. The first variable means direct resources to improve the city in direct benefit for the autoctones. This indicator should be maximized. The regional population age indicator should be minimized in order to avoid regional rural depopulation, by favoring direct immigration given new opportunities of job and increasing fertility rate due to improved perspectives of income. Owner's age is the selected proxy for this variable (BEAN et al., 1994; VATS, 2016; BARDHI, 2017). 


\subsection{Functional Unit}

The functional unit is defined as 1 ton of uniform quality of Canastra cheese leaving the dairy plant gate and packaged as an $1.1 \mathrm{~kg}$ block wrapped in plastic and cardboard. Canastra cheese is further classified as a semi-hard cheese with fat and protein contents of $34.8 \%$ and $24.8 \%$, respectively, on a total mass basis following federal guidelines over Canastra cheese product(ANDRADE et al., 2017).

The Canastra Cheese shows the following physic-chemistry and sensory attributes: semi hard consistency, a buttery taste, compact texture, yellow-white color, white or thin rind and no crack is presented, cylindrical format, height of 4-6 cm, diameter of $15-17 \mathrm{~cm}$, weight of $1-1.2 \mathrm{~kg}$, it has a mildly acidic flavour but not pungent (DORES; NOBREGA; FERREIRA, 2013).

\subsection{Data collection process}

The producers of artisan cheese located in Canastra Valley (named from here as "systems") were used as a case study to illustrate the application of the proposed tool in assessing sustainability.

The dataset collection procedure occurred in 2017-2018 carried out by Brazillian federal Agency named Sebrae/Minas Gerais (Brazilian Institute of support and foster for small enterprises) in Canastra Valley.

Over an estimated population of 970 producers, 757 producers were surveyed. The survey comprises 9 different sections (personal information, milk production, cheese production, destination market, geographical indication characteristic, environmental dimensions, tourism related projects, socioeconomic inputs and management) distributed over 158 closed and open questions. Questions regarding adoption of machinery, technologies and facilities improvement were present but after careful analysis, the data are considered invalid given incongruency of the inputs. 



\section{A bibliometric study of Emergy}

This paper is titled as "A bibliometric study of Emergy"and presents a systematic analysis of previous researches regards emergy in the last twenty years and the postponing reason of this theoretical framework in this thesis.

This study is divided in three phases. The first one consists in a bibliometric analysis of emergy literature. Given emergy being a relatively robust and consolidated concept, emergy as a subject of investigation offers a widely range of opportunities for further studies.

Succinctly, according to the results of this first phase, the emergy consolidation is strongly supported with other methodologies association. Most authors highlights life cycle assessment methodology as a possible enhancer solution.

Thus, the second phase comprise a systematic review of the present literature towards studies whom applied a conjunction of emergy and LCA at their assessment procedure. After a detailed search, it have been found only 19 studies using such stipulated parameters. A systematic review of those literature through Emergy give theoretical background support to a feasible combination of both techniques, which is relevant to support the next phase goals.

The third phase, which would consists in the development of emergy assessment framework of analysis to dairy/cheese production. To the author best knowledge, no study using emergy has yet been done to assess cheese production. As a matter of fact, only few studies using emergy methodology have been conducted in dairies to asses raw milk production which is a prior mandatory input for cheese manufacture.

Lastly, despite Emergy have been considered a reliable and validity method and in a crescent trend of usage, prior studies on Emergy have noted the importance of effective communication of the results beyond scientific shores. Another often raised issue is the growing demand for actionable decisions capable to multiply positive impact in the society. Indeed, this is a critical element in a thesis in progress on a school of management. However, very little was found in the literature which address such concern successfully. By means of this, Emergy methodology was postponed and further efforts towards selection and improvement of present methods were done. 


\section{A bibliometric study of Emergy}

\section{Abstract}

Assessing energy efficiency and environmental impact caused by human activities is a critical step to the development of feasible route towards sustainable development. Emergy is a relatively consolidated concept which regards as a sustainability assessment tool. Emergy related theory and further studies have experienced an steady increase trend in the number of publications between 2000 and 2017 . In this context, this study aims to review emergy literature offering a macro perspective through bibliometry using network analysis and a database of 1123 studies published in the world. China, Italy and USA institutes are key figures for further development of emergy studies and its international diffusion. Also have been observed collective efforts to join other assessment methods to emergy framework analysis. Further development of emergy is still necessary to achieve its full potential as an accessible tool of assessment.

Key-words: emergy, bibliometry, sustainability, analytical methods 


\subsection{Introduction}

Increment of production and consumption leads to a highly dependence of resources, mostly non renewable fuels, widely support by nature ecosystems (FOLEY et al., 2005). In addition, high rate of population growth and rapid economic expansion in a global magnitude accelerate such process, putting human society at a severe risky of future existence(NEUMANN et al., 2015; GERLAND et al., 2014). Therefore, in order to develop robust strategies to sustain human growth endurable, identifying gaps and points of improvement towards current chain of production and consumption is mandatory(BOARD, 2005).

Many evaluation methods have been proposed and deployed withing many diverse areas, such as life cycle analysis (GUINÉE, 2002), material flow analysis (BRUNNER; RECHBERGER, 2004) and ecological footprint analysis (BICKNELL et al., 1998). Nevertheless, those methods are strongly supported by individual and local parameters, consequently not being able to provide satisfactorily a regional big picture progress(PIZZIGALLO; GRANAI; BORSA, 2008; BROWN; ULGIATI, 1997).

Emergy is one approach with the potential that can fulfill those raised gaps. By convention, Emergy is expressed as all forms of energy originate from solar energy(ODUM; BROWN; WILLIAMS, 2000). Thus, directly and indirectly required energy from distinct sources which together manufacture a product or service is able to be computed using a common denominator. Such holistic perspective can take full advantage through indicators of different nature able to evaluate the overall sustainability of complex systems (ULGIATI; ODUM; BASTIANONI, 1994).

Since emergy theory main concept was first suggested in the late 1980 until nowadays (ODUM; ODUM, 1976), emergy as an methodology suited to offer new perspectives on sustainability assessment has received consistently more attentions globally over the years (SALADINI et al., 2016; WHITING; CARMONA; SOUSA, 2017). This is due to the joint of efforts from the scientific community, formulation of updated databases which contains emergy transformity values of a broad range of materials and the consolidation of an international emergy research organization (International Society for the Advancement of Emergy research, ISAER)(BROWN; ULGIATI, 2004).

Emergy has been widely applied in a great variate of arrangements and structures as a practical assessment tool, such like industrial parks (GENG et al., 2010), agricultural systems (OLDE et al., 2016; CAVALETT; ORTEGA, 2009) and waste treatment systems(BJÖRKLUND; GEBER; RYDBERG, 2001). For scientific advancement, emergy studies have been published in a worldwide spectrum of journals(AMARAL; MARTINS; GOUVEIA, 2016).

A bibliometric analysis offers an helpful platform of information for readers and 
researches by providing a macro view in what way scientific community and related papers are related to each other through citations and partnership currently and in the forthcoming future as well(PRICE, 1976; SUBRAMANYAM, 1983; RAAN, 2005).

But still, emergy related bibliometric analysis is sparse. Regarding the scarcity of bibliometric analysis highlighted, the main purpose of this paper is to carry out a related literature examination published from 2000 to 2017 through network theory. The overall structure of the study takes the form of five sections. After introduction part, methodology is presented followed by research finds. Lastly, conclusion and further discussion are exhibited.

\subsection{Methodology}

\subsubsection{Network theory and bibliometric analysis}

Several efforts with the goal to analyze how embedded components of a network are related to each other have been developed specially in the sociology and anthropology field of study (KILLWORTH et al., 1990; VALENTE, 1995). However, if before large amount of attention have been given to small social networks composed by a few tens of human being, suddenly, researches using large scale networks studies joined initial network theoretical foundation.

The main driver of change for large scale network is strongly based on the power of processment obtained through personal computers added to robust but still simple mathematical models able to explain complex phenomenon. In addition, network theory is also a feasible path to test concepts empirically. Various studies over distinct fields have been carried out under network theory perspective. Such as statistical mechanics (GOLDBERGER et al., 2000), biology (BARABASI; OLTVAI, 2004), epidemiology (GRIMM et al., 2005), science computer (JENNINGS, 2001), nutrition (TENG; LIN; ADAMIC, 2012) and scientific collaboration network formally entitled as bibliometry (ADAMIC et al., 2008).

Accordingly to Newman (2004), a bibliometric analysis aim to quantitatively measure scientific publications by a systematically approach through network analysis. All that to identify patterns, structures,features and to measure scientific progress in various fields (NEWMAN, 2004). A major advantage of network analysis is that often not clear phenomenon can be easily grasped due to visual outputs. In this study, network analysis was applied to explore the current status of emergy studies by examining academic collaboration and citation among the most prominent institutes and countries in the field. 


\subsubsection{Data sample and tools}

The sample utilized was extracted though an electronic framework provided by Web of Science (registered). This single web page integrates multiple sources of scientific material which are connected through citation metrics layered by multiple filters and characteristics as author's name, institution where the researcher belongs, keywords used to describe determined work and so forth.

The extraction of data occur ed in October, 2017 using the keyword "Emergy"in the search field. 1172 publications was obtained from primary extraction which have been observed predominance usage of written English between the authors and researches of the field. Such as English is the common scientific language, this study considered only scientific material written in this language which is the total of 1157.

From this sample, 59 review papers (4.63\%), 14 editorial papers (0.84\%), 13 general letters $(0.70 \%)$ and 3 corrections $(0.14 \%)$ were removed. Thus, 863 papers already published at journals and 260 proceeding papers have been considered to the final sample of 1123 to be investigate that is vast majority of the literature until now present. VOS Viewer(2014), an bibliometric tool Eck e Waltman (2010) have been used for further analysis of network.

\subsection{Results}

\subsubsection{General trend of the field}

Table 2 summarize emergy related literature published between the years of 2000 and 2017. It can be noted that a positive upward trend of articles published each year increased steadily. Similarly, the amount of citations year by year observed a sharply increase .For instance, the amount of papers increased from 11 in 2000 to 100 in 2017, with an annual growth rate of $13.8 \%$, indicating that emergy and related fields received increasing considerations, particularly in the last seven years. 
Tabela 2 - Emergy literature performance

\begin{tabular}{cccc}
\hline Year & Article & Citation & Average \\
\hline 2000 & 11 & 1 & 0 \\
2001 & 10 & 13 & 1 \\
2002 & 10 & 17 & 2 \\
2003 & 13 & 49 & 4 \\
2004 & 17 & 94 & 6 \\
2005 & 10 & 52 & 5 \\
2006 & 28 & 183 & 7 \\
2007 & 30 & 252 & 8 \\
2008 & 38 & 383 & 10 \\
2009 & 54 & 758 & 14 \\
2010 & 52 & 1032 & 20 \\
2011 & 70 & 1246 & 18 \\
2012 & 49 & 1383 & 28 \\
2013 & 72 & 1873 & 26 \\
2014 & 87 & 2358 & 27 \\
2015 & 88 & 2351 & 27 \\
2016 & 84 & 2671 & 32 \\
2017 & 100 & 2966 & 30
\end{tabular}

\subsubsection{Distribution of subject categories and journals}

The 1123 publications selected in this study cover 91 subject categories according to the database international standard method of classification. Among all those subjects, five subject categories represents $81 \%$ of all publications. These are Environmental Sciences (372 publications), Ecology (216 publications), Environmental Engineering (185 publications), Energy \& Fuels (110 publications), and Environmental Studies (74 publications).

Table 3 exhibits the total amount of published papers on the before mentioned five main subject categories during 17 years. The interval of 2000-2017 was divided into three equal periods which one covering 6 years. For every category of subject, the total amount of publications extended regularly over the intervals. Environmental sciences category display the most publications, followed by the ecology, engineering Environmental, energy and fuels and lastly environmental studies category. Overall, all categories presented at table 3 sustained a sharp increase tendency especially environmental science and engineering Environmental subject categories. 
Tabela 3 - Top 5 subject categories

\begin{tabular}{ccccc}
\hline Subject & $2000-2005$ & $2006-2011$ & $2012-2017$ & Total \\
\hline Environmental science & 24 & 116 & 232 & 372 \\
Ecology & 30 & 88 & 97 & 215 \\
Engineering Environmental & 12 & 50 & 122 & 185 \\
Energy Fuels & 7 & 41 & 62 & 110 \\
Environmental studies & 4 & 21 & 49 & 75 \\
\hline Total & 78 & 316 & 563 & 957
\end{tabular}

Although emergy related publications had been published in 211 different of journals from 2000 to 2017, table 4 demonstrates the 15 most prominent scientific journals in the emergy associated investigations, responsible for a large portion (54\%) of all publications in the field. All journals are mainstream journals scientific literature in the field of management, engineering and economic directly related to environment. Other key journals also support emergy theoretical studies, but the total numbers of published papers are extremely disperse among other minor journals. Among them, Ecological Modeling is the most productive journals since 159 papers were published in this journal followed closely by Journal of cleaner production. It is important to note the great discrepancy regard productivity among the best and last ranked journal of the table.

Tabela 4 - Top 15 journals

\begin{tabular}{cc}
\hline Journal & Total of papers \\
\hline Ecological modelling & 159 \\
Journal of cleaner production & 104 \\
Ecological engineering & 64 \\
Ecological indicators & 54 \\
Energy & 31 \\
journal of Environmental management & 31 \\
Energy Policy & 30 \\
Sustainability & 28 \\
Resources conservation and recycling & 24 \\
Renewable sustainable energy reviews & 22 \\
Communications in nonlinear science and numerical simulation & 21 \\
Ecological economics & 15 \\
Agriculture ecosystems environment & 11 \\
Applied Energy & 11 \\
journal of Environmental accounting and management & 10
\end{tabular}




\subsubsection{Contribution of Countries and Institutions}

In this part of the study, scientific efforts and contributions towards emergy theoretical development were analyzed by grouping the most prominent countries and institutions using author's research address at the time the paper was published given international mobility factor. Thus, all previous sampled publications were analyzed. 67 countries and 602 institutions contributed to the development of emergy related studies during the period delimited a priory.

Table 5 shows the primary performance of the top 10 most productive countries. Those listed countries were responsible for 954 publications not less than $85 \%$ of total sum of publications. China is the world's leading country on emergy-based publications followed by Unites States, Italy and Brazil. Again, the difference among countries productivity reveals great disparity and high concentration of studies in the field between the best ranked countries.

Tabela 5 - Top 10 countries

\begin{tabular}{cc}
\hline Country & Documents \\
\hline China & 353 \\
Usa & 215 \\
Italy & 178 \\
Brazil & 61 \\
France & 33 \\
Denmark & 28 \\
Japan & 25 \\
Taiwan & 23 \\
Sweden & 22 \\
Spain & 16
\end{tabular}

According to the network graph 3, Italy and USA were the most productive and prominent countries between 2006 and 2010. Both countries were surpassed by China given the rapidly increase of publications since 2011 followed lately by countries as Brazil, Japan and France. But unlike other countries of this list, China got more publications between same origin authors. The USA is the most engaged country in terms of international cooperation, with the largest amount of international collaboration publications it implies that at least one author's addresses is located in another country. These results indicate that China, Italy, and USA are the most important players to the development and application of emergy studies.

Further analysis at the institution level show Chinese institutions relevant weight in the emergy studies. Among the top 10 most productive center of researches and universities listed in table 6, 5 are Chinese. Also, those institutes foster academic cooperation 


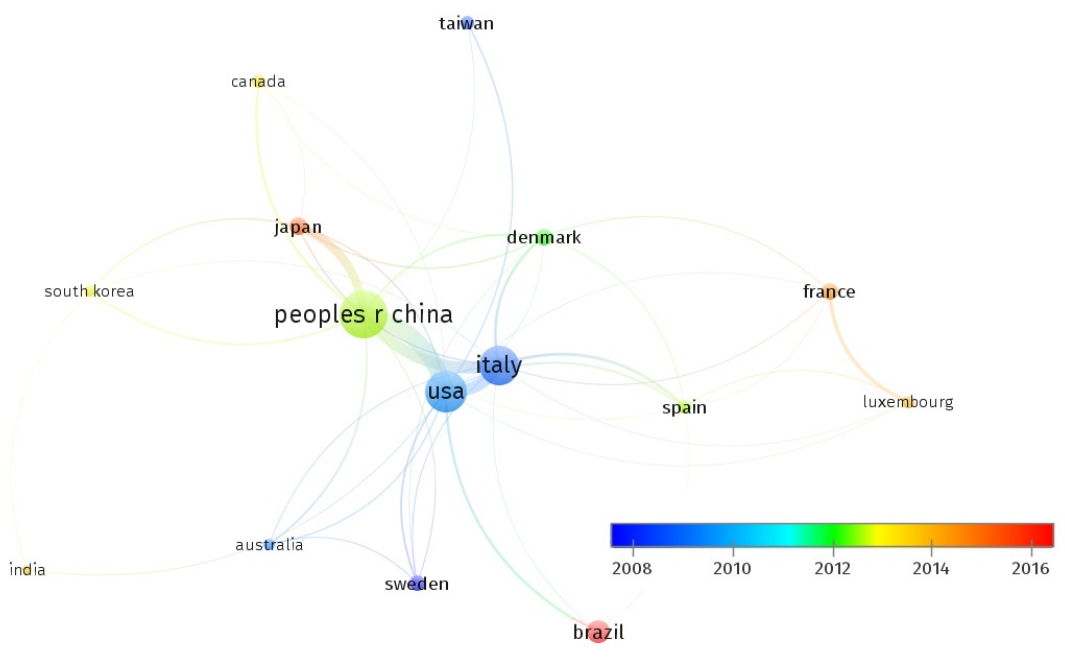

Figura 3 - Network of countries

particularly Beijing Normal University and the Chinese Academy of Science. Both institutions have similar productivity, yet Beijing Normal University maintain close cooperation with same country institutes. According to network graph 6, Beijing Normal University pertains to green cluster, in contrast, Chinese academy of Science belongs to red cluster, a cluster composed by a more heterogeneous country-origin institutes.

Tabela 6 - Top 10 institutes and universities

\begin{tabular}{cc}
\hline University & Citations \\
\hline Beijing Normal University & 96 \\
Chinese Academy of Science & 93 \\
University Siena & 84 \\
University Florida & 67 \\
Peking University & 53 \\
University of Nebraska & 50 \\
Parthenope University Naples & 38 \\
University Maryland & 26 \\
University Chinese Academy Science & 21 \\
China Agronomy University & 20
\end{tabular}

Although, the western institutes (University of Florida and University of Sienna) are more engaged to promote international cooperation, especially with China and Brazil.By contrast of China, those institutes published articles with authors from different countries more often. Perhaps cultural and geographical barrier are better explanatory variables for such condition than institutional barrier since vast majority of scholars can effortlessly find potential research partners due to their similar research interests and reputation. 


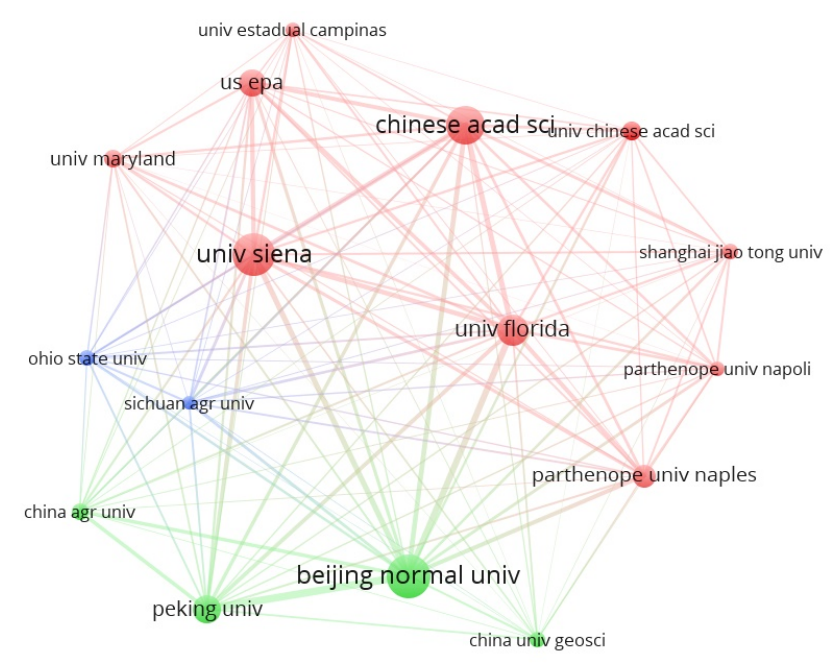

Figura 4 - Network of institutes

\subsubsection{Main research fields}

Keyword is a fundamental component in scientific writing as reader's attention can be easily directed to the main purpose of the research. By using those elements as unit of analysis, this part of study assess 2172 keywords given by the authors themselves. At first, table 7 show that most keywords were infrequently used. Keywords used only once and twice are responsible for approximately $91 \%$ of all the keywords, while keywords used more than 3 times account for $9.4 \%$ and at last 3 keywords have been utilized at least 114 times.

Tabela 7 - Keyword frequency table

\begin{tabular}{ccc}
\hline Keyword & Minimum frequency & $\%$ \\
\hline 2172 & 1 & $80 \%$ \\
441 & 2 & $11 \%$ \\
204 & 3 & $3.4 \%$ \\
130 & 4 & $1.7 \%$ \\
94 & 5 & $1.4 \%$ \\
64 & 6 & $0.5 \%$ \\
$\ldots$ & $\ldots$ & \\
3 & 114 & $0.001 \%$
\end{tabular}

Emergy, Sustainability and Emergy Analysis are most frequent keywords as table 8 exhibits. Total link measures co-occurrence with other key-works and results display a high level of simultaneity which indicates significance degree of conectiveness with other keywords 
Tabela 8 - Top 5 keyword

\begin{tabular}{ccc}
\hline Keyword & occurrence & total link\% \\
\hline Emergy & 312 & 728 \\
Sustainability & 147 & 363 \\
Emergy analysis & 114 & 217 \\
Lca & 49 & 105 \\
Ecosystem services & 33 & 103
\end{tabular}

Network graph 5 illustrates 17 most frequently and dominant topics and subtopics of emergy related publications from 2000 to 2017. The geographical distribution also illustrates how far or close is from each other. Moreover, each keyword have been used at least 17 times.

The most interesting diagnostic of this graph is that most often keywords are directly linked to emergy. These results suggest that emergy concept and theoretical background is a essential part for further studies in sustainability. As sustainable development is in the agenda of many interested parties who own different perspectives and methodologies, not surprisingly, the blue node named sustainability have a central position in the network and interfaced with a wider range of keywords also.

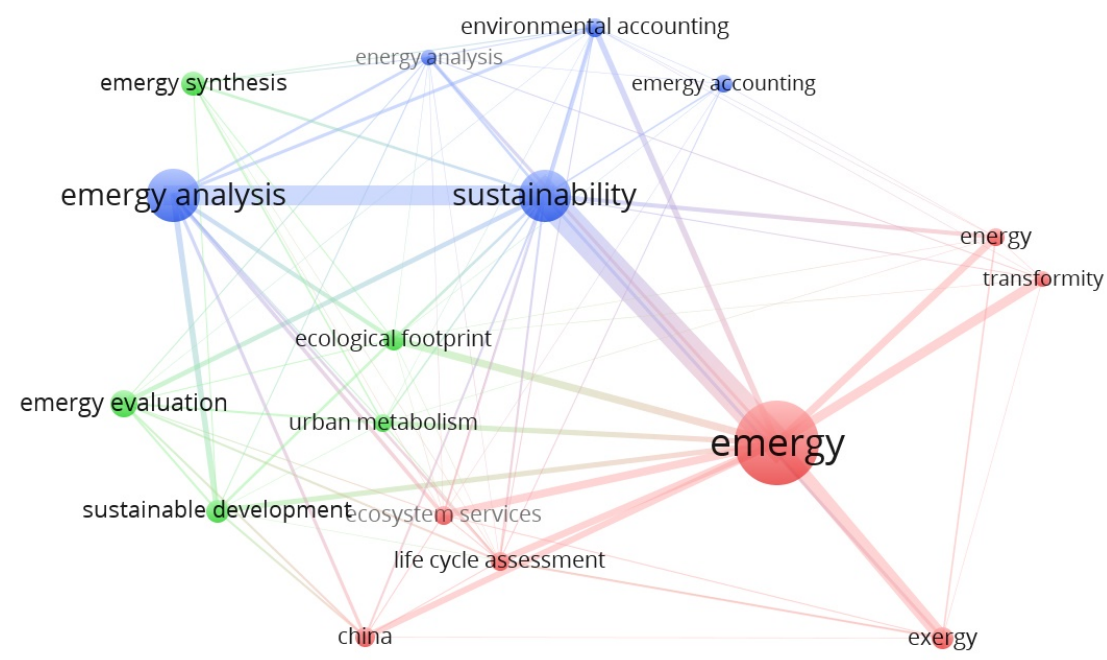

Figura 5 - Network of keywords

From the network graph, it can be seen that by far the greatest demand for applied studies using emergy analysis are related urban metabolism and ecosystem of services nodes. Both topics have a immense importance given global population growth tendency and geographical high concentration at urban areas. Energy efficiency and sustainability assessment of heavily populated urban areas faces numerous drawbacks supported by a 
great number of variables correlated in not a clear manner. Emergy analysis may be a adequate methodology of assessment to face such challenges because its own concept is designed to deal with systems.

Three analytical methods of assessment have been noticed in the graph: life cycle assessment (LCA), ecological footprint(EF), and exergy analysis(EA). Those methods were regularly applied in conjunction with emergy analysis papers. As previously pointed out, emergy analysis has strengths as it accounts local ecosystem services and natural capital. Uncertainty of communication format and high variability of interpretation of the results are the major limitation of emergy currently. However, those three methods picture in the graph also have their strengthens able to overcome emergy potential flaws.

\subsection{Conclusion}

A feasible path to support long term socioeconomic development regarding energy efficiency and environmental sustainability concerns a wide range of stakeholders given high stakes related directly with human existence. Thus, assessing environmental impacts caused by human activities is a critical step to build an efficient and reasonable set of actions. Emergy theoretical concept and framework analysis could contribute towards such goals.

Despite the fact that emergy is a relatively well "established concept when compared to other methods, attention have been drawn from the scientific community for research and application purpose due to the ability to address complex systems. A bibliometric analysis review have been carried out with a focus on literature related to emergy published during 2000 until 2017. All in order to offer a macro perspective of those studies through network analysis visualization tool. Such efforts may be helpful to have a better comprehension of the current moment of emergy studies, gaps faced by as well and to predict possible future direction to this subject.

Emergy related scientific literature have experienced a steady upward of number of publications during 17 years (2000-2017). Also, among all 1123 publications, 91 subject categories have been used to classify them. Environmental science, Ecology, Engineering Environmental, Energy and Fuels and finally Environmental studies are the most significant subject categories of the field. Regarding most prominent scientific journals, Ecological modeling, Journal for Cleaner Production and Ecological Engineering ranked as the most relevant scientific publications.

China, Italy and USA play critical role in the advancement of emergy theory. Those countries foster academic collaboration with a great variate of other countries and between them as well. Among 10 best ranked institutes and universities, 5 are Chinese indicating its pertinence in the emergy theory advancement. Although Beijing Normal University 
foster international academic exchange with other countries, a great part of its influence is towards own territory institutes and universities. On the other hand, Chinese academy of science nurture a close academic relation with western countries as Italy, United States and Brazil. University of Sienna and University of Naples in Italy, University of Florida and University of Nebraska shape a core of vital western institutes responsible to diffuse emergy related theory and application around all the world.

Furthermore, methods of sustainability assessment such as LCA and EF have been recently incorporated with emergy analysis framework. All with the purpose to strengthen emergy theoretical framework.

Taken together, these results suggest that emergy has plenty of space to grow and contribute directly to society. This study offers a macro perspective of until 2017 published emergy related papers using an methodological approach able to provide an intuitively comprehension as network analysis. Moreover, potential agencies and institutes, scientists and stakeholders interested to either develop further or apply emergy framework under real conditions may find this study useful. 



\section{Sustainability assessment propose in a mi- cro farm level perspective for geographical indication regions}

This paper is titled as "Sustainability assessment propose in a micro farm level perspective for geographical indication regions"and presents an analysis designed to investigate the optimum point of adoption in machinery considering a broadly environmental, economic and social attributes simultaneously for producers located in a GI certification region.

Both qualitative and quantitative methods were used in this investigation. First, the sustainability theoretical framework adopted in the upcoming articles of this thesis has a number of attractive features: (1) a multi-criteria perspective, enabling participation of several dimensions with mutual adverse interest, (2) a theoretical framework which support variable selection and comprehension of their relationship, a decisive step of the research and lastly (3) enhanced communication attributes by relative ranking of the units of production allowing easy comprehension.

However, the nature of actionability to improve sustainability in a micro perspective remains unclear in the present corpus of past studies. This paper contributes to strengthen the theoretical framework by exploring producer's daily operation agenda. The adoption of machinery, technology and facilities is the proxy for producer's potential space of actions to delivery improved sustainability. 


\section{Sustainability assessment propose in a micro farm level perspective for geographical indication regions}

\section{Abstract}

A mixed quantitative and qualitative approach was employed aiming to assess the sustainability of artisan cheese producers considering social, environment, economic features correlating adoption of technology. The object of study is the producers of artisan cheese in Canastra Valley. 6 producers with distinct capacity of production and social attributes were selected to analyze.

Results showed that smallest producer and the most technified producer rank in similar position of sustainability. Also have been observed the smallest producer ranked as lowest when not taking account social variables as tradition and owner's age in the same framework of analysis.

Further development of study is still necessary. The study is limited by the scarcity of information due to the small sample size which did not allow to infer or extrapolate. Thus, an additional uncontrolled factor is the subsequent necessity to proof sustainability and adoption of machine causation though causal analysis.

Key-words: sustainability, data envelopment, multi-criteria, geographical indication, cheese, Canastra 


\subsection{Introduction}

A geographical indication (GI) is a label designed to products, primarily rural products, which conform to a delimited geographical location (ALLAIRE; CASABIANCA; THÉVENOD-MOTTET, 2011). The adoption of such label respond as a approval that the product own distinct attributes, is manufactured using traditional, local methods and resources (ADDOR; GRAZIOLI, 2002). French Champagne, Italian Parma Ham, Colombian Coffee and Japanese Wagyu beef are typical products labeled as GI (DESELNICU et al., 2013).

Suh e MacPherson (2007) cite that geographical indication label can have a significant impact on a region's economic performance, cultural heritage and environmental characteristic because it protects the identity of indigenous products and materialize customary pattern of beliefs, actions and behaviors of the region. Recent studies have focused on the positive effects of GIs on farmer livelihoods, local communities, and the environment (BELLETTI; MARESCOTTI; TOUZARD, 2017; CAENEGEM et al., 2014)

It is now well established from a variety of studies, that communities throughout the world have over centuries developed typical products, based on the unique interaction between local know-how (including selection, production and processing) and environmental conditions such as the soil and climate(BARJOLLE; PAUS; PERRET, 2009). Moreover, GI is an intangible artifact intentionally manufactured with several dimensions which should coexisted in a set of specific social, environmental and economic parameters(STASI et al., 2011). The intentional mismanagement or even negligence over GI administration may jeopardize long term sustainability of the label, exposing permanent negative effects on the local socioeconomic fabric and environment (LOUREIRO; MCCLUSKEY, 2000).

In this sense, researchers, policymakers and experts have increasingly added relevance to the strong relationship between GI, long term existence and a multidimensional perspective management practice. However, while the theoretical associations between those variables have been explored by a number of scholars (RAPOSA et al., 2016), very few empirical studies have closely examined the relationship between GI schemes, sustainability and a multi-criteria dimension(DAGNE, 2015).

Besides the distance between the scientific production of GI and sustainability, developing countries have increasingly begun focusing on GIs as a tool to protect local products and traditions(MARTÍNEZ-GARCÍA; DORWARD; REHMAN, 2013; BRAMLEY, 2011). Much of the increase in GI as strategy to foster rural development is the steady increase rejection for industrial agricultural model food, which is associated with food safety concerns, environmental degradation, and rural poverty (PARROTT; WILSON; MURDOCH, 2002).

From consumer's perspective, different segments use GI as distinctive signs as 
Capítulo 5. Sustainability assessment propose in a micro farm level perspective for geographical 60 indication regions

markers of quality, assurance of collective reputation in order to avoid risks of asymmetric information concerning product quality. Thus, potentially more willing to pay for the price premium inherited to this products (DESELNICU et al., 2013).

Decisevely, those economic incentives drives GI producers to adopt different technologies. According to Delord, Montaigne e Coelho (2015), Genius et al. (2013), Ogada, Mwabu e Muchai (2014), the adoption of technologies on geographical indication regions is a key component which drives substantial transformations, leading to widespread of changes in GI.

Rombach, Ricchieri e Bitsch (2017) compared eight geographical indication systems and found positive results in reference to biodiversity conservation and maintenance of cultural landscapes. However, at the same time, they also found that processes of intensification (e.g., farm specialization, mechanization, increased reliance on inputs) - with visible environmental impacts - are present and possible under GI protection.

Agostino e Trivieri (2014), Vita et al. (2013) says that on the business side, GIs supported by increase level of machinery are market-oriented. They often align with emerging trade demands since they tend to have standards for quality, traceability and food safety. Also, as GIs possess many of the characteristics of an upmarket brand, machinery is responsible to increase production output and capture more value. Also, given scalability gain, GI can have an impact on entire supply chains and even other products and services in a region and thereby foster business clustering and rural integration.

Zheng et al. (2014) report that as demand increase, machinery increase production efficiency but also environmental discharge, impacting on local biodiversity. Belletti et al. (2015) finds due to adoption of different range of machines, discharge volume increase after machinery adoption however discharge by product unit reduces due to efficiency increase.

Thus, GI regional areas are more likely to suffer inverse exodus attracting people out of the region able to invest in new facilities and consequently expelling indigenous population resulting in local social fabric dissolution and lost of traditional methods of production, a key component of GI products (CONNEELY; MAHON, 2015).

Further, structuring GI take years and putting poor design or having inadequate governance structures can favor minority interest groups. For instance, badly managed GIs can be dominated by just a few enterprises. In some cases, GIs can exclude the poorest producers or not well organized producers by designing a minimum of investment in technologies unreachable for the vast majority of producers as the case of Mexican Cheese (CRESPO; RÉQUIER-DESJARDINS; VICENTE, 2014). In such case, GI certification can not be provided due to the absence of quorum or acceptance of the people (BELLETTI; MARESCOTTI; TOUZARD, 2017; QUIÑONES-RUIZ et al., 2017). 
Likudis et al. (2014), Rosa (2015) investigates sanitary traits such as product safety due to different level of products and adoption of machines. It finds that product safety increase but blind tests of taste reveals no significant difference between high industrialized product and highly technified artisan producer.

Regarding marketing management, Hajdukiewicz (2014) says that for producer regions, GIs convey several unique characteristics that allow products to distinguish themselves and escape the commodity trap of undifferentiated products trading primarily on the basis of price. This differentiation from commodities and adoption of machine can offer a valuable competitive advantage that is difficult to erode (LIKOUDIS et al., 2016). However, customer perception over GI label erodes drastically as perceived as highly technified or not artisan.

Finally, Vats (2016) examine the relation of machinery adoption and rural densification through territorial development strategies using GI label. The author noted population rejuvenation through increase of retention of population youth and attraction of individual from outside given increase of opportunities. The increase in land prices and cost of living drives vulnerable population out of the region.

The main limitation of those previous studies, despite the strong evidence of machinery influence over geographical indication, little research exists on assessing machine adoption technology impact on GI on an abroad and interlinked approach considering different facets simultaneously inherited to GI labels(PARDOS; RUBIO; FANTOVA, 2008; CAENEGEM; CLEARY, 2017). Late empirical research has broadly concentrate on legislation, legal procedural for certification process, production efficiency, sanitary characteristics of the product and marketing (VANDECANDELAERE et al., 2013; NGOKKUEN; GROTE, 2013) but each separately. Indeed, very little is currently known regarding a sustainable development of GI that consider machinery adoption influence in a multi-criteria perspective. This is due to great variety of variables impacted by and a hard to achieve optimum scenario due to trade-off between those variables (VANDECANDELAERE et al., 2018; MENAPACE; MOSCHINI, 2014; BONADONNA et al., 2017; MOIR, 2016).

This prospective study was designed to investigate the optimum point of adoption in machinery pursuing a broad approach for sustainability assessment taking into account the environmental, economic and social facet synchronously for producers located in a GI certification region.

In order to achieve this objective, this paper is structured as follows: the second section provides a methodological procedure description. In this context, conceptual framework, the theoretical framework, object of study, data collection and analysis process will be presented more in detail. The third section presents the empirical results, including the data collection and model specification inputs. The last section concludes with a brief discussion of the machine adoption implications of the findings. 
Capitulo 5. Sustainability assessment propose in a micro farm level perspective for geographical

\subsection{Methodology}

\subsubsection{Theoretical framework for technology adoption assessment}

García, Dorward e Rehman (2012) note that the use of technologies such as machinery and tools plays an crucial role in GI regions by offering means of increasing profitability and improving competitive advantage.

But also the of increase of waste discharge (CAVALLO et al., 2014b), product decharacterization(FEBLES-GONZÁLEZ et al., 2011), product mischaracterization (JORDANA, 2000), lost of traditional methods of fabrication(BOWEN; ZAPATA, 2009), mass production (ÁLVAREZ et al., 2015) and inequality increase (CAVALLO et al., 2014a; CAVALLO et al., 2014b) are described too and can cause negative impact of the product are related to adoption of machine. Thus, the adoption rate of technology can impact in GI phenomena variables (LIU; BRUINS; HEBERLING, 2018).

In this study, we are going to use Espinoza-Ortega et al. (2007) framework of typology for technology adoption given high similarity of business sector, scale, GI maturity and level of economy development. The author formulate different typologies of innovation adoption given heterogeneous adoption rate of agricultural technology among small scale agricultural producers (MARTÍNEZ-GARCÍA; DORWARD; REHMAN, 2013; JAFFE; NEWELL; STAVINS, 2003). Owner education, age, access to credit, social pressure, technology transfer lead by unions and associations are central to adoption rate (NKONYA; SCHROEDER; NORMAN, 1997; MARIANO; VILLANO; FLEMING, 2012).

To measure the importance of each technology to artisan cheese producers, a Likert-type scale, where 1 of no importance and 5 very important. Farmers' reasons for adoption and non-adoption of each technology were obtained through open ended questions and the particular reasons for each technology were grouped. The number of technologies was divided into three classes following: Crop, Husbandry and Administration Technologies (MARTÍNEZ-GARCÍA; DORWARD; REHMAN, 2013; ARRIAGA-JORDÁN et al., 2002).

In the original paper, 37 technologies were listed and importance were asked to each producer. 12 technologies were classified as utmost importance and are brought in this study. Table 9 resumes all selected technologies. They have similar importance although investment values may differ. The variable BPM is a certification given by an sanitary auditory. Association to a Cooperative is a variable related to a cooperative reference from Canastra Region named as Associação dos Produtores de Queijo Canastra (Aprocan) (FRAZÃO et al., 2019; GUIMARÃES et al., 2011). The adoption of those technologies is measure by a Boolean value (yes or not). 
Tabela 9 - Technologies levels

\begin{tabular}{ccc}
\hline Crop or Forage related technologies level & Animal husbandry technologies & Administration Technification level \\
Improved Grassland & Artificial insemination & Access to agricultural credit \\
Pasture Management & Hammer mills & Data recording \\
Fertilizers and Herbicides & Milking machines & Production Best practices (BPM) \\
Tractors & Cow Comfort & Association to a Cooperative \\
\hline
\end{tabular}

\subsubsection{Data envelopment analysis - a multi-criteria algorithm for relative optimization}

The idea of data envelopment analysis (DEA) can be applied to multiple criteria decision making (MCDM) problems, if a final decision making solution is determined by seeing efficiencies (or inefficiencies) of alternatives by decision making units (DMUs) be identified with alternatives in multi-criteria decision analysis problems (AHMAD; BERG; SIMONS, 2006; JENKINS; ANDERSON, 2003). In this article, the abbreviation DMU will be used to refer to surveyed dairy farms.

Historically, DEA was suggested by Banker, Charnes e Cooper (1984), Charnes, Cooper e Rhodes (1978), and built on the idea of Briec (1997) which is concerned with the estimation of technical efficiency and efficient frontiers. The CCR model (TALLURI; SARKIS, 2002) generalized the single output/single input ratio efficiency measure for each DMU to multiple outputs/multiple inputs situations by forming the ratio of a weighted sum of outputs to a weighted sum of inputs. DEA is a method for measuring the relative efficiency of DMUs performing similar tasks in a production system that consumes multiple inputs to produce multiple outputs (COOPER; SEIFORD; TONE, 2007).

Relationships between DEA and multiple criteria decision analysis have been studied from several viewpoints by many authors. Belton e Stewart (1999) measured efficiency as a weighted sum of input and output. Ma et al. (2002) showed the equivalence between the CCR model and some linear value function model for multiple outputs and multiple inputs.Joro e Viitala (2004) proved structural correspondences between DEA models and multiple objective linear programming using an achievement scalarizing function.

In the following discussion, we assume that there exist $n$ DMUs to be evaluated. Each DMU consumes varying amounts of $m$ different inputs to produce $p$ different outputs. Specifically, DMU $j$ consumes amounts $x_{j}:=\left(x_{i j}\right)$ of inputs $\left.(i=1, \ldots m)\right)$ of inputs and produces amounts $y_{j}:=\left(y_{k j}\right)$ of outputs $\left.(k=1, \ldots p)\right)$ For these constants, which generally take the form of observed data, we assume $\left(x_{i j}>0\right.$ for each $\left.(i=1, \ldots, m)\right)$ and $\left(y_{k j}>0\right)$ for each $k=1, \ldots, p$. Further, we assume that there are no duplicated units in the observed data. The $(p x n)$ output matrix for the $(n)$ DMUs is denoted by $(Y)$, and the $(m x n)$ input matrix for the $n$ DMUs is denoted by $X . x_{0}:=\left(x_{1}, \ldots, x_{m}\right)$ and $y_{0}:=\left(\left(y_{1}, \ldots, y_{m}\right)\right.$ are amounts of inputs and outputs of DMUs, which is evaluated. In addition, $e$ is a small positive number and $1^{T}=(1, \ldots, 1)$ is a vector of all ones (NAKAYAMA; ARAKAWA; 
YUN, 2003).

So far, a number of DEA models have been developed. Among them, the CCR model, the BCC model and the FDH model are well known as DEA models foundation (COOPER; SEIFORD; TONE, 2000). These models are based on the domination structure in the primal form, and moreover these are characterized by how to determine the production possibility set in the dual form: the convex cone, the convex hull and the free disposable hull for the observed data, respectively.

With this in regard, an input orientation, one focuses on maximal movement toward the efficient frontier through proportional reduction of inputs, the CCR model model has been selected. The CCR model, which was suggested by Charnes, Cooper e Rhodes (1978), is a fractional linear programming problem and can be solved by being transformed into an equivalent linear programming one. Therefore, the primal problem (CCR) with an input oriented model can be formulated as the following (COOPER; SEIFORD; ZHU, 2011):

$$
\begin{gathered}
\text { Maximize }_{u k}, v i \\
\sum_{k=1}^{p} u_{k} y_{k_{0}} \\
\text { Subject to } \sum_{i=1}^{m} v_{i} x_{i 0}=1 \\
\text { Where } \sum_{k=1}^{p} \mu_{k} y k-\sum_{i=1}^{m} v_{i} x_{i 0} \leq 0, j=1, \ldots n \\
\text { And } \mu_{k} \geq \epsilon, v_{i} \geq \epsilon, k=1, \ldots, p ; i=1, \ldots, m .
\end{gathered}
$$

The dual problem $C C R_{D}$ to the CCR problem is given by:

$$
\operatorname{Minimize}_{\theta, \lambda, s_{x}, s_{y}} \theta-\epsilon\left(1^{T} s_{x}+1^{T} s_{y}\right.
$$

$$
\begin{array}{r}
\text { Which is subject to } X \lambda-\theta x_{0}+s_{x}=0, \\
Y \lambda-y_{0}-s_{y}=0, \\
\lambda \leq 0, s_{x} \leq 0, s_{y} \leq 0, \\
\theta \epsilon \Re, \\
\lambda \epsilon \Re^{n}, \\
{ }_{x} \epsilon \Re^{m}, \\
{ }_{y} \epsilon \Re^{p}
\end{array}
$$


The efficiency in the CCR model is introduced as follows:

Definition 1 (CCR - efficiency) A $D M U_{0}$ is CCR - efficient if and only if the optimal value $\sum_{k=1}^{p} \mu_{k} y_{k_{0}}$ to the problem (CCR) equals one. Otherwise, the DMU is said to be CCR-inefficient.

Definition 2 (CCRD - efficiency) A $D M U_{0}$ is CCRD - efficient if and only if the optimal solution $\left(\theta, \lambda, s_{x}, s_{y}\right)$ to the problem (CCRD), the following two conditions are satisfied when:

1. $\theta$ is equal to one

2. the slack variables $s_{x}$ and $s_{y}$ are all zero

3. Otherwise, the DMU is CCRD - inefficient.

As highlighted by Cooper, Seiford e Zhu (2011), the above two definitions are equivalent due to the well known duality of linear programming. Additionally, the production possibility set $P_{1}$ in the dual form of the CCR model is the convex cone generated by the observed data, which implies that the scale efficiency of a DMU is constant, that is to say, constant returns to scale. Namely, $P_{1}$ can be denoted by:

$$
P_{1} \&=(y, x) \mid Y \lambda \geq y, Z \lambda \leq x, \lambda \geq 0
$$

and the definition of CCR - efficiency can be transformed into the following:

Definition 3 DMU is said to be Pareto efficient in $P_{1}$ if and only if there does not exist $(y, x) \in P_{1}$ such that $(y,-x) l e q\left(y_{0},-x_{0}\right)$

It is readily seen that the Pareto efficiency in $P_{1}$ is equivalent to the CCR-efficiency.

The data cleaning, wrangling, analysis, algorithm deployment, plotting, statistical tests were implemented in python 3.6 using numpy (WALT; COLBERT; VAROQUAUX, 2011), pandas (MCKINNEY et al., 2010), matplotlib (HUNTER, 2007), sklearn (PEDREGOSA et al., 2011) and pulp for data envelopment analysis (MITCHELL; OSULLIVAN; DUNNING, 2011).

\subsubsection{Functional Unit}

The functional unit is defined as 1 ton of uniform quality of Canastra cheese leaving the dairy plant gate and packaged as an $1.1 \mathrm{~kg}$ block wrapped in plastic and cardboard. Canastra cheese is further classified as a semi-hard cheese with fat and protein contents of $34.8 \%$ and $24.8 \%$, respectively, on a total mass basis following federal guidelines over Canastra cheese product(ANDRADE et al., 2017). 
Capitulo 5. Sustainability assessment propose in a micro farm level perspective for geographical 66 indication regions

The Canastra Cheese shows the following physic-chemistry and sensory attributes: semi hard consistency, a buttery taste, compact texture, yellow-white color, white or thin rind and no crack is presented, cylindrical format, height of 4-6 cm, diameter of $15-17 \mathrm{~cm}$, weight of $1-1.2 \mathrm{~kg}$, it has a mildly acidic flavour but not pungent (DORES; NOBREGA; FERREIRA, 2013).

\subsection{Results}

Initially, this study aimed to carry out a cross-sectioned conclusive quantitative research using such variable from the entire dataset. However, considering such setback, this study relied on a study case approach selecting a set of distinct producer's profile regarding technology adoption. The researcher contact Serra da Canastra main association named Aprocan.

8 Aprocan employees were asked individually to select 4 producers with high level, 4 producers of medium level and 4 producers of low level of technology from a initial sample of 40 producers. The 2 most voted producers of each class were selected to compose our final sample. Giving time constrain to data collection, Aprocan detached an employee to guide us through the road along 3 days to visit and interview all 6 producers.

\subsubsection{Assessing technification level}

The table 10 describes each producer's level of technification. The average of level points and median is 6.3 and 6 respectively. The standard deviation is 1.77 , the minimum and maximum value is 5 and 10 respectively. The range value is 5 .

All six surveyed producers have adopted fertilisers and herbicides, automatic milking machines, access to agricultural credit, tractor and all producers follow BPMA guides. Thus, all surveyed producers have default technologies such as filtered water, vaccines and periodic exams, isolated production cheese zone and a ripening cheese house due to minimum requirement to join Aprocan.

Producers 3 and 4 adopted FPMA and Cow Comfort facilities in addition. As cow suffer heat stress in warm temperatures which reduces milk yield, cow comfort is a instalation which provides several facilities as a segregated roof insulation for resting and an kit of brushes to cows self-grooming.

Finally, It is apparent from this table that very few producers adopted all listed technologies as producers 5 and 6. Both producers have partnership arrangement with specialized companies which provide extension services for pasture management, grassland improvement and artificial insemination practices. Recently, producer 6 hired an contractor for data collection, recording and management. According to the producer, the 
purpose of data gathering is to subsidies production optimization initiatives.

Tabela 10 - Technologies levels

\begin{tabular}{ccccccc}
\hline Technology & ID 1 & ID 2 & ID 3 & ID 4 & ID 5 & ID 6 \\
Fertilisers and Herbicides & $\mathrm{x}$ & $\mathrm{x}$ & $\mathrm{x}$ & $\mathrm{x}$ & $\mathrm{x}$ & $\mathrm{x}$ \\
Milking machines & $\mathrm{x}$ & $\mathrm{x}$ & $\mathrm{x}$ & $\mathrm{x}$ & $\mathrm{x}$ & $\mathrm{x}$ \\
Acess to agricultural credit & $\mathrm{x}$ & $\mathrm{x}$ & $\mathrm{x}$ & $\mathrm{x}$ & $\mathrm{x}$ & $\mathrm{x}$ \\
Production Best practice (BPMA) & $\mathrm{x}$ & $\mathrm{x}$ & $\mathrm{x}$ & $\mathrm{x}$ & $\mathrm{x}$ & $\mathrm{x}$ \\
Tractors & $\mathrm{x}$ & $\mathrm{x}$ & $\mathrm{x}$ & $\mathrm{x}$ & $\mathrm{x}$ & $\mathrm{x}$ \\
Cow Comfort & & & & $\mathrm{x}$ & $\mathrm{x}$ & $\mathrm{x}$ \\
Financial Best practice (FPMA) & & & $\mathrm{x}$ & $\mathrm{x}$ & $\mathrm{x}$ & $\mathrm{x}$ \\
Hammer mills & & & & & $\mathrm{x}$ & $\mathrm{x}$ \\
Pasture Management & & & & & $\mathrm{x}$ & $\mathrm{x}$ \\
Improved Grassland & & & & & & $\mathrm{x}$ \\
Digital Data recording & & & & & & $\mathrm{x}$ \\
Artificial insemination & & & & & $\mathrm{x}$ & \\
\hline Total Points & 5 & 5 & 6 & 6 & 9 & 11 \\
\hline
\end{tabular}

\subsubsection{Performance on sustainability for the Canastra producers: intervals, hi- erarchy and policy implications}

The sustainability of the surveyed producers depends on the performance of each producer translated by their different indicators within the theoretical framework sectors of the 5SEnSU model.

Briefly, table 11 presents an input matrix of each producer. Further analysis showed that inputs magnitude increases from left to right except tradition and owner's age variable. What is interesting about the data in this table is that producers 2,3,4 and 5 have a quasi-linear increment of inputs and outputs. On average, when analyzed the gathered dataset, $90 \%$ of the respondents reported that be according to producer's 2 profile. This general profile is that mean age of owners with cheese production in the region was 553.3 years and produce cheese since childhood as a daily routine chore. More recently, given Canastra region increase of popularity, the number of new immigrated producers from external regions, either by family relationship with local producers and/or seeking opportunities to develop new business, it is expected to increase over the years this segment of population. Such segment is represented by the producer 3,4 and 5 .

Closer inspection of the table shows the oldest producer (ID1) begin to produce since he was 14 years old. This producer was born and raised his children in the region. He began to produce cheese 57 years ago for own consumption following regional manufacturing techniques. Nowadays, he is a very renowned producer and very often requested to participate television programs and documentaries. With successive increases in intensity of the awareness, the revenue for each kilo moved further the average price of this sample. In addition, he is the smallest producer among the group. 
Capítulo 5. Sustainability assessment propose in a micro farm level perspective for geographical 68 indication regions

Interestingly, the producer ID 6 was observed to be the largest producer and the youngest one among the group. He produces artisan cheese for 4 years and have settled in Canastra with his whole family from an predominantly urban region. In all cases, the informants reported that the initial investment was used to acquire several equipements, hire technical staff and education tuition fee for specialization courses. Although regional development bank partialy funded this investment, the biggest part proceed from the owners fund. A clear benefit of total local hired work force and owner's age in the prevention of rural exodus could be identified in this case.

Tabela 11 - Matrix of inputation values

\begin{tabular}{lccccccc}
\hline K & Variable & ID $\mathbf{1}$ & ID 2 & ID $\mathbf{3}$ & ID $\mathbf{4}$ & ID 5 & ID $\mathbf{6}$ \\
K1 & Electricity & 1 & 1 & 2 & 3 & 3 & 3 \\
K1 & Area & 105 & 171 & 223 & 301 & 358 & 457 \\
K2 & CH $_{4}$ & 5950 & 5500 & 12300 & 10500 & 22750 & 36750 \\
K2 & Whey & 110 & 132 & 253 & 209 & 528 & 484 \\
K3 & Revenue & 345 & 300 & 575 & 475 & 1248 & 1232 \\
K3 & Size Herd & 17 & 22 & 41 & 35 & 91 & 105 \\
K4 & Work Force & 3 & 3 & 5 & 5 & 8 & 11 \\
K4 & Tradition & 57 & 48 & 12 & 15 & 5 & 4 \\
K5 & Tax & 81 & 63 & 132 & 118 & 349 & 344 \\
K5 & Owner's Age & 71 & 65 & 51 & 55 & 42 & 35 \\
\hline
\end{tabular}

As exposed in the calculation procedure modeling, producers with higher efficiency are more sustainable, since their overall performance is closer to the near-optimum goals. Table 12 presents each producer sustainability efficiency and machinery level. From the table, it can be seen that by far high contrast between producer 1 and producer 6 which a highly technified in contrast to a low level technified but both achieve similar sustainability efficiency.

Tabela 12 - Sustainability level and machinery level for the producers

\begin{tabular}{ccccc}
\hline Rank & ID & Sustainability efficiency index 1 & Sustainability efficiency index 2 & machinery index \\
1 & ID1 & 1 & 0.65 & 5 \\
3 & ID2 & 0.84 & 0.71 & 5 \\
6 & ID3 & 0.55 & 0.73 & 6 \\
5 & ID4 & 0.63 & 0.84 & 6 \\
4 & ID5 & 0.72 & 0.93 & 9 \\
2 & ID6 & 0.94 & 1 & 10 \\
\hline
\end{tabular}

Producer ID2 and ID5 are ranked as 3 and 4 position even when producer ID 5 is a highly technified producer, which presents near double of machinery level than ID2. Revenue, tradition and owner's age were important weights that favor producer ID2. The 
graph 6 represents the curve of machinery Level index (primary y-axis) and sustainability efficiency (second y-axis) having distributed along the x-axis, which represents each producer profile. Through visual examination of the graph, no strong correlation was found between the sustainability index and the technfication score in this case. Interestingly, we can notice efficiency level index follow a positive polynomial quadratic function while machinery level decreases linearly. As mentioned in the literature review, the observed increase in sustainability could be attributed by different spheres such as tradition brought by the producer in its product, translated in better margin of profit on selling price.

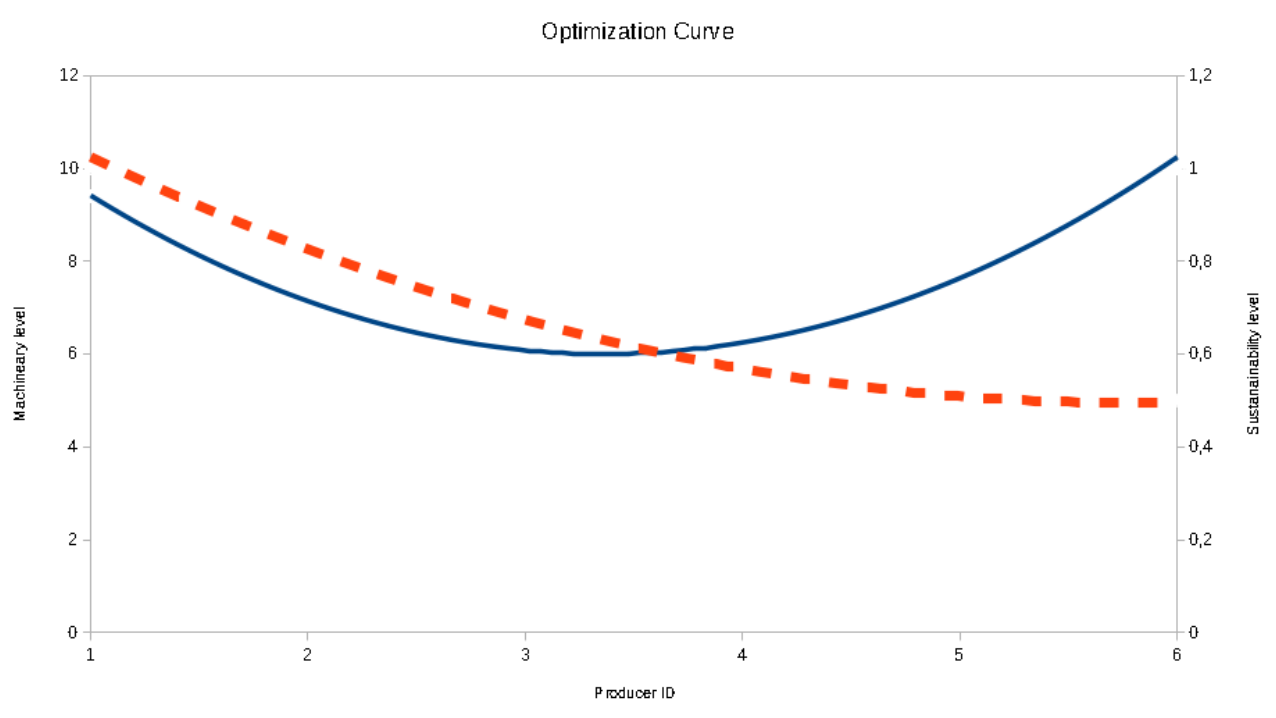

Figura 6 - Optimization Curve Frontier

The same model have been performed removing all variables correlated to the social dimension as owner's age and tradition brought by the owner. The outcome of this model has resulted in strongly correlation of sustainability index over machinery level adoption. In contrast to earlier findings of the previous model, highly invested producers can be benefited achieving a high sustainability level index, by not contemplating social facets simultaneously in the assessment of sustainability. These results therefore need to be interpreted with caution given sample representative.

Overall, these results indicate that an integrated multi-criteria perspective should be pursued given the arise number of postulated investigations showing convergence between perceived cultural capital erosion, unrestrained exploitation of the regional natural resources, decrease in the sales prices and exclusion of local residents in GI regions due to social exposure and misleading. 
Capitulo 5. Sustainability assessment propose in a micro farm level perspective for geographical

\subsection{Conclusion}

Technology adoption is an important driving factor to foster local economic. However, as GI requires attention to social and environmental sectors as well, prior studies have studied more emphatically those dimensions only in a bi-dimension angle. For instance, not considering social implications over minimum requirements of technology investment in a GI. In reviewing the literature, no study was found on the association between technology adoption and a more broad dimension assessment framework able to deal with different dimensions simultaneously and pursue optimal points of efficiency. The present study was designed to determine the effect of social, environment, economic features over adoption technology to guide a decision making process towards efficiency in relevant dimensions.

The application of the 5sensu model for variable selection is a key component of this study because it brings theoretical support such as the holistic view of the system, the recognition of the double functions for the environment and society, and the importance of using a multi-criteria approach when dealing with sustainability. Such approach allows measuring the system's sustainability performance in order to rank and classify them in levels of sustainability. Thus, data envelopment analysis supports the calculation algebra within the proposed framework as a multi-criteria analysis, allows the sustainability performance evaluation of the different sectors considering the goals of the selected indicators. To measure degree of technology adoption of each surveyed producer, the utilized framework was able to cover all different technologies presented in the data collection process in Canastra Valley.

With respect to the research question, it was found that the study allowed ranking the sustainability level of each surveyed producer, where the performance in the different sectors is clearly presented. Producers were ranked according to their sustainability levels, as well as in adoption of technology level. In this sense, results showed that ID 1 and ID 6 holds the best rank when all indicators are considered although producer 1 is considered the smallest producer among the sample. However, producer 1 is ranked in the lowest rank not taking account social variables as tradition and owner's age, crucial for a long term sustainability development of Gi's. Such result is mainly due to the low output capacity of the producer 1 and 2, which are in general the main profile of producers in Canastra Valley.

These findings may help us to understand the impact of technology over GI by providing an integrated structure for micro perspective assessment but also an actionable leverage represented by different technologies and their respective investment. Future studies on the current topic are therefore recommended. There is abundant room for further progress in determining adoption technology impact on GI sustainable development. While having access to the dataset in this study provided support to the develop- 
ment of the study, quality defects and data incongruency may jeopardize decision-making process supported by these datasets. The collection, gathering, cleansing, storage and retrieve of data by itself should be considered an important contribution to all stakeholders. For instance, France, Italy and Swiss have officially allocated departments and agencies responsible for such tasks. Those primary set of datasets are supplied directly to foster agencies, academical institutions and companies in order to improve the competitive of these regions through direct and indirect public policies arrangements. Notwithstanding these limitations, the study suggests that a more robust survey should be developed considering not only Boolean questions but also quantitative/numeric questions related on. A natural progression of this work is to develop a longitudinal approach to track each subject over time. Such study could assess the long-term effects of agricultural credit in small farms. Finally, different geographical region's producers can be surveyed as Bento Gonçalves (RS), Araxá (MG) and so on in order to provide more definitive evidence. 



\section{Sustainability assessment in a macro farm level perspective in geographical indication regions}

This paper is titled as "Sustainability assessment in a macro farm level perspective in geographical indication regions"and presents an integrated quantitative approach to identify and assess sustainability of farm typologies considering a broadly environmental, economic and social spectrum simultaneously located in a GI certification region.

A quantitative approach was employed combining unsupervised clustering algorithms for typology construction, statistical tests for groups dissimilarity and intra-homogeneity significance and a multi-criteria algorithm for sustainability calculation using a theoretical background support for variable selection and their respective comprehension. This study provided an important opportunity to advance the understanding of macro orientation of assessment in sustainability.

Again, the nature of actionability to improve sustainability in a macro perspective remains unclear in the present corpus of past studies. This paper contributes to strengthen the theoretical framework using same variables as previous study by exploring general strategy management perspective of GI's.

If carefully observed it may suggest that every farm is singular and faces particular problems and dilemmas related to decisions to be made, whose set of solution could also be unique. However, it is not a viable option in practice. So, the small scale dairy farmers needs to be classified to form similar groups for who similar recommendations and procedures can be made more effectively. From a macro perspective of public policy and general coordination strategy management over GI regions, such approach might fairly improve the efforts to improve general sustainability of each cluster. The quantitative framework and their respective combination of tools and procedures here provides one of the first investigations into macro perspective. 


\section{Sustainability assessment in a macro farm level perspective in geographical indication regions}

\section{Abstract}

Geographical indication label is a crescent regional development strategy and a long term sustainability development of Gi's requires dedicated attention to assessment and correctives measures.

In this context, a quantitative approach was employed aiming to assess the sustainability of artisan cheese producers considering social, environment, economic orientation in a macro strategy perspective. The object of study is the entire population of artisan cheese producers in Canastra Valley. Farm typology and their respective assessment and analyse of sustainability were performed selected.

Results showed that clustering process indicated a high homogeneity of the farms within the three clusters, and meaningful differences in farm types were characterized by relevant dissimilarities in terms of resource availability. The main differences between the clusters were the tradition, whey produced, total cheese output, gross revenue and paid tax. between the clusters were the tradition, whey produced, total cheese output, gross revenue and paid tax. These variables have a strong impact in the design of farm level strategies, affecting directly the choice of the farms inputs in terms of an integrated and broad concept of long term sustainability.

Further development of study is still necessary. The high homogeneity that was found within the clusters could be related more to the stratification that was carried out when selecting the target population (specialized cheese production systems of southeast Brazil). Moreover, investigations in further GI areas may prevent over fitness of the proposed model by training over a larger sample of GI.

Key-words: sustainability, data envelopment, multi-criteria, geographical indication, cheese, Canastra 


\subsection{Introduction}

A geographical indication (GI) is a label designed to products, primarily rural products, which conform to a delimited geographical location (ALLAIRE; CASABIANCA; THÉVENOD-MOTTET, 2011). The adoption of such label respond as a approval that the product own distinct attributes, is manufactured using traditional, local methods and resources (ADDOR; GRAZIOLI, 2002). French Champagne, Italian Parma Ham, Colombian Coffee and Japanese Wagyu beef are typical products labeled as GI (DESELNICU et al., 2013).

Suh e MacPherson (2007) cites that geographical indication label can have a significant impact on a region's economic performance, cultural heritage and environmental sectors because it defend the identity of endemic products and materialize customary pattern of beliefs, actions and behaviors of the region. Recent studies have focused on the positive effects of GIs on farmer livelihoods, local communities, and the environment (BELLETTI; MARESCOTTI; TOUZARD, 2017; CAENEGEM et al., 2014)

It is now well established from a variety of studies, that communities throughout the world have over centuries developed typical products, based on the unique interaction between local know-how (including selection, production and processing) and environmental conditions such as the soil and climate(BARJOLLE; PAUS; PERRET, 2009). Moreover, GI is an intangible artifact intentionally manufactured with several dimensions which should coexisted in a set of specific social, environmental and economic parameters(STASI et al., 2011). The intentional mismanagement or even negligence over GI administration may jeopardize long term sustainability of the label, exposing permanent negative effects on the local socioeconomic fabric and environment (LOUREIRO; MCCLUSKEY, 2000).

In this sense, researchers, policymakers and experts have increasingly added relevance to the strong relationship between GI, long term existence and a multidimensional perspective management practice. However, while the theoretical associations between those variables have been explored by a number of scholars (RAPOSA et al., 2016), very few empirical studies have closely examined the relationship between GI schemes, sustainability and a multi-criteria dimension(DAGNE, 2015).

Besides the distance between the scientific production of GI and sustainability, developing countries have increasingly begun focusing on GIs as a tool to protect local products and traditions(MARTÍNEZ-GARCÍA; DORWARD; REHMAN, 2013; BRAMLEY, 2011). Much of the increase in GI as strategy to foster rural development is the steady increase rejection for industrial agricultural model food, which is associated with food safety concerns, environmental degradation, and rural poverty (PARROTT; WILSON; MURDOCH, 2002).

Moreover, the intensification and specialization of agricultural production in GI 
Capítulo 6. Sustainability assessment in a macro farm level perspective in geographical indication 76 regions

regions followed global and local drivers such as global competition and demand increase have caused substantial damage to both the environment and natural resources. At the same time, the survival of a number of small farms is presently threatened by both low productivity and low incomes, affecting social spectrum such as rural exodus(COMMINS, 2004).

Quantitative system approaches that propose the assessment of sustainability and re-designing of entire livelihood strategies in a systemic way proved to be highly promising to explore possibilities for farm innovation aimed at sustainable development(MĄDRY et al., 2013). The effectiveness of these approaches can be improved by integrating farm typologies in the research process (KÖBRICH; REHMAN; KHAN, 2003).

Typology identification is an efficient method to summarize the diversity of farming systems, intrinsic to every rural area(RIGHI et al., 2011). If carefully observed it may suggest that every farm is singular and faces particular problems and dilemmas related to decisions to be made, whose set of solution could also be unique. However, it is not a viable option in practice. So, farmers needs to be classified to form similar groups for whom similar recommendations and procedures can be made more effectively(EUPEN et al., 2012).

This approach can be used to assess and infer the farm level in agricultural development research that analyses in a macro spatial perspective. As the farm is the key level from which decisions on land, natural resources management and administration are made, policy evaluation/design can take advantage from an assessment of farm typology to understand the trade-offs between sustainability and different farming systems (EMTAGE; HERBOHN; HARRISON, 2006; TAVERNIER; TOLOMEO, 2004).

However, although the effectiveness of these approaches for farm typologies is widely accepted, they present two relevant disadvantages when applied in the context of strongly-oriented participatory research which involves different stakeholders and their respective point of view of a given agricultural sector.

Firstly, the methodologies based on cluster analysis (CA) in farm typology are still sensible to initial selection of variables. Different outputs and interpretations in a same study case have been displayed varying only one variable (BIDOGEZA et al., 2009; JOFFRE; BOSMA, 2009; MILÁN; ARNALTE; CAJA, 2003). This can also be seen, as agricultural systems have been classified mostly using qualitative measures based on subjective assessments(TAVERNIER; TOLOMEO, 2004).

Secondly, sustainability of farming systems studies has been historically dependent on constant productivity for long periods of time. Although there are several approaches in the literature to evaluate agricultural sustainability, mostly previous studies of farm typology indeed focus on production efficiency variables(MILÁN; ARNALTE; 
CAJA, 2003). However, sustainability needs abroad understand which embraces social, economic and environment dimensions. Which usually, sustainability issues result in a trade-off between environmental, economic and social dimensions, making assessment no trivial(PITTELKOW et al., 2015).

The objectives of the present work are threefold. The first object take steps contributing to fill this gap on typology in sustainability studies proposing a framework for variable selection in an attempt to overcome subjectivity by discussing its application to a case study in Brazil (BIDOGEZA et al., 2009; JOFFRE; BOSMA, 2009; MILÁN; ARNALTE; CAJA, 2003). This procedure has been developed to be integrated within the context of management and scientific research, that were strongly based on the interaction among researchers, farmers, extensionists, private advisors and decisions makers.

The second objective is to examine how this procedure can be integrated in a quantitative system approach as a tool to investigate, select variables of interest, classify, assess and communicate at farm level results of different livelihood strategies at the regional level.

The last contribution of this paper refers to the case study itself. The considerable amount of the data obtained from field research may be used to generate several socioagronomic indexes. Among those are the ones pertaining to its agricultural sustainability. According to Landais (1998), this information may influence public policy for the region in terms of support, research, financing and others.

The methodological approach taken in this study is a methodology based on a quantitative approach, integrating a variable selection procedure embed in a theoretical framework able to deal with several dimensions of sustainability simultaneously, followed by an unsupervised method of clustering and finally and an multi-objective assessment method able to handle conflictuous objectives between the variables of different livelihood strategies at the regional level.

This paper has been divided into four parts. Second part it gives a brief overview of the methodology regards this study. Third, it will then go on to results. The fourth section presents the conclusion of the study proposal.

\subsection{Materials and Methods}

\subsubsection{Grouping farms in clusters}

Initially, all variables were standardized by function unit to avoid the influence of different levels of variation due to the unity of measure. Outliers were excluded using a percentile bellow $1 \%$ and above $99 \%$ value exclusion due to to their efficiency and readily reproducible statistical technique. 
Capítulo 6. Sustainability assessment in a macro farm level perspective in geographical indication

Farm groupings were generated by using a combination of principal component analysis(PCA) and K-means. Those method is particularly useful in studying sustainability assessment due to standardization procedure, convenience to use small samples from each cluster, comprehension over a large and representative phenomenon and visualization of the formed clusters (EUPEN et al., 2012; KOSTROWICKI, 1977; TAVERNIER; TOLOMEO, 2004).

K-means clustering was used to group the farms according to the group average link method (WAGSTAFF et al., 2001). Groups of farms were identified by elbow rule and coefficient of silhouette. Such a choice, which determines the number of clusters, was handled with a heuristic procedure, through a subjective inspection of the graphs (SINGH; YADAV; RANA, 2013).

The most representative farm groupings, in terms of the number of farms included, were selected for farm typology characterization. Some small clusters were also considered for the typology characterization based on their dissimilarity with the largest groups, in order to represent boundary situations of resource availability. The choice of which small clusters to include in the characterization was carried out by studying the relative distances between the groups.

A fundamental step for any unsupervised algorithm is to determine the optimal number of clusters into which the data may be clustered. The Elbow method is one of the most popular methods to determine this optimal value of $\mathrm{k}$. Inertia is the sum of squared distances of samples to their closest cluster center. To determine the optimal number of clusters, we have to select the value of $\mathrm{k}$ at the "elbow" is the point after which the inertia start decreasing in a linear fashion(BHOLOWALIA; KUMAR, 2014). Another method to determine the optimal value is silhouette coefficient(ARANGANAYAGI; THANGAVEL, 2007). This technique calculate using the mean intra-cluster distance (a) and the mean nearest-cluster distance (b) for each sample. The Silhouette Coefficient for a sample is (b - a) $/ \max (a, b)$. To clarify, b is the distance between a sample and the nearest cluster that the sample is not a part of. This function returns the mean Silhouette Coefficient over all samples. The best value is 1 and the worst value is -1 . Values near 0 indicate overlapping clusters. Negative values generally indicate that a sample has been assigned to the wrong cluster, as a different cluster is more similar.

In the variable level, analysis of variance (ANOVA) were tested against each other variable in the contained cluster whether two or more population means are equal as null hypothesis, and therefore generalizes the t-test beyond two means (CELEBI; KINGRAVI; VELA, 2013).

Finally, PCA performs dimension reduction via singular value decomposition (SVD) to extend noise reduction properties. Then, the first and second dimensions with the largest explained variance are selected to align with $\mathrm{y}$-axis and $\mathrm{x}$-axis respectively (DING; 
HE, 2004). The previous formed k-means and their formed centroid coordinates are plotted using first and second dimension aligned coordinates.

\subsubsection{Assessing sustainability of each cluster}

Data envelopment analysis(DEA) have been originally proposed by Charnes e Neralić (1990) to determine the efficiency of productive units, known as Decision-Making Units (DMU for short). These models take into account the resources used by the DMUs and the results they obtain. DEA models optimise the efficiency index of each individual DMU in order to estimate an efficient piece-wise linear frontier. These DMUs become the benchmarks for the inefficient ones (AHMAD; BERG; SIMONS, 2006; JENKINS; ANDERSON, 2003).

The two best-known DEA models are CCR and BCC(ALI, 1993). Traditionally, two different orientations are possible for these models when looking for the efficient frontier: input orientation and output orientation. The first one aims to promote DMU efficiency by an equiproportional reduction of the inputs levels. On the other hand, the aim of output orientation is to promote DMU efficiency by an equiproportional increase of the output levels.

There are two equivalent mathematical formulations for each DEA model. The first one is called the multipliers model and the second one is the envelope model. There is a dual relationship between these two models. From the multipliers model we obtain the efficiency index and the multipliers (weights) for each variable. From the envelopment model we also obtain the efficiency index. Moreover, this model also provides benchmarks and targets for each inefficient DMU.

Their proprieties must be known to model in DEA and interpret their results correctly. Two of the most important properties are as follows:

In any DEA model, every DMU that presents the best output $\mathrm{j} /$ input $\mathrm{i}$ ratio is necessarily efficient. This requires the causal relation between each output and each input to be checked in any DEA formulation (JORO; VIITALA, 2004). If this relation does not exist, meaningless results may appear. In other words, a badly formulated model might show a DMU to be efficient, for instance, based on its coffee production (output) in relation to its rice growing area (input), which is obviously nonsensical(BANKER; CHARNES; COOPER, 1984; CHARNES; COOPER; RHODES, 1978).

The main property of the CCR model is the proportionality between inputs and outputs at the frontier. This means that any increase (decrease) in the value of the inputs corresponds to a proportional increase (decrease) in the value of the outputs. DMUs can be grouped into efficiency categories. They could subjectively be classed as having low, middle or high efficiency, for instance Belton e Stewart (1999). 
Capítulo 6. Sustainability assessment in a macro farm level perspective in geographical indication 80 regions

The data cleaning, wrangling, analysis, algorithm deployment, plotting, statistical tests were implemented in python 3.6 using numpy (WALT; COLBERT; VAROQUAUX, 2011), pandas (MCKINNEY et al., 2010), matplotlib (HUNTER, 2007), sklearn (PEDREGOSA et al., 2011) and pulp to calculate the efficiency indexes in data envelopment analysis (MITCHELL; OSULLIVAN; DUNNING, 2011).

\subsection{Results}

\subsubsection{Descriptive statistical analysis}

Table 16 shows the average values and relative frequency for inputs and outputs in the model. Relative frequency means the ratio between the number of plots with a non-zero value for the variable to which the frequency refers and the total number of plots.

The first table provides the summary statistic for the two groups, presenting similar values for each variable except monthly revenue, dailly total milk production and size of herd - a general difference of $30 \%$ on those highlighted variables. Closer inspection of the table shows initial evidence that same number of workforce staff able to manage bigger herds and increase milk/cheese and revenue output. Surprisingly, revenue price is similar to both group. A likely explanation is given to geographic indication label granted to the region of Canastra Valley producers.

According to the population summary (median) the farms in the region could be described as small, not intensive production systems based on family labour, with a low equipment endowment in terms of irrigation and mechanization. Farms were represented by an average surface area of 52 hectares, of open-field vegetable cultivation and access to natural water source. According to Medeiros, Horodyski e Passador (2017), the utilizable farm area was larger than the utilized area on average. This is explained by the fact that farmers usually keep some fields on natural pasture for cattle grazing, aimed at self consumption. The average number of hired labour, employees and members belonging to the family was 34 , with the lowest coefficient of variation among all variables. 
Tabela 13 - Summary table of the variables

\begin{tabular}{ccccccccc}
\hline variable & count & mean & std & min & $\mathbf{2 5 \%}$ & $\mathbf{5 0 \%}$ & $\mathbf{7 5 \%}$ & $\max$ \\
Age(Year) & 757 & 52 & 13 & 18 & 42 & 52 & 62 & 91 \\
Land(hectare) & 757 & 91 & 105 & 3 & 24 & 52 & 115 & 556 \\
Tradition(Year) & 757 & 17 & 10 & 1 & 9 & 15 & 25 & 40 \\
Herd Size(head) & 757 & 26 & 18 & 1 & 10 & 25 & 40 & 80 \\
Electricity(KVA) & 757 & 1 & 2 & 1 & 1 & 1 & 2 & 3 \\
Whey $(\mathrm{Kg})$ & 757 & 127 & 95 & 1 & 54 & 99 & 180 & 405 \\
$\mathrm{CH}_{4}(\mathrm{Kg})$ & 757 & 2102 & 1500 & 77 & 790 & 1909 & 3080 & 6720 \\
Workforce & 757 & 3 & 1 & 2 & 3 & 4 & 7 & 11 \\
Revenue(R\$) & 757 & 163 & 125 & 22 & 64 & 127 & 228 & 645 \\
Tax $(\mathrm{R} \$)$ & 757 & 29 & 25 & 0 & 11 & 20 & 40 & 154 \\
\hline
\end{tabular}

However, average values can be only partially informative when representing the population features since all variables were reflected by highly skewed distributions as presented in the figure 12. All quantitative variables presented the highest absolute frequencies for the lower values of the measured range. Few outliers were separated from the majority, showing consistently lower values. This trend was particularly evident for the variables Land usage, $\mathrm{CH}_{4}$, WHEY, Herd Size, Revenue and Tax.

Thus, different distributions can be observed. Age and workforce display a normal distribution portraying a small size farm that employ 4 works aged approximately between 40 and 50 years old. Tradition describes a uniform distribution, signaling the existence of different generations of producers fixated in the Canastra Valley.
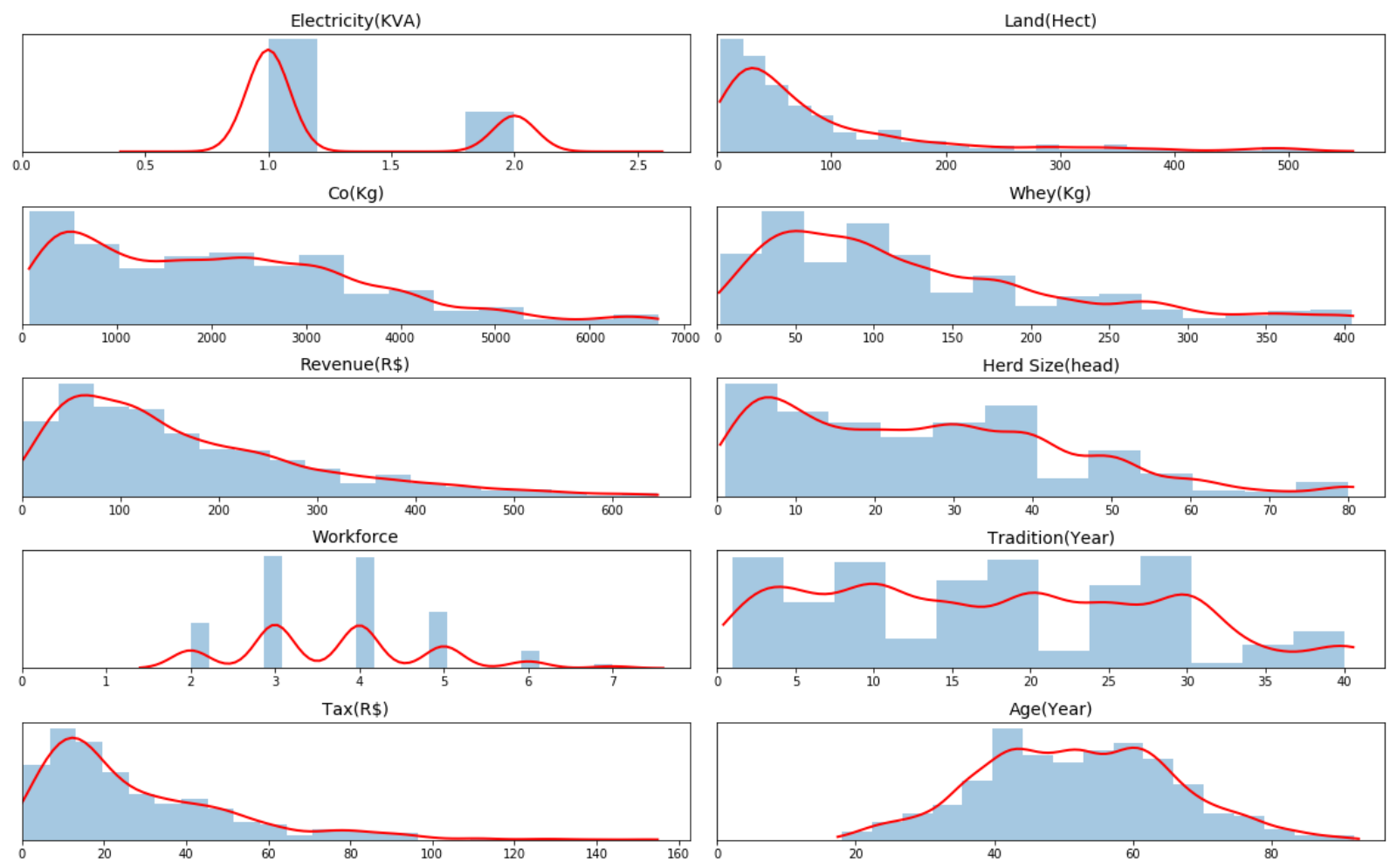

Figura 7 - Histogram of the variables 


\subsubsection{Definition of the farms grouping}

Farm groupings were defined by inertia value and silhouette coefficient to select the optimal $\mathrm{k}$ value for clustering. Figure 8 presents the breakdown of inertia obtained in the interactive process of clustering. It can be seen from the data in the figure that the $\mathrm{K}$ value of 3 reported a significant linearization than 4, following visual inspection. According to Ralambondrainy (1995), with a ranging within $10 \% 20 \%$ the results of inertia potentially provide a significant dissimilarity among the formed centroids.

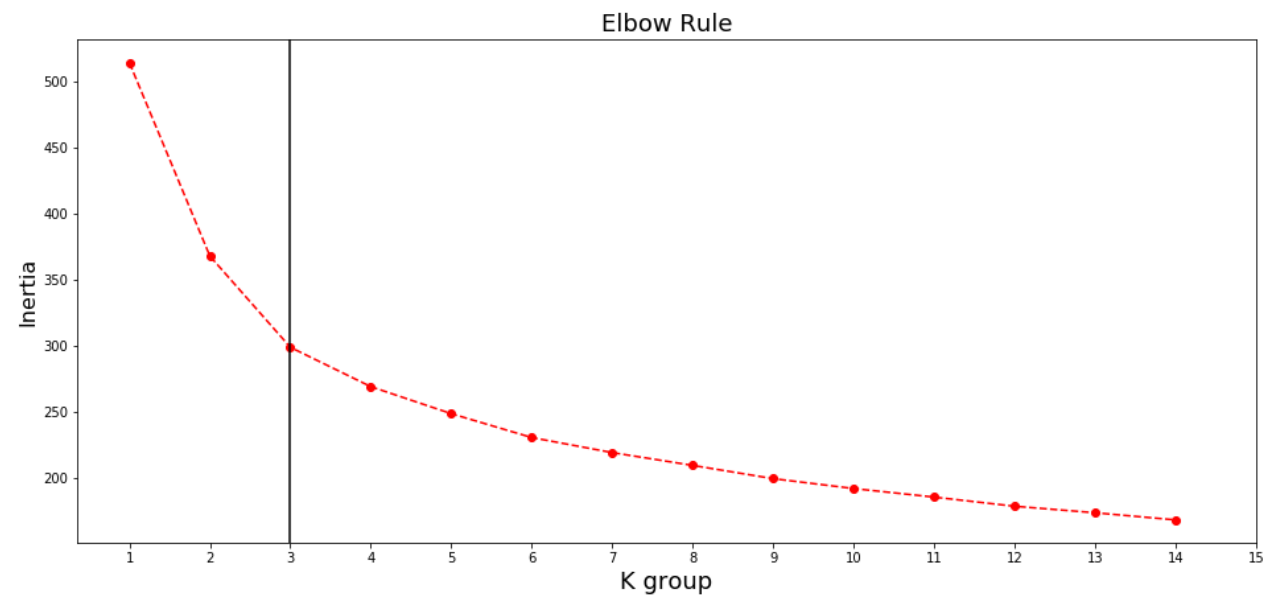

Figura 8 - Elbow

From the graph 9, the silhouete coefficient over all samples obteined best dissimilarity in $\mathrm{k}=3$ resulting in 0.71 . According to Rousseeuw (1987), the technique produced a satisfactory performance bearing the metric above 0.5 .

At this similarity level, 3 clusters were defined. Table 14 illustrates that group 1 were much larger than all other groups and together included $62 \%$ of the sample $\left(c_{1}=\right.$ 470), indicating a high homogeneity between the farms within the region.

Groups 2 and 3 represented $21 \%$ and $17 \%$ of the entire sample, respectively $\left(\mathrm{c}_{2}=\right.$ $158, \mathrm{c}_{3}=128$, each including more than 100 farms. These three clusters were considered to be important in representing the structure of the farming systems and were therefore selected the characterization of the farm types.

Tabela 14 - Number of farms included in each of the 3 main groupings defined by cluster analysis

\begin{tabular}{cccc}
\hline Cluster & Number of farms of each cluster & \% & Cum(\% \\
1 & 128 & $17 \%$ & $17 \%$ \\
2 & 470 & $62 \%$ & $79 \%$ \\
3 & 158 & $21 \%$ & $100 \%$ \\
\hline
\end{tabular}



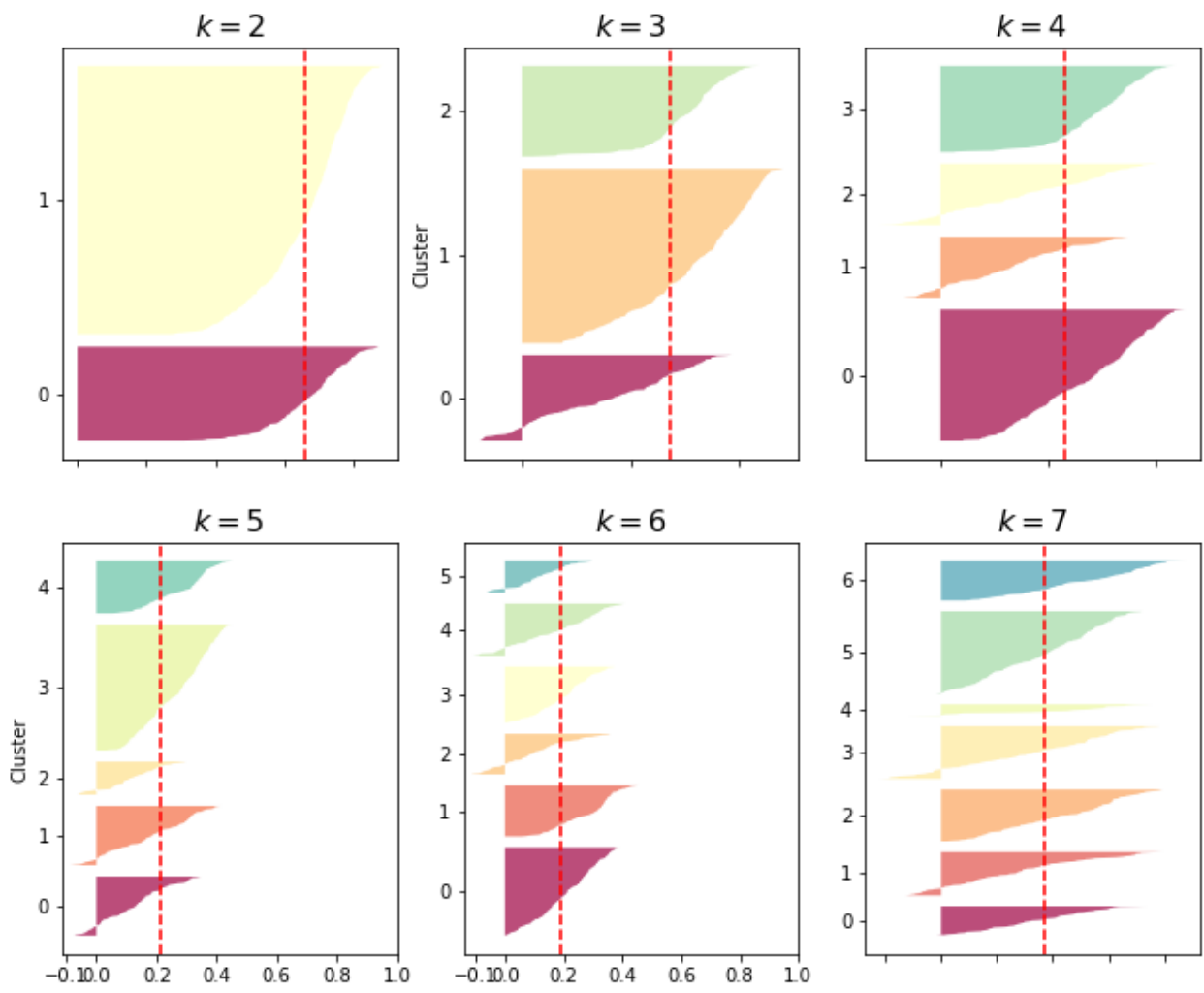

Figura 9 - Silhouete

In figure 10, after data normalization and PCA procedure carried out, for visualization purpose, the 2 most important components variance explained of the PCA representation was 0.57. According to Ralambondrainy (1995), with a variance ranging within 0.50 the results of PCA for the first 2 components provide a useful two dimensional picture using k-means classification outputs.

From the data in figure 11, the k-means plots represents the 3 farm groupings defined by the overlapping of PCA results at a similarity level of $57 \%$, corresponding to the 2 axis, $\mathrm{x}$ and $\mathrm{y}$. Each of the clusters, distinguished by different colors, belongs to the same centroid parent, where each points identify the farms. From this visual representation, we can see that group 1 and 2 have lower variance and speediness of the farms, concentrating in the mean intra-cluster in contrast to group 3. Although, the 3 presented clusters are self-contained and few areas of overlap between the formed clusters are noticed.

Together these results provide important insights into farm grouping and the coordinates in the plots enable to compare the distances between the groups, providing visual inspection to support decision making process selecting specific farms and using such plot as a general guidance for further investigation. 


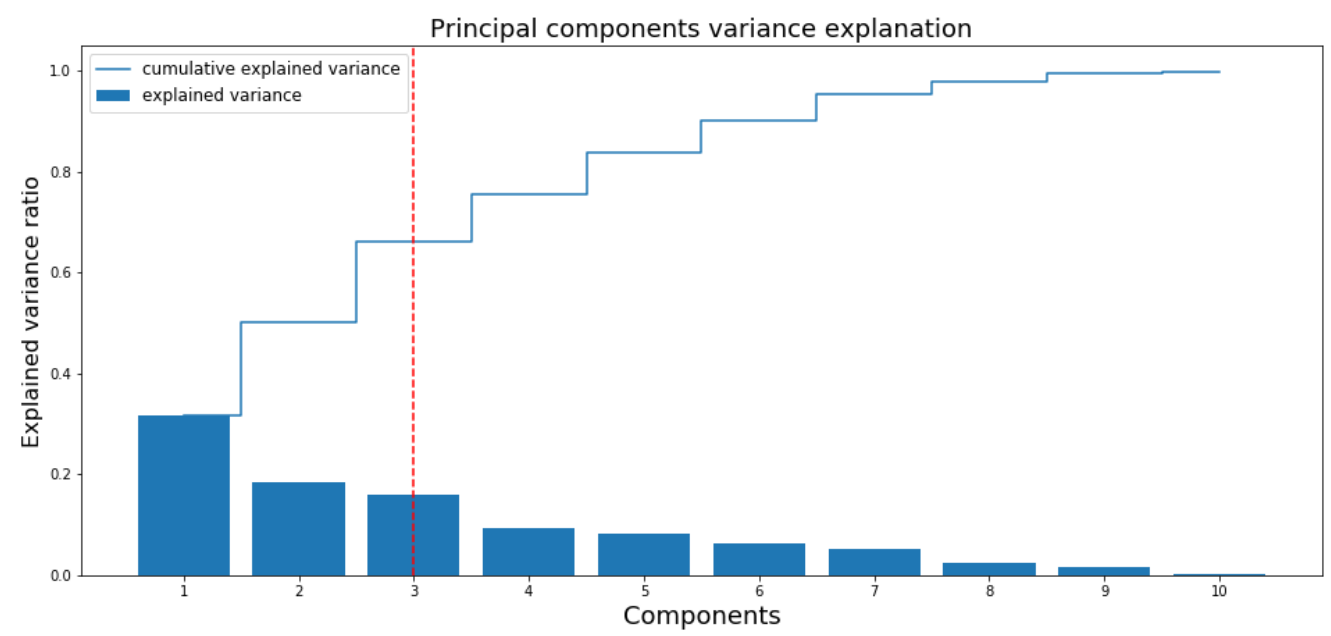

Figura 10 - Variance explained by the PCA

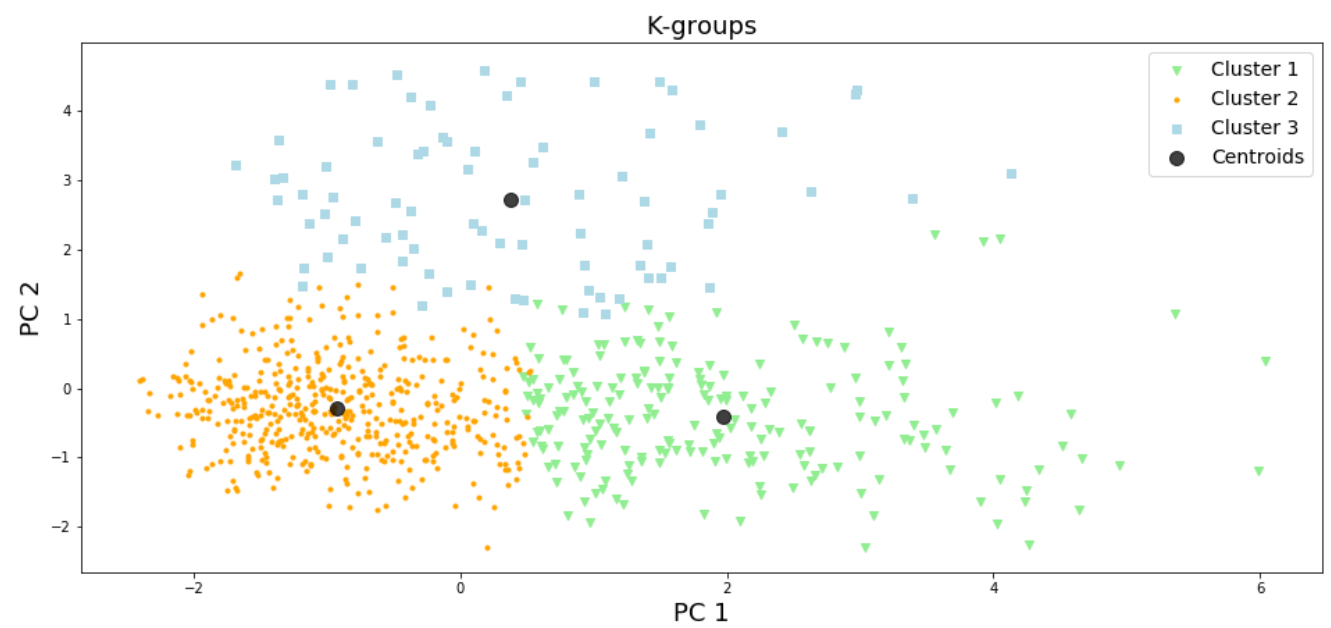

Figura 11 - K-means representation

\subsubsection{Assessing sustainability of the formed groups}

The DEA BCC model was chosen for this paper. This is justified, as there is no evidence that in Canastra increases in area or in labour would cause a proportional increase in production. Output orientation was chosen to measure efficiency, state benchmark and targets for each inefficient DMU maximizing output level (production) by utilizing fixed amount of inputs (resources).

Output orientation was chosen to check whether production justifies the used resources or not. It should be emphasised that both inputs can be controlled. As a matter of fact, having less temporary workers or fewer member of the family working the land can reduce labour. In the same way, cultivated area can be decreased by selling parts of it or by preserving native scrubs. This would be important to diminish the problem of 
scrub area loss in the Brazilian native forest region. To define sustainability typologies, a DEA model was run for all formed cluster. So, each given cluster have a efficiency index and their respective relative ranking.

Tabela 15 - Data envelopment analysis summary

\begin{tabular}{cccc}
\hline Cluster & Cluster I & Cluster II & Cluster III \\
Age(Year) & 46 & 51 & 53 \\
Land(Hect) & 51 & 41 & 58 \\
Tradition(Year)* & 8 & 25 & 40 \\
Price(Kg) & 8 & 8 & 9 \\
Herd Size(head)* & 35 & 19 & 34 \\
Electricity(KVA)* & 3 & 1 & 2 \\
Whey $(\mathrm{Kg}) *_{\mathrm{CH}_{4}(\mathrm{Kg})}^{188}$ & 2695 & 72 & 225 \\
Workforce $_{\text {Cheese }(\mathrm{Kg})^{*}}$ & 4 & 1539 & 2245 \\
Revenue(R\$)* & 35 & 10 & 3 \\
Tax $(\mathrm{R} \$)^{*}$ & 52 & 88 & 17 \\
Efficiency index & $100 \%$ & 14 & 22 \\
\hline & & & $57 \%$ \\
\hline
\end{tabular}

Table 15 shows the summary statistics for the three clusters. On average, the average efficiency were shown to have $31.66 \%$. As shown in the table, Cluster 1 ranked first position integrating absolute 1 . The second ranked cluster scores $57 \%$ of the efficiency compared to the first one. In the third position, cluster 3 efficiency is $45 \%$ relatively efficient to the first cluster and close to the second cluster a difference in $12 \%$ percents points.

Cluster 1 presents youngest owner's age comparing among the formed clusters. However, the average age of the owners in all clusters is 50 years old, way above the national average age - 33.5 and the State of Minas Gerais - 34.26 as well. The long term sustanaibility of the region is deeply dependent of the migration and increase of fertility given high labor intensity of the product and label.

The average price for selling Canastra cheese is also similar, $\mathrm{R} \$ 8$ - $\mathrm{R} \$ 9$ per kilo. According to (CRESPO; RÉQUIER-DESJARDINS; VICENTE, 2014), the average price was $3 \mathrm{R} \$$ kilo in 2013, an increment of $100 \%$ in the last 5 years. Such benefit can be detected in the population of producers and there is no statistical difference across the clusters.

After correction of minor typing erros in the original dataframe, the variable land also does have similar values across the clusters and does not have statistical significative difference even among them due to the presence of farmers who possess 35 time bigger than the average of the properties, particularly producers in classified in the cluster I. Land is an crucial input for the production however, such input does not impact in the efficiency index given their similarity which means the biocapacity limit of the territory is similar to the entire set of producers. 
Capítulo 6. Sustainability assessment in a macro farm level perspective in geographical indication 86 regions

Over tradition variable, the average number of years spent by the producers learning and manufacturing Canastra cheese is 26 years. All clusters exhibit statistical significant difference between them. Cluster III shows the highest value followed by cluster 2 and 1.

Cluster III is a segment formed of the population who were born and raise locally producing cheese since ever, mainly for subsistence, trade and supply past mining areas. Following the comparison between clusters, while cluster I and II have similar age, a significant difference in the tradition variable was recorded in. After examination of education degree and past professional record from the surveyed dataset, cluster I presents higher degree of education and previous record of work in urban areas, such peculiarity is similar to cluster II but presents lower degree of education. According to Medeiros, Horodyski e Passador (2017), after Canastra crescent economical decay in the decades of 70, a great portion of the population immigrate to recent installed steel companies areas. After a few decades, a mass dismissal provoked strongly lower education worker due to privatization process, making this fraction of worker return to Canastra and having inherited familiar properties and begin production of cheese due to economic necessity. Contrary to what cluster II pass through, subjects of cluster I returned back to Canastra, years later after a steady career overseas, as a result of arise of more promising scenario of opportunities in cheese production in conjunction with better quality of life.

Concisely, it can be noticed the highest consumption of resource is displayed in cluster I, followed by cluster III and II. The consumption of electricity may be due to intensive use of machinery and facility utilities. Herd size, a crucial variable for the production of milk and their derivatives have similar size. The production of whey is higher in cluster III followed closely by cluster I. Whey is a sub-product of the milk curling, minimizing this variable increases cheese solidification. There are strong indication of the combination of different cows races, grass varieties and crop management which reduces whey production. $\mathrm{CH}_{4}$ value is similar to all clusters, in this case, enteric fermentation is similar given similar size of the herd and natural pasture feed.

Overall, these results is materialized in the total kilo of cheese produced daily. Cheese output double in cluster I compared to cluster III, and triples compared to cluster II. This directly affect the revenue of the enterprise and increases paid tax to the region. The number of hired workforce remains similarly to all 3 clusters revealing different levels of productivity and ability to handle the production.

The intervention of extensionist programs, public policy managers, administrators and producers are enhanced through better comprehension of the attributes of each farmers represented themselves in representative clusters. Those are critical factors noted by the literature of agricultural small production systems (SHIFERAW et al., 2014; ADEGBOLA; GARDEBROEK, 2007). The development of macro strategies to foster sus- 
tainable local development that are suitable for each farm should experience considerable progress by understanding farmers' reasons and recommend an adequate strategic plan of development(EUPEN et al., 2012).

\subsection{Conclusion}

Quantitative identification and characterization can be a useful method to identify farm typologies and facilitates the inclusion of expert knowledge. This approach is particularly appropriate to be used, in combination with professional extensionists, to select representative farms for in field analysis or to treat model results of group virtual farms for the scaling-up of research outcomes at regional level.

However, variable selection for typology creation is a crucial step and 5sensu theoretical framework allows to select several variables and their respective conflict. While most studies only create a typology, this study also provides an assessment framework which allows to analyse their relative efficiency. This result allows to support for public policy decision-making in a perspective long term sustainability.

To this study, the availability of a complete census database, including all the farms of the region, represented a powerful advantage to avoid sampling errors, which are often not taken into account. On the other hand, the flexibility in the definition of the classification variables was limited to those available in the agricultural census. For instance, the inclusion of soil quality data might be important to be included in the typology of this case study since important differences in feasible production activities are related to soil characteristics.

In summary, the results of the clustering process indicated a high homogeneity of the farms within the three clusters, and meaningful differences in farm types were characterized by relevant dissimilarities in terms of resource availability. The significance of such differences for the design of farm and regional level strategies, aimed at sustainable development, was favourably valuated by data envelopment analysis.

The main differences between the clusters were the tradition, whey produced, total cheese output, gross revenue and paid tax. These variables have a strong impact in the design of farm level strategies, affecting directly the choice of the farms inputs in terms of an integrated and broad concept of long term sustainability. The ability to handle similar herd and maximize production was shown to be related to labour and mechanization. Different farm types in each cluster utilized the same proportions of the available land to cultivate vegetable crops and husbandry.

Notwithstanding the fact that the method is favoured by the public policy agencies, some limitations of the method can be mentioned regarding its potential to represent farm 
Capítulo 6. Sustainability assessment in a macro farm level perspective in geographical indication 88 regions

diversity, compared to other methods used in this field of investigation.

The approach adopted in this study permitted both a high transparency of group composition in reference to variables and the inclusion of expert knowledge in the process of variable selection. On the other hand, it may have been the cause for a higher level of distinction of groups. However, the high homogeneity that was found within the clusters could be related more to the stratification that was carried out when selecting the target population (specialized cheese production systems of southeast Brazil). Moreover, investigations in further GI areas may prevent over fitness of the proposed model by training over a larger sample of GI areas.

It should be made clear that although relatively efficiency is widely used in literature, its ranking classification does not mean a general improvement in the DMUs evaluation or an state of art in the field. It means only a greater homogeneity among the whole set of objects under evaluation. This could have come about either because inefficient DMUs became more efficient or, else, because efficient DMUs became less so.

This is a strong assumption takes using relative efficiency comparison but as in this study the entire population data is under investigation, relative efficiency error is minimized to quasi-zero. For studies relied on samples, it is mandatory to have a true random selection to increase inference power of the data envelopment analysis. Finally, the farm typology presented in this article will be used to carry out a transfer knowledging to the region of the object of study on a local development public policy effort. 


\section{Sustainability assessment in a micro farm level perspective using genetic algorithm for global optimization in a geographical indication regions}

This article is entitled 'Sustainability assessment in a micro farm level perspective using genetic algorithm for global optimization having as a object of study a geographical indication regions' and presents an analysis aimed at examining the global optimal point of sustainability, taking a broad environmental, economic and social feature into account synchronously.

The last 2 studies use an optimization function in a relative comparison of the sample, the efficient unit of production ranks in a direct comparison from inefficient ones. These previous studies provide important insights for resource allocation and strategy design for managers and decision-makers. Nonetheless, such objective function can achieve values that are sub optimal. In order to consider to find a global optimum, a multi-criteria evolutionary algorithms (EAs) have been used to undertake those local constrains and to produce a set of feasible and optimized solutions that are not yet present in the population studied.

Using the previous set of selected variables, theoretical framework and topic of analysis, this paper helps to reinforce the theoretical framework of sustainability by discussing and presenting a full spectrum of feasible targets to achieve sustainability in a optimum scenario framed in the object of study if self. This feature allows to mitigate the necessity of expensive studies of benchmarks against other production systems, a very common limitation among those studies of sustainability. Such optimization technique and strategic management purpose, in order to improve sustainability from a global perspective remains unclear in the current group of previous studies and research. 


\section{Sustainability assessment in a micro farm level perspective using genetic algorithm for global optimization in a geographical indication regions}

\section{Abstract}

A quantitative approach was employed aiming to assess the sustainability of artisan cheese producers considering social, environment, economic attribute aiming to find a set of optimum global solution. The object of study is the entire population of artisan cheese producers in Canastra Valley. A multiple-criteria genetic algorithm were performed and their respective assessment and analyse of sustainability were performed.

Results showed in almost all optimum conditions the average output of environment discharge is kept lower than the average of the region. 3 feasible paths were presented in the solution set. The first leads to reduction of information asymmetry by increased availability of consumers aware of GI's attributes and reaching more prone consumers to pay a high price. The seconds leads to increase of herd size and electricity usage, resulting in production efficiency. Lastly, enhancement of the producer profit by adding value in the experience provided by the manufacture of cheese such as rural tourism, delivery of courses and so on in their portfolio.

Considerably more work will need to be done to determine either necessary financial investment or return on investment. This is an important topic of further studies due to the recent growth and development of credit lines for sustainable practices of small farm properties in GI's. A natural progression of this work is to continuously analyse and data gathering in a longitudinal context to provide valuable information which may be used to improve Canastra Valley and other GI's areas regional development policies.

Key-words: sustainability, multi-criteria, evolutionary algorithm,geographical indication, Canastra cheese 


\subsection{Introduction}

Cheese production is a prominent vector causing environment, economic and social impacts as well (SCHMIT; KAISER, 2006). In this regard, such product are responsible for a great portion over daily basis intake of food globally, crescent attention have been given to this system considering crescent demand and structural changes in the production line over time(AGUIAR; HURST, 2005). The manufacture of cheese consist in a pool of several arrangements but always composed by feed production, dairy and dairy processor(CAPPER; CADY; BAUMAN, 2009). From this ingredient, a great range of cheese derived products can be found in the supermarket shelves.

Among derived products, the demand for artisan cheese has been in crescent demand by a robust ascension of the middle class particularly in under development countries(FOSTER et al., 2007). More specifically, geographical indicated products.

A geographical indication (GI) is a label designed to products, primarily rural products, which conform to a delimited geographical location (ALLAIRE; CASABIANCA; THÉVENOD-MOTTET, 2011). The adoption of such label respond as a approval that the product own distinct attributes, is manufactured using traditional, local methods and resources (ADDOR; GRAZIOLI, 2002). French Champagne, Italian Parma Ham, Colombian Coffee and Japanese Wagyu beef are typical products labeled as GI (DESELNICU et al., 2013).

Suh e MacPherson (2007) cites that geographical indication label can have a significant impact on a region's economic performance, cultural heritage and environmental charge because it protects the identity of indigenous products and materialize customary pattern of beliefs, actions and behaviors of the region.

Through such qualities, several countries have experienced a gradual but consistent reversal trend on GI purchase over industrial foods (SCHMIT; KAISER, 2006). The increase global demand, especially those from underdeveloped countries as China's, has resulted in impacts effect of which resource depletion is one of the most important ones(XIAOBING; KIREEVA, 2007).

It has been well established that to define GI systems, it is imperative considering economics, energy, and environment owning to the fact that agriculture is a multifunctional system (COOMBE; IVES; HUIZENGA, 2014; BRAMLEY; BIENABE, 2012).

Moreover, Caenegem e Cleary (2017) point out the need of a abroad and interlinked approach considering different facets simultaneously inherited to GI labels (MENAPACE; MOSCHINI, 2014; BONADONNA et al., 2017; MOIR, 2016). Late empirical research has broadly concentrate separately on legislation, legal procedural for certification process, production efficiency, sanitary features of the product and marketing (VANDECANDELAERE et al., 2013; NGOKKUEN; GROTE, 2013). 
Capitulo 7. Sustainability assessment in a micro farm level perspective using genetic algorithm for 92 global optimization in a geographical indication regions

Sustainability of farming systems studies has been historically dependent on constant productivity for long periods of time. Although there are several approaches in the literature to evaluate agricultural sustainability, mostly previous studies indeed focus on production efficiency variables(PITTELKOW et al., 2015). However, sustainability requires abroad understand which embraces social, economic and environment dimensions(MOSCHINI; MENAPACE; PICK, 2008). Which usually, sustainability issues result in a trade-off between environmental, economic and social dimensions, making assessment no trivial. In this point, a sustainable development of GI need to contemplate a multi-criteria perspective due to great variate of variables impacted by and a difficult to accomplish optimum scenarios due to trade-off between those variables (VANDECANDELAERE et al., 2018).

Because the outcomes of conducted studies in different regions demonstrate a high degree of ineffectiveness in GI production, the researchers tested parametric and non-parametric techniques to distinguish efficient producers from inefficient ones using a multi-criteria approach, mostly focused on natural resources and economic conditions (ANGULO-MEZA; LINS, 2002).

A review of the literature present that data envelopment analysis (DEA) was among the most recurrent methods, by which investigator tested to find optimum solutions used in agricultural production systems (MEIJUAN; GUOHONG, 2003). The substantial disadvantage of these methods used in the operated studies was that these approach were not able to calculate global optimum values(WANG; OCHOA; HARRISON, 2010). But rather, DEA finds the optimum values based relatively on same sample units under consideration. Thus, they may not be global optimum but a local sub optima(AZADEH; ASADZADEH; MOVAGHAR, 2011). Indeed, in these methods the only objective of the study was to select the decision making units (DMU) which either consumed resources or output created goods efficiently in comparison with all DMUs under consideration. In other words, those precedent research main objective was to sort efficient DMUs from inefficient ones(MAO; KOO, 1997) in a local rank.

To deal different objectives in optimization techniques and find global optimum solutions for the studied sample, evolutionary algorithms (EA) can be employed (WHITTAKER et al., 2009; FALLAHPOUR et al., 2016). EA is a global optimization method which scale well under higher dimensional problems. (ZHANG; TAO, 2017) cites improved flexibility to accommodate a great array of variables that do exhibit non linear relationship. Thus, they are robust regarding noisy fluctuation or non-stationary (SUN; ZHANG; TSANG, 2005; ZHANG; WANG; LU, 2018).

Genetic algorithm (GA) is a branch of EA, which generates solutions to optimization disputes using techniques inspired by natural evolution's, such as inheritance, mutation, selection, and crossover(ASADI et al., 2014). A literature review clearly de- 
monstrates that GA has been widely applied in different fields of agricultural production systems (VALIDI; BHATTACHARYA; BYRNE, 2014; ADEYEMO; OTIENO, 2010; PACINI et al., 2004; SINGH; MISRA et al., 2015).

The most classic GA optimization methods used a single sequential objective function that combines the two or more objectives during optimization in a subsequent order one after the other (ABRAHAM; JAIN, 2005; KAYA; SARHAN; ALHAJJ, 2014). Later studies use an improved multi-objective optimization GA that simultaneously optimize multiple objective functions (KUKKONEN; LAMPINEN, 2004). One key advantage with the multi-optimization techniques is that they calculate and support visualization the trade-off between the two or more objective functions during computation process (BOUDJELOUD; POULET, 2005; ZHANG; CHIONG, 2016).

With regard to the descriptions above, the objectives of the present work are threefold. The first objective is to develop a quantitative system approach as a tool able to bring a set of globally optimized production systems at the farm level regarding a multicriteria perspective of sustainability. In order to address the first objective, the second object of this study have methodological nature which is the implementation of a multiobjective genetic algorithm (MOGA). The last contribution of this paper refers to the case study itself. The considerable amount of the data obtained from field research may be used to generate several socioeconomic indexes. Among those are the ones pertaining to its agricultural sustainability. According to Landais (1998), this information may influence public policy for the region in terms of support, research, financing and others.

This paper has been divided into four parts. Second part it gives a brief overview of the methodology regards this study. Third, it will then go on to results. The fourth section presents the conclusion of the study proposal.

\subsection{Materials and Methods}

\subsubsection{Multi-objective genetic algorithm}

GA is a technique aiming to solve constrained problems by optimization of procedures inspired by nature, and its processes are performed based on biological evolution(ZITZLER; DEB; THIELE, 2000; SINGH; MISRA et al., 2015). GA intermittently diversify the population of individual solutions of the problem through mutation (named as evolution or child). At each step of this evolution, two members of the population were randomly chosen as parents, and children are considered as the next generation after a crossover event. Thus, the population evolves toward an optimal solution limited by a fitness function or hard defined value(KAYA; SARHAN; ALHAJJ, 2014). The following steps shows the procedure by which GA solves problems: 
Capítulo 7. Sustainability assessment in a micro farm level perspective using genetic algorithm for 94 global optimization in a geographical indication regions

1. A initial population of chromosomes is manufactured.

2. The fitness boundary is delineated

3. A loop is formed iteratively to generate a new population. The following steps are repeated until completion

4. Selection

5. Crossover

6. Mutation

7. Accepting

8. The new generating is used to run the algorithm.

9. Stopping criteria are evaluated.

10. No reaching the stopping criteria, the third step re-initiate

In high dimension problems, which can be solved by multi-objective genetic algorithms, the goal is to obtain highest fitness over conflicting objective functions in order to generate a range of non-dominated solutions known as Pareto-optimal solutions (ZITZLER; LAUMANNS; THIELE, 2001).

The non-dominated solutions can be plotted in a two or three dimensional plot to visualize the trade-off curvature between the tested objective functions(RAJABI-BAHAABADI et al., 2015). Non-dominated Sorted Genetic Algorithm (NSGA-II) (DEB et al., 2000) is one of the widely used MOGA among evolutionary algorithms for the selection and placement of inputs.

Non-dominated sorting and elitism are two important properties used by NSGAII to assure that the optimization solutions are divergent and have a good spread in all the objective functions feasible path (VELDHUIZEN; LAMONT, 2000). So, the NSGA-II algorithm was selected to perform multi-objective optimization in this study.

Equation bellow mathematically formalize a multi-objective optimization problem(ZHANG; CHIONG, 2016):

$$
\begin{aligned}
& \min / \max \left(f_{1}(x), F_{\max } / \min , \ldots, F_{k}(x)\right. \\
& \text { s.t } \in X
\end{aligned}
$$

Where the integer $\mathrm{K}>=2$ is the number of objectives and the set $\mathrm{X}$ is the feasible set of decision vectors. The vector-valued objective function can be written as follows:

$$
f: X \rightarrow R^{k}, f_{1}(x) \ldots f_{k}(x) T
$$


An $x_{*}$ is called a feasible solution and $f\left(x^{*}\right) \epsilon R$ is a feasible solution. In a real multiobjective optimization, a feasible solution which is capable of minimizing all objectives simultaneously cannot be obtained. To deal with this constraint, Pareto optimal solutions is employed(KUMAR; GURIA, 2017). Truly, only solutions that are not dominated by any solution within the whole search space are real members of the set of Pareto-optimal solutions; meaning that these solutions cannot be improved in any of the objectives without downgrading at least one of the other studied objectives functions(XUE; SANDERSON; GRAVES, 2003).

The objective functions can be generally defined as follows:

$$
F_{\max } / \min =\sum_{i=1}^{j} C_{i} X_{i}+\alpha
$$

where $F_{\max } / \min , \ldots, F_{k}(x)=$ maximizing or minimizing objective function, $x_{i}=$ input variables, $C_{i}=$ coefficients of the model.

Therefore, ten objective functions were defined as follows. Accordingly, in order to set maximization functions appropriately, they should be multiplied by (-1) or (1) to maximization or minimization respectively to the objectives functions as follows:

$$
\begin{aligned}
& F_{\text {electricity }}=(-1) \times\left(\alpha_{1} X_{1}+\alpha_{2} X_{2}+\alpha_{3} X_{3} \ldots+\alpha_{10} X_{10}\right) \\
& F_{\text {land }}=(-1) \times\left(\beta_{1} X_{1}+\beta_{2} X_{2}+\beta_{3} X_{3} \ldots+\beta_{10} X_{10}\right) \\
& F_{C H_{4}}=\left(\gamma_{1} X_{1}+\gamma_{2} X_{2}+\gamma_{3} X_{3} \ldots+\gamma_{10} X_{10}\right) \\
& F_{\text {whey }}=\left(\delta_{1} X_{1}+\delta_{2} X_{2}+\delta_{3} X_{3} \ldots+\delta_{10} X_{10}\right) \\
& F_{\text {revenue }}=(-1) \times\left(\zeta_{1} X_{1}+\zeta_{2} X_{2}+\zeta_{3} X_{3} \ldots+\zeta_{10} X_{10}\right) \\
& F_{\text {herd }}=(-1) \times\left(\eta_{1} X_{1}+\eta_{2} X_{2}+\eta_{3} X_{3} \ldots+\eta_{10} X_{10}\right) \\
& F_{\text {force }}=(-1) \times\left(\theta_{1} X_{1}+\theta_{2} X_{2}+\theta_{3} X_{3} \ldots+\theta_{10} X_{10}\right) \\
& F_{\text {tradition }}=(-1) \times\left(\iota_{1} X_{1}+\iota_{2} X_{2}+\iota_{3} X_{3} \ldots+\iota_{10} X_{10}\right) \\
& F_{\text {tax }}=(-1) \times\left(\kappa_{1} X_{1}+\kappa_{2} X_{2}+\kappa_{3} X_{3} \ldots+\kappa_{10} X_{10}\right) \\
& F_{\text {age }}=\left(\lambda_{1} X_{1}+\lambda_{2} X_{2}+\lambda_{3} X_{3} \ldots+\lambda_{10} X_{10}\right)
\end{aligned}
$$

A mandatory process in MOGA is definition of the constraints given a problem. There are three forms of constraints which can be employed in a MOGA optimization. This use were only upper and lower bounds which were considered to run the model (RAY et al., 2009).

1. Linear equality: i.e. $A \times X=B$.

2. Linear inequality: i.e. $A \times X<=b$.

3. A set of predefined upper and lower bounds : i.e. lowerbound $<=X<=$ upperbound 
Capítulo 7. Sustainability assessment in a micro farm level perspective using genetic algorithm for 96 global optimization in a geographical indication regions

In general, variance distribution, quadratic percentile error and previous studies optimum setting are the most frequent method adopted to set the bounds in sampled studies. Given the whole population surveyed state, configuration of the boundaries is their respective maximum and minimum value of each studied variable.

The data cleaning, wrangling, analysis, algorithm deployment, plotting, statistical tests were implemented in python 3.6 using numpy (WALT; COLBERT; VAROQUAUX, 2011), pandas (MCKINNEY et al., 2010), matplotlib (HUNTER, 2007), sklearn (PEDREGOSA et al., 2011) and DEAP package for GA analysis was used to implement a multi-objective genetic algorithm (MOGA) (MITCHELL; OSULLIVAN; DUNNING, 2011) for this study. All variables were standardized by total to avoid the influence of different levels of variation due to the unity of measure.

\subsection{Results}

\subsubsection{Descriptive statistical analysis}

Table 16 shows the average values and relative frequency for inputs and outputs in the model. Relative frequency means the ratio between the number of plots with a non-zero value for the variable to which the frequency refers and the total number of plots.

The first table provides the summary statistic for the two groups, presenting similar values for each variable except monthly revenue, daily total milk production and size of herd - a general difference of $30 \%$ on those highlighted variables. Closer inspection of the table shows initial evidence that same number of workforce staff able to manage bigger herds and increase milk/cheese and revenue output. Surprisingly, revenue price is similar to both group. A likely explanation is given to geographic indication label granted to the region of Canastra Valley producers.

According to the population summary (median) the farms in the region could be described as small, not intensive production systems based on family labour, with a low equipment endowment in terms of irrigation and mechanization. Farms were represented by an average surface area of 52 hectare, of open-field vegetable cultivation and access to natural water source. According to Medeiros, Horodyski e Passador (2017), the utilizable farm area was larger than the utilized area on average. This is explained by the fact that farmers usually keep some fields on natural pasture for cattle grazing, aimed at selfconsumption. The average number of hired labour, employees and members belonging to the family was 34 , with the lowest coefficient of variation among all variables. 
Tabela 16 - Summary table of the variables

\begin{tabular}{ccccccccc}
\hline variable & count & mean & std & min & $\mathbf{2 5 \%}$ & $\mathbf{5 0 \%}$ & $\mathbf{7 5 \%}$ & $\max$ \\
Age(Year) & 757 & 52 & 13 & 18 & 42 & 52 & 62 & 91 \\
Land(hectare) & 757 & 91 & 105 & 3 & 24 & 52 & 115 & 556 \\
Tradition(Year) & 757 & 17 & 10 & 1 & 9 & 15 & 25 & 40 \\
Herd Size(head) & 757 & 26 & 18 & 1 & 10 & 25 & 40 & 80 \\
Electricity(KVA) & 757 & 1 & 2 & 1 & 1 & 1 & 2 & 3 \\
Whey $(\mathrm{Kg})$ & 757 & 127 & 95 & 1 & 54 & 99 & 180 & 405 \\
$\mathrm{CH}_{4}(\mathrm{Kg})$ & 757 & 2102 & 1500 & 77 & 790 & 1909 & 3080 & 6720 \\
Workforce & 757 & 3 & 1 & 2 & 3 & 4 & 7 & 11 \\
Revenue(R\$) & 757 & 163 & 125 & 22 & 64 & 127 & 228 & 645 \\
Tax $(\mathrm{R} \$)$ & 757 & 29 & 25 & 0 & 11 & 20 & 40 & 154 \\
\hline
\end{tabular}

However, average values can be only partially informative when representing the population features since all variables were reflected by highly skewed distributions as presented in the figure 12. All quantitative variables presented the highest absolute frequencies for the lower values of the measured range. Few outliers were separated from the majority, showing consistently lower values. This trend was particularly evident for the variables Land usage, $\mathrm{CH}_{4}$, WHEY, Herd Size, Revenue and Tax.

Thus, different distributions can be observed. Age and workforce display a normal distribution portraying a small size farm that employ 4 works aged approximately between 40 and 50 years old. Tradition describes a uniform distribution, signaling the existence of different generations of producers fixated in the Canastra Valley.
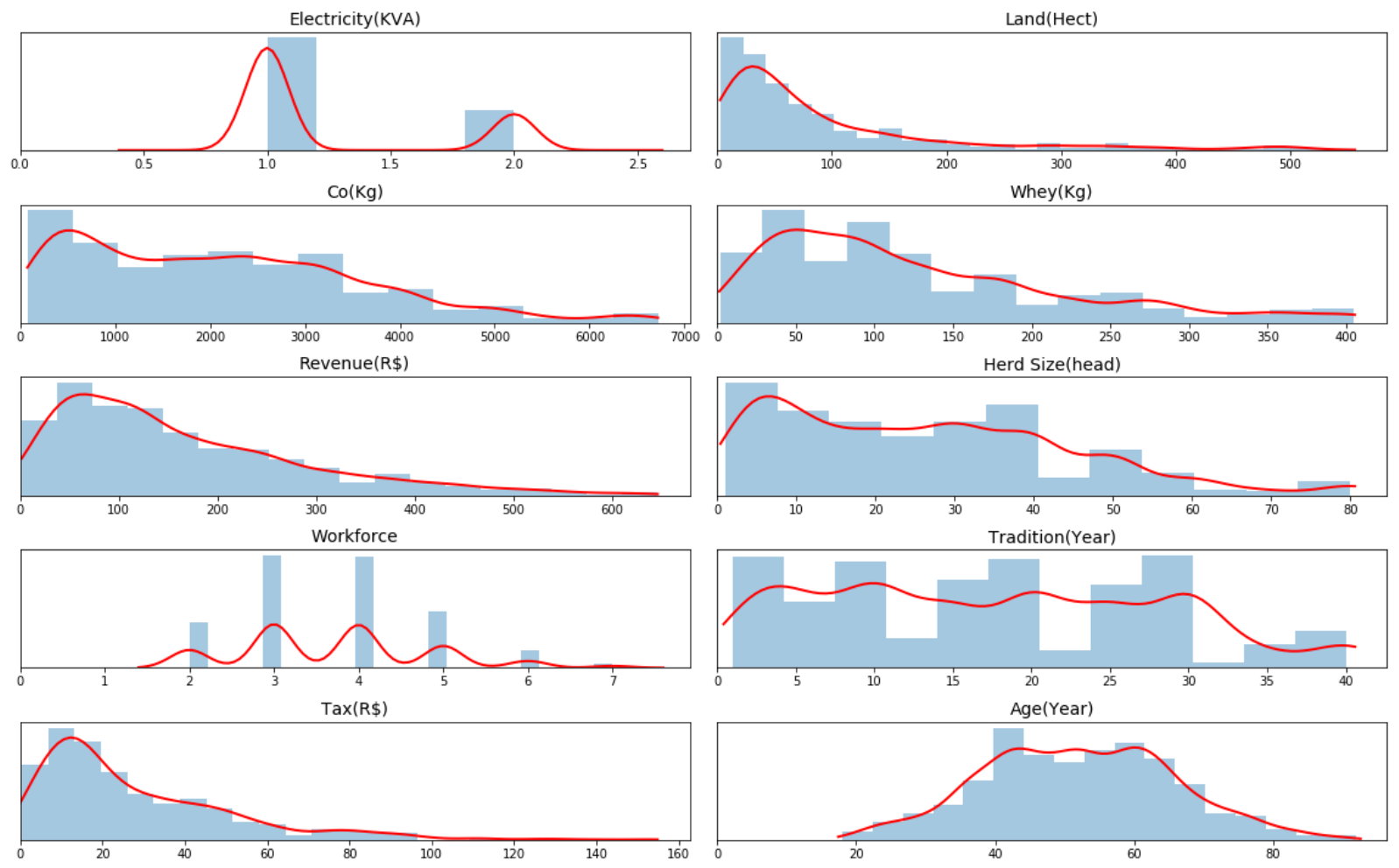

Figura 12 - Histogram of the variables 
Capitulo \%. Sustainability assessment in a micro farm level perspective using genetic algorithm for 98 global optimization in a geographical indication regions

\subsubsection{Optimization results using MOGA}

MOGA is capable of searching different regions of a solution space simultaneously, therefore, it can find a diverse set of solutions for difficult problems with non-convex, discontinuous, and multi-modal solutions spaces(XUE; SANDERSON; GRAVES, 2003). The process of finding optimum solutions by MOGA is repeated until a termination condition has been reached. Common terminating conditions are as follows:

1. A fixed number of generations is reached.

2. The highest ranking solutions fitness is reaching or has reached a plateau such that successive iterations no longer produce better results.

3. Combinations of the above.

A major advantage of fixed number of generations to convergence is that when a predetermined allocated computation processment power and/or window time is compulsory to pursue(ABBASS, 2002). This study select an early stopping criteria after plateau reaching for the reason that total processment time in a complete optimization batch requires 4-5 hours.

Fig 13 shows that applied MOGA is terminated and optimum solutions are generated. For example, figure 13 has plotted the Pareto front for the first two objective functions showing that MOGA has been converged in a optimum point for both functions.

Thus, MOGA computed the total outputs and total inputs were maximized $/$ minimized simultaneously while generating a set of 41 optimal solutions. To find the best solutions, some criteria were defined as follows:

1. The total $\mathrm{CH}_{4}$ should be less than the average of the region.

2. The total WHEY should be less than the average of the region.

3. The PRICE should be above or equal than the average of the region.

4. The TRADITION should be above or equal than the minimum of the region.

Accordingly, 11 optimum solutions out of 41 which were generated by MOGA were selected. The optimum solutions set is described in table 17 . 


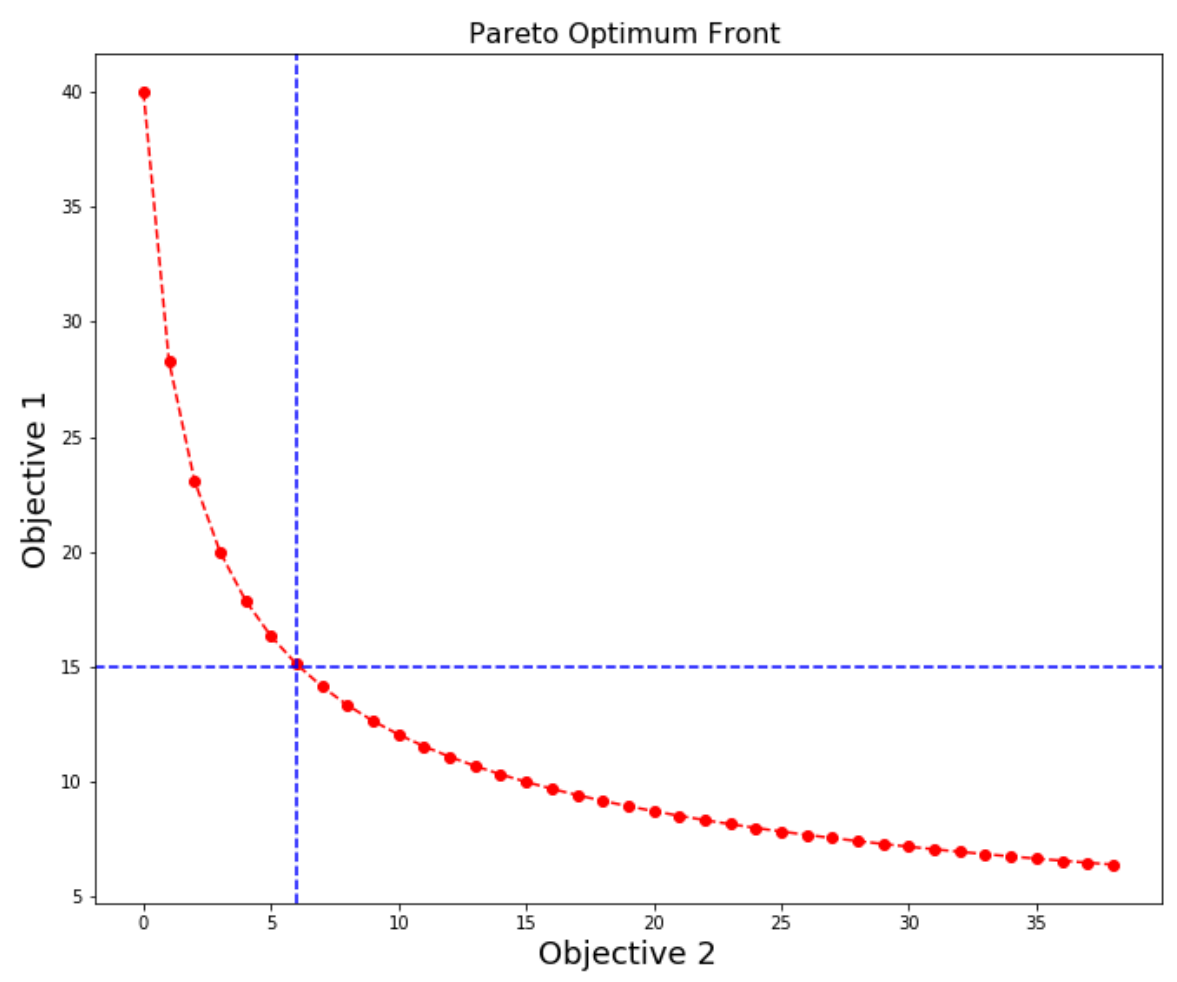

Figura 13 - Pareto optimum demonstration using 2 objective functions

Tabela 17 - The set of optimized solutions

\begin{tabular}{cccccccccccc}
\hline Variable & ID 1 & ID 2 & ID 3 & ID 4 & ID 5 & ID 6 & ID 7 & ID 8 & ID 9 & ID 10 & ID 11 \\
Age(Year) & 46 & 51 & 53 & 42 & 47 & 49 & 52 & 48 & 45 & 55 & 61 \\
Land(hectare) & 51 & 41 & 58 & 155 & 131 & 147 & 62 & 52 & 73 & 83 & 78 \\
Tradition(Year) & 8 & 25 & 40 & 6 & 10 & 7 & 15 & 21 & 14 & 9 & 13 \\
Price(Kg) & 8 & 8 & 9 & 8 & 9 & 8 & 9 & 10 & 10 & 9 & 9 \\
Herd Size(head) & 35 & 19 & 34 & 70 & 65 & 57 & 51 & 41 & 68 & 41 & 44 \\
Electricity(KVA) & 3 & 1 & 2 & 3 & 3 & 3 & 2 & 2 & 1 & 3 & 2 \\
Whey(Kg) & 121 & 72 & 104 & 741 & 583 & 460 & 356 & 378 & 502 & 467 & 567 \\
CH $_{4}(\mathrm{Kg})$ & 2095 & 1539 & 2245 & 4978 & 4756 & 4202 & 3050 & 5441 & 5427 & 3619 & 4511 \\
Workforce & 4 & 4 & 6 & 7 & 5 & 7 & 8 & 5 & 6 & 5 & 6 \\
Cheese $(\mathrm{Kg})$ & 35 & 10 & 17 & 90 & 71 & 63 & 60 & 42 & 44 & 39 & 35 \\
Revenue(R\$) & 301 & 88 & 154 & 457 & 400 & 504 & 354 & 381 & 396 & 482 & 366 \\
Tax $(\mathrm{R} \$)$ & 52 & 14 & 22 & 64 & 57 & 55 & 61 & 50 & 43 & 50 & 47 \\
\hline
\end{tabular}

The results signify that there is a high potential space for improvement in the production system observing the entire setting of functions.

Based on the last column of table 17 in almost all optimum conditions the average output of environment discharge is kept lower than the average of the region and the total $\mathrm{CH}_{4}$ emission is not only less than the average but approximate to the median value observed in the studied area. 
Capitulo 7. Sustainability assessment in a micro farm level perspective using genetic algorithm for 100 global optimization in a geographical indication regions

For example, based on the obtained solution highlighted in the table, the total $\mathrm{CH}_{4}$ emissions can be reduced to the value of $1800 \mathrm{~kg} \mathrm{CH}$, which is significantly fewer than the average of the region. Under this condition, the total calculated output has a benefit cost ratio of 11.2 while its average in the region was $2102 \mathrm{~kg}$.

A more deep analysis, observing case ID1, ID2 and ID3 these producers is set as optimum units while maintain inputs $\left(\mathrm{CH}_{4}\right.$, whey, herd Size) and observing a general older age and higher tradition in a fixed rate while increasing the average price earned per kilo and consequently the economic sustainability, contributing to the overall sustainability.

(ARFINI, 1999) states that many GI agricultural markets are typically characterized as imperfect markets due to the high level of information asymmetry on the quality of marketed products between producers, consumers and the entire chain of intermediaries.

The consumer cannot be sure that his/her needs will be fulfilled and risks that the food will not comply with his/her expectations, finally yielding in decreased overall use(BELlETTI; MARESCOTTI; TOUZARD, 2017). This is why the consumer tries to adopt a self-defending behavior, such as repetitive purchases, faithfulness to a label and/or shop, tendency to not take risks by buying products he/she does not know, buying expensive or reputedly high-quality products, thus somehow paying a sort of insurance premium for quality safety (APRILE; CAPUTO; JR, 2012).

The fact remains that consumers use price as a quality indicator based on different reasons, as in the following :

1. The awareness that the products have different quality characteristics (UHL; BROWN, 1971; WANG; LI, 2012);

2. The belief that the prices reflect the costs incurred by the company to produce the goods (MINTEN; REARDON, 2008)

3. The belief that the prices indicate the consistency of the market demand for the goods, supposing that the most sought-after ones are also the best quality ones (POLLARD et al., 2014);

4. Association labels, indicating that the members belong to the same industrial, trade or co-operative association and that the goods have been produced or marketed in compliance with the rules established by these associations or public organ institution (BOATTO; DEFRANCESCO; TRESTINI, 2011);

According to Lee e Staelin (1997), Kienzler e Kowalkowski (2017), the small and medium-sized Enterprises (SMEs), which characterize the structure of the Brazilian agricultural-food system located in GI regions have meet great difficulty in developing a 
skimming pricing strategies (with relative high price) in markets with high product differentiation when facing a cost disadvantage due to scale economies, which is the case of this first set(DESELNICU et al., 2011).

However, reduction of information asymmetry in GI regions has been reported through increased availability and use of real time interactive digital communication channels such as social networking and video portal streamer enabling small producers to reach out a crescent segment of consumers aware of the GI's labels(BALLANTYNE, 2011; MURPHY, 2017; ROKKA; CANNIFORD, 2016). Those researchers related a sharp increase of demand for products perceived as highly artisan or not highly technique, led by small producers. Those researchers reported a strong relationship between average price increase per kilo paid and incremental exposition in the digital channels(AGARWAL; BARONE, 2005). Daily basis production recording, owner's face exposition and direct interaction are the most effective management actions reported(CAPITELLO et al., 2014).

On the other hand, ID 4, ID5 and ID 6 increase total $\mathrm{CH}_{4}$ and WHEY output substantially but reduces the average emission per kilo cheese. It can be observe a fixed rate over the other variables except herd size, land and electricity, a proxy for machinery and facilities adoption. The increase of herd size and electricity optimizes production efficiency leading to usage of inputs and infrastructure more effectively(SCUDERI; PECORINO, 2015).

Regarding the implications of such strategy, Hajdukiewicz (2014) says that for producer regions, GIs convey several unique characteristics that allow products to distinguish themselves and escape the commodity trap of undifferentiated products trading primarily on the basis of price. This differentiation from commodities and adoption of machine can offer a valuable competitive advantage that is difficult to erode (LIKOUDIS et al., 2016). However, customer perception over GI label erodes drastically as perceived as highly technified or not artisan.

An important region demand is the increasing of employability in order to improve rural areas retention. ID 7, ID8, ID9, ID10 and ID11 increase workforce, tradition, electricity, herd size, land and revenue were above the mean and reduced owner's age while fixing the other variables values.

Interestingly, the owner's age is relative young, percentile 25th, assuming a higher educational qualification but with tradition years between 3 and 4 years, above the minimum age but still bellow the mean value. Also, while the increase of electricity, herd size and land is not proportional as the previous set of solutions, the ratio between revenue and workforce is way above. A possible explanation for this might be that configuring an enriched management environment is able to enhance the revenue tied to the cheese per se due to specialization of different tasks such as tourism, marketing/communication, delivery of courses, trade and export(BESKY, 2014; ATA; SSO, 2007). Regarding the 
Capitulo 7. Sustainability assessment in a micro farm level perspective using genetic algorithm for 102 global optimization in a geographical indication regions

conflictuous variable between age and tradition, the certification process to operate under the license of the Canastra region requires the knowledge domain, primarily diffused by associations such as Aprocan and internship. After the probation process, the producer is able to manufacture by their selves (RENKO et al., 2011; SUN et al., 2011).

Summarily, all optimized solutions presented here are feasible solutions using the dataset. It means that when a system is optimized, we do not force the production system to reduce all application rates but we are meant to combine different application of inputs in a way that all objective functions are met simultaneously.

It should be highlighted that the values presented in table 17 are the most optimum amount of agricultural inputs which can be employed in a cultivation season, meaning that all agricultural inputs are used completely effectively while in reality it is not possible that a system behaves fully efficiently(AGOSTINO; TRIVIERI, 2014). But those results can be a reliable guide support for farm managers to find practical ways for the increase of sustainability of their operations in abroad range perspective(GRUNERT; AACHMANN, 2016).

\subsection{Conclusion}

In this study, artisan cheese was selected to present and discuss the idea about application of EAs in agricultural production systems, more specifically GI region. In a donor and receiver approach - the production chain is composed by a network impacting environment, society and unit production simultaneously.

Reviewing the literature demonstrates that in all production systems, there are deep and serious concerns about efficient use of resources because it is bound up with economic and environmental performance. The total efficiency of a system under consideration depends on the efficiency of its subsystems. Therefore, the proposed approach can be applied to each stage separately. It means that the considered system can be divided into its sub-sections and then the suggested approach can be used in each sub-section, by a maximizing/minimizing function accordingly.

While the evaluation of environmental performance of different production systems is regarded a very hot topic and many scholars dedicate themselves to investigating the ways by which the environmental performance can be improved, a problem may arise. In these studies, typically an enormous effort is made to show the spots of improvement of the evaluated system by comparison of the unit productions.

The controversial issue is that any improvement in the performance of the accounted dimensions, they may affect the system output simultaneously. In this case a multi-objective evolutionary algorithm seems a good solution because it can simultane- 
ously satisfy both several stakeholders perspectives who concern about the long term sustainability and in this case, agricultural producers who concern more about operation and economic performance of their production systems. As the results of the present study shows, a multi objective evolutionary algorithm can guide multiple stakeholders due to inherit capacity to deal with multiple variables.

To sum up, a MOGA was used to optimize agricultural inputs in artisan cheese production. 10 objective functions were defined in order to find the best optimum solutions. MOGA produced 11 distinctive combinations of agricultural inputs which were all global optimum. The results revealed that in almost all optimum conditions the average output of environment discharge is kept lower than the average of the region and the total $\mathrm{CH}_{4}$ emission is not only less than the average but approximate to the median value observed in the studied area. The total $\mathrm{CH}_{4}$ emissions can be reduced significantly fewer than the average of the region.

It shows that current promotion and distribution system in those studied unit production is not efficient at all. A feasible path of sustainable development to small producers is effort towards reduction of information asymmetry in GI regions maintaining input resource fixed. It has been reported through increased availability of consumers aware of GI's attributes and more prone to pay a high price. Another direction pointed out is increase of herd size and electricity, a direct proxy for machinery, resulting in production efficiency leading to usage of inputs and infrastructure more effectively. It does increase total $\mathrm{CH}_{4}$ and whey output substantially but reduces the average emission per kilo cheese. Finally, the traditional production system dependent only on manufacture and selling of the cheese can benefit employability by increasing the ratio between revenue and workforce. A enriched management environment is able to enhance the revenue tied to the cheese by it self due to specialization of different tasks such as tourism, marketing/communication, delivery of courses, trade and export.

To this study, the availability of a complete census database, including all the farms of the region, represented a powerful advantage to avoid sampling errors, which are often not taken into account as a frequent limitation of MOGA prerequisite. 



\section{General conclusions}

The purpose of the current studies was to determine a quantitative procedure for sustainability assessment able to deal with a broad range of characteristic in GI's in a micro, macro and global farm-level. In order to achieve these goals, four papers were developed, each one aiming to bring different perspective to contribute in the discipline field.

The first study has identified emergy as powerfully and arise methods to assess sustainability in abroad range in several sectors, due to their scientific robustness. Initially, this method were aimed to compose the theoretical framework for sustainability assessment. However, many authors point out the difficult of dissemination of the results outside the scientific community and by turning those assessments in actionable information in the micro and macro perspective of the production units.

The second study major finding was that technology adoption is an important driving factor to elevate GI producers competitiveness. The best ranked producers among the studied set were surprisingly the highest technified and the lowest technified producer, where the the second one is highly leveraged out in intangible assets such as public awareness of his roots, tradition and society contribution. Everything materialized in large revenue by per kilo. However, when taking off social variables of the assessment model, this producer ranks in the lowest rank by considering only economic and environmental efficiency and not taking account social variable such as tradition and owner's age, crucial for a long term sustainability development of Gi's.

The investigation of the third study has shown that the clustering process indicated a high homogeneity of the farms within the three clusters. The main differences between the clusters were the tradition, whey produced, total cheese output, gross revenue and paid tax. These variables have a strong impact in the design of farm level strategies, affecting directly the choice of the farms inputs in terms of an integrated and broad concept of long term sustainability. The ability to handle similar herd and maximize production was shown to be related to labour and mechanization. Different farm types in each cluster utilized the same proportions of the available land to cultivate vegetable crops and husbandry.

Finally, the fourth study through MOGA optimization revealed that there is a high potential space for improvement in the production system observing the entire setting of functions. In general, the average output of environment discharge is kept lower than the average of the region. The total of $\mathrm{CH}_{4}$ emission is not only less than the average but approximate to the median value observed in the studied area. Information asymmetry 
reduction through digital channels communication, production efficiency increment and addition of value by service disposition are emerged global strategies provided by the genetic algorithm model which can be guidelines for the producers.

Taken together, these results strengthens the idea that a sustainable development of GI's requires a broad perspective assessment able to deal with conflictuous characteristics in a micro and macro perspective. While past studies taken account sociological or environmental aspects, setting aside economic content, the present study takes account production efficiency and profitability, an elementary condition for regional development.

Another contribution is the multi-criteria adopted methods able to deal with multiple objectives and multiple purpose. Data envelopment analysis provides a relative efficiency rank among the subject of studies. Such facet helps to managers have a general overview and help them to better allocation of resources in a internal perspective or within organization, where manager control is much more easily achieved. MOGA generates a feasible set of globally optimized set of solutions with no referring to a relative constrain. This results may set this results as personal benchmarks guiding managers to achieve those solutions respecting each producer preference and strategy.

Shortly, the present studies provides a first comprehensive assessment of sustainability in GI establishing a quantitative framework and leading to easy communication for managers to achieve better sustainability by changing impactful leverages such as technification, maintenance of clusters proportions or following competitive strategies for each farm. All wrap up in different perspectives of production.

The most important limitation lies in the fact that necessary financial investment or return of investment forecast have not been account in this study. This is an important topic of further studies due to the recent growth and establishing agricultural lines of credit for the sustainable practices of family agribusiness properties in GI's.

Also, the study is limited by the scarcity of more recent and continuous stream of information. The data gathering process begin in the early stage of the PH.d program taken by the author of the study and finish after 2 years of collecting process. As we can observe, the latency of data may impact in the studies proposed here.

Moreover, the capacity to extrapolate these results is subject to certain limitations on account of the variables selected to this study. Although the sustainability assessment conceptual framework provided by the 5sensu has proved itself to be appropriate, variable selection is a critical step which requires a great understatement and able to conciliate several point of views in the decision making process. This study, for practical and time constrain, have not consulted all stakeholders of the Canastra Valley to include a participatory step for variable selection of the model.

In spite of its limitations, the study certainly adds to our understanding of the 
sustainability assessment in GI's by providing a robust quantitative framework for assessment, classification and communication of the results much abroad to the academy space.

This research has thrown up many questions in need of further investigation. Considerably more work will need to be done to determine financial investment and agricultural credit access impact over economical, social and environmental sectors of sustainability in GI's and their long term implications. A natural progression of this work is to continuously analyse in a longitudinal context because Canastra Valley's pioneer have a prior knowledge which may be used to enhance other GI's areas regional development policies. 



\section{References}

ABBASS, H. A. The self-adaptive pareto differential evolution algorithm. In: IEEE. Proceedings of the 2002 Congress on Evolutionary Computation. CEC'02 (Cat. No. 02TH8600). [S.1.], 2002. v. 1, p. 831-836. Citado na página 98.

ABRAHAM, A.; JAIN, L. Evolutionary multiobjective optimization. In: Evolutionary Multiobjective Optimization. [S.1.]: Springer, 2005. p. 1-6. Citado na página 93.

ACKER, D. G. Improving the quality of higher education in agriculture globally in the 21st century: Constraints and opportunities. Journal of International Agricultural and Extension Education, v. 6, n. 2, p. 47-53, 1999. Citado na página 20.

ADAMIC, L. A. et al. Knowledge sharing and yahoo answers: everyone knows something. In: ACM. Proceedings of the 17th international conference on World Wide Web. [S.1.], 2008. p. 665-674. Citado na página 46.

ADDOR, F.; GRAZIOLI, A. Geographical indications beyond wines and spirits: A roadmap for a better protection for geographical indications in the wto/trips agreement. J. World Intell. Prop., HeinOnline, v. 5, p. 865, 2002. Citado 3 vezes nas páginas 59, 75 e 91.

ADEGBOLA, P.; GARDEBROEK, C. The effect of information sources on technology adoption and modification decisions. Agricultural Economics, Wiley Online Library, v. 37, n. 1, p. 55-65, 2007. Citado na página 86.

ADEYEMO, J.; OTIENO, F. Differential evolution algorithm for solving multi-objective crop planning model. Agricultural Water Management, Elsevier, v. 97, n. 6, p. 848-856, 2010. Citado na página 93.

AGARWAL, S.; BARONE, M. J. Emerging issues for geographical indication branding strategies. 2005. Citado na página 101.

AGOSTINO, M.; TRIVIERI, F. Geographical indication and wine exports. an empirical investigation considering the major european producers. Food Policy, Elsevier, v. 46, p. 22-36, 2014. Citado 2 vezes nas páginas 60 e 102.

AGUIAR, M.; HURST, E. Consumption versus expenditure. Journal of political Economy, The University of Chicago Press, v. 113, n. 5, p. 919-948, 2005. Citado na página 91.

AHMAD, N.; BERG, D.; SIMONS, G. R. The integration of analytical hierarchy process and data envelopment analysis in a multi-criteria decision-making problem. International Journal of Information Technology $\&$ Decision Making, World Scientific, v. 5, n. 02, p. 263-276, 2006. Citado 2 vezes nas páginas 63 e 79.

AKADIRI, S. S. et al. Renewable energy consumption in eu-28 countries: policy toward pollution mitigation and economic sustainability. Energy Policy, Elsevier, v. 132, p. 803-810, 2019. Citado na página 24. 
ALBERTÍ, J. et al. Towards life cycle sustainability assessment of cities. a review of background knowledge. Science of the total environment, Elsevier, v. 609, p. 1049-1063, 2017. Citado na página 26.

ALI, A. I. Streamlined computation for data envelopment analysis. European journal of operational research, Elsevier, v. 64, n. 1, p. 61-67, 1993. Citado na página 79.

ALLAIRE, G.; CASABIANCA, F.; THÉVENOD-MOTTET, E. Geographical origin: A complex feature of agro-food products. Labels of origin for food: local development, global recognition, p. 1-12, 2011. Citado 4 vezes nas páginas 19, 59, 75 e 91.

ÁLVAREZ, E. V. B. et al. "vitrina campesina": Contribution of ict to agritourism development in the maule region, chile. Proceedings ICABR 2015, p. 44, 2015. Citado na página 62 .

AMARAL, L. P.; MARTINS, N.; GOUVEIA, J. B. A review of emergy theory, its application and latest developments. Renewable and Sustainable Energy Reviews, Elsevier, v. 54, p. 882-888, 2016. Citado na página 45.

ANDRADE, R. P. et al. Yeasts from canastra cheese production process: Isolation and evaluation of their potential for cheese whey fermentation. Food Research International, Elsevier, v. 91, p. 72-79, 2017. Citado 2 vezes nas páginas 41 e 65.

ANGULO-MEZA, L.; LINS, M. P. E. Review of methods for increasing discrimination in data envelopment analysis. Annals of Operations Research, Springer, v. 116, n. 1-4, p. 225-242, 2002. Citado na página 92.

APRILE, M. C.; CAPUTO, V.; JR, R. M. N. Consumers' valuation of food quality labels: the case of the european geographic indication and organic farming labels. International Journal of Consumer Studies, Wiley Online Library, v. 36, n. 2, p. 158-165, 2012. Citado na página 100.

ARANGANAYAGI, S.; THANGAVEL, K. Clustering categorical data using silhouette coefficient as a relocating measure. In: IEEE. International Conference on Computational Intelligence and Multimedia Applications (ICCIMA 2007). [S.1.], 2007. v. 2, p. 13-17. Citado na página 78.

ARFINI, F. The value of typical products: the case of Prosciutto di Parma and Parmigiano Reggiano cheese. [S.1.], 1999. Citado na página 100.

ARRIAGA-JORDÁN, C. et al. On-farm comparison of feeding strategies based on forages for small-scale dairy production systems in the highlands of central mexico. Experimental Agriculture, Cambridge University Press, v. 38, n. 4, p. 375-388, 2002. Citado na página 62.

ASADI, E. et al. Multi-objective optimization for building retrofit: A model using genetic algorithm and artificial neural network and an application. Energy and Buildings, Elsevier, v. 81, p. 444-456, 2014. Citado na página 92.

ATA, W. L. E. S. T.; SSO, A. P. L. R. Tourism quality labels: An incentive for the sustainable development of creative clusters as tourist attractions? In: Tourism, creativity and development. [S.1.]: Routledge, 2007. p. 129-146. Citado na página 101. 
AUGUSTIN-JEAN, L.; SEKINE, K. From products of origin to geographical indications in japan: Perspectives on the construction of quality for the emblematic productions of kobe and matsusaka beef. In: Geographical Indications and International Agricultural Trade. [S.l.]: Springer, 2012. p. 139-163. Citado na página 20.

AZADEH, A.; ASADZADEH, S. M.; MOVAGHAR, S. A. Implementation of data envelopment analysis-genetic algorithm for improved performance assessment of transmission units in power industry. International Journal of Industrial and Systems Engineering, Inderscience Publishers, v. 8, n. 1, p. 83-103, 2011. Citado na página 92.

BALLABRIGA, F. C.; MARTINEZ-MONGAY, C. et al. Sustainability of EU public finances. [S.l.]: European Commission, Directorate-General for Economic and Financial Affairs, 2005. Citado na página 24.

BALLANTYNE, D. Sustaining the promise of terroir: the case of the central otago wine region. In: 6th Academy of Wine Business Research Conference (AWBR). [S.l.: s.n.], 2011. p. 9-11. Citado na página 101.

BANKER, R. D.; CHARNES, A.; COOPER, W. W. Some models for estimating technical and scale inefficiencies in data envelopment analysis. Management science, INFORMS, v. 30, n. 9, p. 1078-1092, 1984. Citado 2 vezes nas páginas 63 e 79.

BARABASI, A.-L.; OLTVAI, Z. N. Network biology: understanding the cell's functional organization. Nature Reviews Genetics, Nature Publishing Group, v. 5, n. 2, p. 101-113, 2004. Citado na página 46.

BARDHI, R. Development of geographical indication in albania: A case study of northern chestnut. European Journal of Physical and Agricultural Sciences Vol, v. 5, n. 1, 2017. Citado na página 40.

BARHAM, E. Translating terroir: the global challenge of french aoc labeling. Journal of rural studies, Elsevier, v. 19, n. 1, p. 127-138, 2003. Citado na página 29.

BARJOLLE, D.; PAUS, M.; PERRET, A. O. Impacts of geographical indications-review of methods and empirical evidences. [S.l.], 2009. Citado 3 vezes nas páginas 19, 59 e 75.

BAUER, H. H.; HEINRICH, D.; SCHÄFER, D. B. The effects of organic labels on global, local, and private brands: More hype than substance? Journal of Business Research, Elsevier, v. 66, n. 8, p. 1035-1043, 2013. Citado na página 28.

BEAN, F. D. et al. Geographic concentration, migration, and population redistribution among the elderly. Demography of aging, National Academy Press Washington, DC, p. 319-355, 1994. Citado na página 40.

BELLETTI, G. et al. Linking protection of geographical indications to the environment: Evidence from the european union olive-oil sector. Land Use Policy, Elsevier, v. 48, p. 94-106, 2015. Citado na página 60.

BELLETTI, G.; MARESCOTTI, A.; TOUZARD, J.-M. Geographical indications, public goods, and sustainable development: The roles of actors' strategies and public policies. World Development, Elsevier, v. 98, p. 45-57, 2017. Citado 5 vezes nas páginas 19, 59, 60, 75 e 100. 
BELTON, V.; STEWART, T. J. Dea and mcda: Competing or complementary approaches? In: Advances in decision analysis. [S.l.]: Springer, 1999. p. 87-104. Citado 2 vezes nas páginas 63 e 79 .

BENOÎT, C. et al. The guidelines for social life cycle assessment of products: just in time! The international journal of life cycle assessment, Springer, v. 15, n. 2, p. 156-163, 2010. Citado na página 37.

BÉRARD, L.; MARCHESNAY, P. Les productions agricoles et alimentaires locales traditionnelles: savoir-faire, patrimoine et normes in inra cirad cnearc. Systèmes agroalimentaires localisés et construction de territoires, document provisoire, Montpellier, p. 43-50, 1998. Citado na página 35.

BERKE, P.; MANTA, M. Planning for sustainable development: measuring progress in plans. [S.1.]: Lincoln Institute of Land Policy Cambridge, MA, 1999. Citado na página 24.

BERKE, P. R.; CONROY, M. M. Are we planning for sustainable development? an evaluation of 30 comprehensive plans. Journal of the American planning association, Taylor \& Francis, v. 66, n. 1, p. 21-33, 2000. Citado na página 24.

BERLAN, A. Social sustainability in agriculture: an anthropological perspective on child labour in cocoa production in ghana. The Journal of Development Studies, Taylor \& Francis, v. 49, n. 8, p. 1088-1100, 2013. Citado na página 20.

BERNUÉS, A. et al. Quantifying the multifunctionality of fjord and mountain agriculture by means of sociocultural and economic valuation of ecosystem services. Land Use Policy, Elsevier, v. 48, p. 170-178, 2015. Citado na página 30.

BERNUES, A. et al. Socio-cultural and economic valuation of ecosystem services provided by mediterranean mountain agroecosystems. PloS one, Public Library of Science, v. 9, n. 7, p. e102479, 2014. Citado na página 30.

BESKY, S. The labor of terroir and the terroir of labor: Geographical indication and darjeeling tea plantations. Agriculture and Human Values, Springer, v. 31, n. 1, p. 83-96, 2014. Citado 2 vezes nas páginas 30 e 101.

BHOLOWALIA, P.; KUMAR, A. Ebk-means: A clustering technique based on elbow method and k-means in wsn. International Journal of Computer Applications, Citeseer, v. 105, n. 9, 2014. Citado na página 78.

BICKNELL, K. B. et al. New methodology for the ecological footprint with an application to the new zealand economy. Ecological economics, Elsevier, v. 27, n. 2, p. 149-160, 1998. Citado na página 45.

BIDOGEZA, J. et al. A typology of farm households for the umutara province in rwanda. Food Security, Springer, v. 1, n. 3, p. 321-335, 2009. Citado 2 vezes nas páginas 76 e 77.

BIELECKA, E.; POKONIECZNY, K.; KAMIŃSKI, P. Study on spatial distribution of horizontal geodetic control points in rural areas. Acta Geodaetica et Geophysica, Springer, v. 49, n. 3, p. 357-368, 2014. Citado na página 40. 
BIERMANN, F.; KANIE, N.; KIM, R. E. Global governance by goal-setting: the novel approach of the un sustainable development goals. Current Opinion in Environmental Sustainability, Elsevier, v. 26, p. 26-31, 2017. Citado na página 26.

BJÖRKLUND, J.; GEBER, U.; RYDBERG, T. Emergy analysis of municipal wastewater treatment and generation of electricity by digestion of sewage sludge. Resources, Conservation and Recycling, Elsevier, v. 31, n. 4, p. 293-316, 2001. Citado na página 45.

BOARD, M. A. Millennium ecosystem assessment. Washington, DC: New Island, v. 13, 2005. Citado na página 45.

BOATTO, V.; DEFRANCESCO, E.; TRESTINI, S. The price premium for wine quality signals: does retailers' information provision matter? British Food Journal, Emerald Group Publishing Limited, 2011. Citado na página 100.

BONADONNA, A. et al. Traditional cheese production and an eu labeling scheme: The alpine cheese producers' opinion. Agriculture, Multidisciplinary Digital Publishing Institute, v. 7, n. 8, p. 65, 2017. Citado 2 vezes nas páginas 61 e 91.

BOTTELLI, F. The terroir concept for food products: the case of the cheese market in Brazil. Tese (Doutorado), 2020. Citado na página 32.

BOUDJELOUD, L.; POULET, F. Visual interactive evolutionary algorithm for high dimensional data clustering and outlier detection. In: SPRINGER. Pacific-Asia Conference on Knowledge Discovery and Data Mining. [S.1.], 2005. p. 426-431. Citado na página 93.

BOWEN, S. Embedding local places in global spaces: Geographical indications as a territorial development strategy. Rural Sociology, Wiley Online Library, v. 75, n. 2, p. 209-243, 2010. Citado na página 20.

BOWEN, S.; ZAPATA, A. V. Geographical indications, terroir, and socioeconomic and ecological sustainability: The case of tequila. Journal of rural studies, Elsevier, v. 25, n. 1, p. 108-119, 2009. Citado na página 62.

BRAMLEY, C. A review of the socio-economic impact of geographical indications: considerations for the developing world. In: WIPO Worldwide Symposium on Geographical Indications. [S.1.: s.n.], 2011. v. 22. Citado 3 vezes nas páginas 19, 59 e 75.

BRAMLEY, C.; BIENABE, E. Developments and considerations around geographical indications in the developing world. Queen Mary Journal of Intellectual Property, Edward Elgar Publishing Ltd, v. 2, n. 1, p. 14-37, 2012. Citado 2 vezes nas páginas 19 e 91.

BRAMLEY, C.; BIÉNABE, E.; KIRSTEN, J. The economics of geographical indications: towards a conceptual framework for geographical indication research in developing countries. The economics of intellectual property, WIPO, v. 109, 2009. Citado 2 vezes nas páginas 30 e 31 .

BREVIK, E. C. et al. Connecting the public with soil to improve human health. European Journal of Soil Science, Wiley Online Library, v. 70, n. 4, p. 898-910, 2019. Citado na página 29. 
BRIEC, W. A graph-type extension of farrell technical efficiency measure. Journal of Productivity Analysis, Springer, v. 8, n. 1, p. 95-110, 1997. Citado na página 63.

BROWN, M.; ULGIATI, S. Emergy-based indices and ratios to evaluate sustainability: monitoring economies and technology toward environmentally sound innovation. Ecological engineering, Elsevier, v. 9, n. 1-2, p. 51-69, 1997. Citado na página 45.

BROWN, M. T.; ULGIATI, S. Energy quality, emergy, and transformity: Ht odum's contributions to quantifying and understanding systems. Ecological Modelling, Elsevier, v. 178, n. 1-2, p. 201-213, 2004. Citado na página 45.

BRUNNER, P. H.; RECHBERGER, H. Practical handbook of material flow analysis. The International Journal of Life Cycle Assessment, Springer, v. 9, n. 5, p. 337-338, 2004. Citado na página 45.

BRUNORI, G. et al. Are local food chains more sustainable than global food chains? considerations for assessment. Sustainability, Multidisciplinary Digital Publishing Institute, v. 8, n. 5, p. 449, 2016. Citado na página 19.

BUCKLEY, P. J. et al. The determinants of chinese outward foreign direct investment. In: Foreign Direct Investment, China and the World Economy. [S.l.]: Springer, 2010. p. 81-118. Citado na página 20.

BURTON, I. Report on reports: Our common future: The world commission on environment and development. Environment: Science and Policy for Sustainable Development, Taylor \& Francis, v. 29, n. 5, p. 25-29, 1987. Citado na página 23.

CAENEGEM, W. V.; CLEARY, J. The importance of place: Geographical indications as a tool for local and regional development. [S.1.]: Springer, 2017. Citado 3 vezes nas páginas 38, 61 e 91 .

CAENEGEM, W. V. et al. Pride and profit: Geographical indications as regional development tools in australia. Journal of Economic \& Social Policy, Centre for Policy Research Inc. and the Faculty of Business and Computing ..., v. 16, n. 1, p. 90, 2014. Citado 2 vezes nas páginas 59 e 75 .

CAPITELLO, R. et al. Social media strategies and corporate brand visibility in the wine industry. EuroMed Journal of Business, Emerald Group Publishing Limited, 2014. Citado na página 101.

CAPPER, J. L.; CADY, R.; BAUMAN, D. The environmental impact of dairy production: 1944 compared with 2007. Journal of animal science, Oxford University Press, v. 87, n. 6, p. 2160-2167, 2009. Citado na página 91.

CAVALETT, O.; ORTEGA, E. Emergy, nutrients balance, and economic assessment of soybean production and industrialization in brazil. Journal of Cleaner Production, Elsevier, v. 17, n. 8, p. 762-771, 2009. Citado na página 45.

CAVALLO, E. et al. Attitudes and behaviour of adopters of technological innovations in agricultural tractors: A case study in italian agricultural system. Agricultural Systems, Elsevier, v. 130, p. 44-54, 2014. Citado na página 62. 
CAVALLO, E. et al. Strategic management implications for the adoption of technological innovations in agricultural tractor: the role of scale factors and environmental attitude. Technology Analysis \& Strategic Management, Taylor \& Francis, v. 26, n. 7, p. 765-779, 2014. Citado na página 62.

CELEBI, M. E.; KINGRAVI, H. A.; VELA, P. A. A comparative study of efficient initialization methods for the k-means clustering algorithm. Expert systems with applications, Elsevier, v. 40, n. 1, p. 200-210, 2013. Citado na página 78.

CHANG, D.; LEE, C.; CHEN, C.-H. Review of life cycle assessment towards sustainable product development. Journal of Cleaner Production, Elsevier, v. 83, p. 48-60, 2014. Citado na página 27.

CHARNES, A.; COOPER, W. W.; RHODES, E. Measuring the efficiency of decision making units. European journal of operational research, Elsevier, v. 2, n. 6, p. 429-444, 1978. Citado 3 vezes nas páginas 63, 64 e 79.

CHARNES, A.; NERALIĆ, L. Sensitivity analysis of the additive model in data envelopment analysis. European Journal of Operational Research, Elsevier, v. 48, n. 3, p. 332-341, 1990. Citado na página 79.

CHARTERS, S.; SPIELMANN, N.; BABIN, B. J. The nature and value of terroir products. European Journal of Marketing, Emerald Publishing Limited, 2017. Citado 3 vezes nas páginas 28,29 e 30.

CIEGIS, R.; RAMANAUSKIENE, J.; STARTIENE, G. Theoretical reasoning of the use of indicators and indices for sustainable development assessment. Engineering Economics, v. 63, n. 4, 2009. Citado na página 24.

CLAEYS, P. Sustainability of eu fiscal policies: A panel test. Journal of Economic Integration, JSTOR, p. 112-127, 2007. Citado na página 24.

CLARK, W. C.; DICKSON, N. M. Sustainability science: the emerging research program. Proceedings of the national academy of sciences, National Acad Sciences, v. 100, n. 14, p. 8059-8061, 2003. Citado na página 23.

COMMINS, P. Poverty and social exclusion in rural areas: characteristics, processes and research issues. Sociologia ruralis, Wiley Online Library, v. 44, n. 1, p. 60-75, 2004. Citado na página 76.

CONNEELY, R.; MAHON, M. Protected geographical indications: Institutional roles in food systems governance and rural development. Geoforum, Elsevier, v. 60, p. 14-21, 2015. Citado na página 60.

CONRAD, A. The protection of geographical indications in the trips agreement. Trademark Rep., HeinOnline, v. 86, p. 11, 1996. Citado na página 31.

COOMBE, R. J.; IVES, S.; HUIZENGA, D. Geographical indications: The promise, perils and politics of protecting place-based products. Sage handbook on intellectual property, Thousand Oaks, CA, Sage Publications, p. 207-223, 2014. Citado 2 vezes nas páginas 19 e 91. 
COOPER, W. W.; SEIFORD, L. M.; TONE, K. Data envelopment analysis. Handbook on Data Envelopment Analysis, 1st ed.; Cooper, WW, Seiford, LM, Zhu, J., Eds, Springer, p. 1-40, 2000. Citado na página 64.

COOPER, W. W.; SEIFORD, L. M.; TONE, K. The basic ccr model. Data envelopment analysis: a comprehensive text with models, applications, references and DEA-solver software, Springer, p. 21-39, 2007. Citado na página 63.

COOPER, W. W.; SEIFORD, L. M.; ZHU, J. Data envelopment analysis: History, models, and interpretations. In: Handbook on data envelopment analysis. [S.l.]: Springer, 2011. p. 1-39. Citado 2 vezes nas páginas 64 e 65.

COULON, J. B. et al. Etude du lien entre terroir et produit dans le cas des fromages aoc: influence de la composition floristique des fourrages sur les caractéristiques chimiques et sensorielles des fromages affinés. Rencontres autour des recherches sur les ruminants, p. 304-307, 2000. Citado na página 29.

COULON, J. B.; PRIOLO, A. Influence of forage feeding on the composition and organoleptic properties of meat and dairy products: bases for a"terroir"effect. In: BRITISH GRASSLAND SOCIETY. 19. General Meeting of the European Grassland Federation. [S.1.], 2002. v. 7. Citado na página 29.

COUNCIL, N. R. et al. Our common journey: a transition toward sustainability. [S.l.]: National Academies Press, 1999. Citado na página 23.

CRESPO, J.; RÉQUIER-DESJARDINS, D.; VICENTE, J. Why can collective action fail in local agri-food systems? a social network analysis of cheese producers in aculco, mexico. Food Policy, Elsevier, v. 46, p. 165-177, 2014. Citado 2 vezes nas páginas 60 e 85.

CROWDER, L. V. et al. Agricultural education for sustainable rural development: Challenges for developing countries in the 21st century. The Journal of Agricultural Education and Extension, Taylor \& Francis, v. 5, n. 2, p. 71-84, 1998. Citado na página 20 .

CRUZ, B. E. V. d.; HESPANHOL, R. A. M. et al. Indicação geográfica e queijos artesanais: marco legal e desafios a uma política para este segmento no brasil. Confins. Revue franco-brésilienne de géographie/Revista franco-brasilera de geografia, Théry, Hervé, n. 37, 2018. Citado 2 vezes nas páginas 9 e 36.

DAGNE, T. W. Beyond economic considerations:(re) conceptualizing geographical indications for protecting traditional agricultural products. IIC-International Review of Intellectual Property and Competition Law, Springer, v. 46, n. 6, p. 682-706, 2015. Citado 2 vezes nas páginas 59 e 75.

DAROLT, M. R. et al. Alternative food networks and new producer-consumer relations in france and in brazil. Ambiente $\& 5$ Sociedade, SciELO Brasil, v. 19, n. 2, p. 1-22, 2016. Citado na página 33.

DASKALOPOULOU, I.; PETROU, A. Utilising a farm typology to identify potential adopters of alternative farming activities in greek agriculture. Journal of rural studies, Elsevier, v. 18, n. 1, p. 95-103, 2002. Citado na página 35. 
DEB, K. et al. A fast elitist non-dominated sorting genetic algorithm for multi-objective optimization: Nsga-ii. In: SPRINGER. International conference on parallel problem solving from nature. [S.l.], 2000. p. 849-858. Citado na página 94.

DELORD, B.; MONTAIGNE, É.; COELHO, A. Vine planting rights, farm size and economic performance: do economies of scale matter in the french viticulture sector? Wine economics and Policy, Elsevier, v. 4, n. 1, p. 22-34, 2015. Citado na página 60.

DESELNICU, O. et al. What determines the success of a geographical indication? a price-based meta-analysis for gis in food products. In: AAEA \& NAREA Joint Annual Meeting. [S.l.: s.n.], 2011. Citado na página 101.

DESELNICU, O. C. et al. A meta-analysis of geographical indication food valuation studies: what drives the premium for origin-based labels? Journal of Agricultural and Resource Economics, JSTOR, p. 204-219, 2013. Citado 5 vezes nas páginas 31, 59, 60, 75 e 91.

DIAZ-BALTEIRO, L.; GONZÁLEZ-PACHÓN, J.; ROMERO, C. Measuring systems sustainability with multi-criteria methods: A critical review. European Journal of Operational Research, Elsevier, v. 258, n. 2, p. 607-616, 2017. Citado na página 20.

DING, C.; HE, X. K-means clustering via principal component analysis. In: Proceedings of the twenty-first international conference on Machine learning. [S.l.: s.n.], 2004. p. 29. Citado na página 79.

DIXON, J. A.; FALLON, L. A. The concept of sustainability: origins, extensions, and usefulness for policy. Society \& Natural Resources, Taylor \& Francis, v. 2, n. 1, p. 73-84, 1989. Citado na página 23.

DORES, M. T. d.; NOBREGA, J. E. d.; FERREIRA, C. L. d. L. F. Room temperature aging to guarantee microbiological safety of brazilian artisan canastra cheese. Food Science and Technology, SciELO Brasil, v. 33, n. 1, p. 180-185, 2013. Citado 2 vezes nas páginas 41 e 66.

DRUZIAN, J. I.; NUNES, I. L. Indicações geográficas brasileiras concedidas até julho de 2012 e impacto sobre bens agrícolas e/ou agroindustriais. Revista GEINTEC-Gestão, Inovação e Tecnologias, v. 2, n. 4, p. 413-426, 2012. Citado na página 30.

ECK, N. J. V.; WALTMAN, L. Software survey: Vosviewer, a computer program for bibliometric mapping. Scientometrics, Springer, v. 84, n. 2, p. 523-538, 2010. Citado na página 47.

EMTAGE, N.; HERBOHN, J.; HARRISON, S. Landholder typologies used in the development of natural resource management programs in australia - a review. Australasian Journal of Environmental Management, Taylor \& Francis, v. 13, n. 2, p. 79-94, 2006. Citado na página 76.

ESMAIL, B. A.; GENELETTI, D. Multi-criteria decision analysis for nature conservation: A review of 20 years of applications. Methods in Ecology and Evolution, Wiley Online Library, v. 9, n. 1, p. 42-53, 2018. Citado na página 38. 
ESPINOZA-ORTEGA, A. et al. Small-scale dairy farming in the highlands of central mexico: Technical, economic and social aspects and their impact on poverty. Experimental Agriculture, Cambridge University Press, v. 43, n. 2, p. 241-256, 2007. Citado 2 vezes nas páginas 38 e 62 .

EUPEN, M. V. et al. A rural typology for strategic european policies. Land Use Policy, Elsevier, v. 29, n. 3, p. 473-482, 2012. Citado 3 vezes nas páginas 76, 78 e 87.

FAGUNDES, P. de M. et al. Geographical indication as a market orientation strategy: An analysis of producers of high-quality wines in southern brazil. Journal of Database Marketing $\&$ Customer Strategy Management, Springer, v. 19, n. 3, p. 163-178, 2012. Citado na página 31.

FALLAHPOUR, A. et al. An integrated model for green supplier selection under fuzzy environment: application of data envelopment analysis and genetic programming approach. Neural Computing and Applications, Springer, v. 27, n. 3, p. 707-725, 2016. Citado na página 92.

FEAGAN, R. The place of food: mapping out the 'local'in local food systems. Progress in human geography, Sage Publications Sage CA: Thousand Oaks, CA, v. 31, n. 1, p. 23-42, 2007. Citado 2 vezes nas páginas 29 e 30.

FEBLES-GONZÁLEZ, J. et al. Cuban agricultural policy in the last 25 years. from conventional to organic agriculture. Land Use Policy, Elsevier, v. 28, n. 4, p. 723-735, 2011. Citado na página 62.

FENSTERSEIFER, J. E. The emerging brazilian wine industry. International journal of wine business research, Emerald Group Publishing Limited, 2007. Citado na página 31.

FERRARI, M. The narratives of geographical indications. International Journal of Law in Context, Cambridge University Press, v. 10, n. 2, p. 222-248, 2014. Citado 2 vezes nas páginas 20 e 31 .

FINNVEDEN, G. et al. Recent developments in life cycle assessment. Journal of environmental management, Elsevier, v. 91, n. 1, p. 1-21, 2009. Citado na página 25.

FOLEY, J. A. et al. Global consequences of land use. science, American Association for the Advancement of Science, v. 309, n. 5734, p. 570-574, 2005. Citado na página 45.

FOSTER, C. et al. Environmental impacts of food production and consumption: final report to the department for environment food and rural affairs. Manchester Business School, University of Manchester, 2007. Citado na página 91.

FRAZÃO, J. et al. Os impactos das ações empreendedoras da aprocan na região da canastra. Revista Calafiori, v. 3, n. 2, p. 5-26, 2019. Citado na página 62.

FUKUDA-PARR, S. From the millennium development goals to the sustainable development goals: shifts in purpose, concept, and politics of global goal setting for development. Gender \& Development, Taylor \& Francis, v. 24, n. 1, p. 43-52, 2016. Citado na página 26.

GANNOUN, H. et al. Ecological clarification of cheese whey prior to anaerobic digestion in upflow anaerobic filter. Bioresource Technology, Elsevier, v. 99, n. 14, p. 6105-6111, 2008. Citado na página 39. 
GARCIA, C. et al. Geographical indications and biodiversity in the western ghats, india. Mountain Research and Development, BioOne, v. 27, n. 3, p. 206-210, 2007. Citado na página 20.

GARCÍA, C. G. M.; DORWARD, P.; REHMAN, T. Farm and socio-economic characteristics of smallholder milk producers and their influence on technology adoption in central mexico. Tropical Animal Health and Production, Springer, v. 44, n. 6, p. 1199-1211, 2012. Citado na página 62.

GENG, Y. et al. Emergy analysis of an industrial park: the case of dalian, china. Science of the total environment, Elsevier, v. 408, n. 22, p. 5273-5283, 2010. Citado na página 45.

GENIUS, M. et al. Information transmission in irrigation technology adoption and diffusion: Social learning, extension services, and spatial effects. American Journal of Agricultural Economics, Oxford University Press, v. 96, n. 1, p. 328-344, 2013. Citado na página 60.

GERLAND, P. et al. World population stabilization unlikely this century. Science, American Association for the Advancement of Science, v. 346, n. 6206, p. 234-237, 2014. Citado na página 45.

GIANNETTI, B.; ALMEIDA, C.; BONILLA, S. Comparing emergy accounting with well-known sustainability metrics: The case of southern cone common market, mercosur. Energy Policy, Elsevier, v. 38, n. 7, p. 3518-3526, 2010. Citado na página 27.

GIANNETTI, B. F. et al. Five sector sustainability model: A proposal for assessing sustainability of production systems. Ecological Modelling, Elsevier, v. 406, p. 98-108, 2019. Citado 4 vezes nas páginas 9, 37, 38 e 39.

GIDDINGS, B.; HOPWOOD, B.; O'BRIEN, G. Environment, economy and society: fitting them together into sustainable development. Sustainable development, Wiley Online Library, v. 10, n. 4, p. 187-196, 2002. Citado 2 vezes nas páginas 23 e 25.

GLAVIČ, P.; LUKMAN, R. Review of sustainability terms and their definitions. Journal of cleaner production, Elsevier, v. 15, n. 18, p. 1875-1885, 2007. Citado na página 24.

GOGLIO, P.; OWENDE, P. M. A screening lca of short rotation coppice willow (salix sp.) feedstock production system for small-scale electricity generation. Biosystems Engineering, Elsevier, v. 103, n. 3, p. 389-394, 2009. Citado na página 39.

GOLDBERGER, A. L. et al. Physiobank, physiotoolkit, and physionet components of a new research resource for complex physiologic signals. Circulation, Am Heart Assoc, v. 101, n. 23, p. e215-e220, 2000. Citado na página 46.

GOODMAN, D.; DUPUIS, E. M.; GOODMAN, M. K. Alternative food networks: Knowledge, practice, and politics. [S.l.]: Routledge, 2012. Citado na página 29.

GRIMM, V. et al. Pattern-oriented modeling of agent-based complex systems: lessons from ecology. science, American Association for the Advancement of Science, v. 310, n. 5750, p. 987-991, 2005. Citado na página 46. 
GROTE, U. Environmental labeling, protected geographical indications and the interests of developing countries. Estey Journal of International Law and Trade Policy, v. 10, n. 1753-2016-141181, p. 94-110, 2009. Citado na página 19.

GRUNERT, K. G.; AACHMANN, K. Consumer reactions to the use of eu quality labels on food products: A review of the literature. Food Control, Elsevier, v. 59, p. 178-187, 2016. Citado na página 102.

GUIMARÃES, J. et al. Características físico-químicas do queijo minas artesanal da canastra. Revista do Instituto de Laticínios Cândido Tostes, v. 66, n. 380, p. 16-22, 2011. Citado na página 62.

GUINÉE, J. Life cycle sustainability assessment: what is it and what are its challenges? In: Taking stock of industrial ecology. [S.l.]: Springer, Cham, 2016. p. 45-68. Citado 2 vezes nas páginas 25 e 27.

GUINÉE, J. B. Handbook on life cycle assessment operational guide to the iso standards. The international journal of life cycle assessment, Springer, v. 7, n. 5, p. 311, 2002. Citado 2 vezes nas páginas 27 e 45.

GUINEE, J. B. et al. Life cycle assessment: past, present, and future. [S.1.]: ACS Publications, 2011. Citado na página 25.

GUROVA, O. Patriotism as creative (counter-) conduct of russian fashion designers. Consumer Culture Theory, v. 20, p. 151-168, 2019. Citado na página 28.

HAJDUKIEWICZ, A. European union agri-food quality schemes for the protection and promotion of geographical indications and traditional specialities: an economic perspective. Folia Horticulturae, De Gruyter Open, v. 26, n. 1, p. 3-17, 2014. Citado 2 vezes nas páginas 61 e 101.

HÁK, T.; JANOUŠKOVÁ, S.; MOLDAN, B. Sustainable development goals: A need for relevant indicators. Ecological Indicators, Elsevier, v. 60, p. 565-573, 2016. Citado na página 20.

HALLSTEDT, S. et al. An approach to assessing sustainability integration in strategic decision systems for product development. Journal of Cleaner Production, Elsevier, v. 18, n. 8, p. 703-712, 2010. Citado na página 27.

HARVEY, M.; WHITE, L.; FROST, W. Wine and identity: branding, heritage, terroir. [S.l.]: Routledge, 2014. Citado na página 30.

HASSAN, A. M.; LEE, H. The paradox of the sustainable city: definitions and examples. Environment, development and sustainability, Springer, v. 17, n. 6, p. 1267-1285, 2015. Citado na página 24.

HASSAN, B.; MOHAMED, B. Role of smes in the economic and social development: Case of terroir products in souss massa draa region (morocco). Economic and Social Development: Book of Proceedings, Varazdin Development and Entrepreneurship Agency (VADEA), p. 699, 2014. Citado na página 29.

HELLWEG, S.; CANALS, L. M. i. Emerging approaches, challenges and opportunities in life cycle assessment. Science, American Association for the Advancement of Science, v. 344, n. 6188, p. 1109-1113, 2014. Citado na página 27. 
HOSSAINI, N. et al. Ahp based life cycle sustainability assessment (lcsa) framework: a case study of six storey wood frame and concrete frame buildings in vancouver. Journal of Environmental Planning and Management, Taylor \& Francis, v. 58, n. 7, p. 1217-1241, 2015. Citado na página 38.

HUNTER, J. D. Matplotlib: A 2d graphics environment. Computing in science $\mathcal{G}$ engineering, IEEE Computer Society, v. 9, n. 3, p. 90, 2007. Citado 3 vezes nas páginas 65,80 e 96.

HURLEY, J.; HORNE, R. Review and analysis of tools for the implementation and assessment of sustainable urban development. future, v. 7, n. 6, 2006. Citado na página 24.

INHAN, L.; ROVERE, R. L. L. Inovação e conhecimento tácito: trânsito e conflitos nas indicações geográficas brasileiras. 2016. Citado na página 35.

IQBAL, J. et al. Employing sensory marketing as a promotional advantage for creating brand differentiation and brand loyalty. Pakistan Journal of Commerce and Social Sciences (PJCSS), Lahore: Johar Education Society, Pakistan (JESPK), v. 10, n. 3, p. 725-734, 2016. Citado 2 vezes nas páginas 28 e 29.

JAFFE, A. B.; NEWELL, R. G.; STAVINS, R. N. Technological change and the environment. In: Handbook of environmental economics. [S.l.]: Elsevier, 2003. v. 1, p. 461-516. Citado na página 62.

JANSEN, L. The challenge of sustainable development. Journal of Cleaner Production, Elsevier, v. 11, n. 3, p. 231-245, 2003. Citado na página 24.

JENKINS, L.; ANDERSON, M. A multivariate statistical approach to reducing the number of variables in data envelopment analysis. European Journal of Operational Research, Elsevier, v. 147, n. 1, p. 51-61, 2003. Citado 2 vezes nas páginas 63 e 79.

JENNICHES, S. Assessing the regional economic impacts of renewable energy sources-a literature review. Renewable and Sustainable Energy Reviews, Elsevier, v. 93, p. 35-51, 2018. Citado na página 26.

JENNINGS, N. R. An agent-based approach for building complex software systems. Communications of the ACM, ACM, v. 44, n. 4, p. 35-41, 2001. Citado na página 46.

JOFFRE, O. M.; BOSMA, R. H. Typology of shrimp farming in bac lieu province, mekong delta, using multivariate statistics. Agriculture, ecosystems \& environment, Elsevier, v. 132, n. 1-2, p. 153-159, 2009. Citado 2 vezes nas páginas 76 e 77.

JORDANA, J. Traditional foods: challenges facing the european food industry. Food Research International, Elsevier, v. 33, n. 3-4, p. 147-152, 2000. Citado na página 62.

JORO, T.; VIITALA, E.-J. Weight-restricted dea in action: from expert opinions to mathematical models. Journal of the Operational Research Society, Taylor \& Francis, v. 55, n. 8, p. 814-821, 2004. Citado 2 vezes nas páginas 63 e 79.

KAATZ, E. et al. Advancing key outcomes of sustainability building assessment. Building Research $\mathscr{G}$ Information, Taylor \& Francis, v. 34, n. 4, p. 308-320, 2006. Citado na página 23. 
KAMIMURA, B. A. et al. Brazilian artisanal cheeses: An overview of their characteristics, main types and regulatory aspects. Comprehensive Reviews in Food Science and Food Safety, Wiley Online Library, v. 18, n. 5, p. 1636-1657, 2019. Citado 3 vezes nas páginas 32,33 e 36.

KASEMIR, B. et al. Integrated assessment of sustainable development: multiple perspectives in interaction. International Journal of Environment and Pollution, Inderscience Publishers, v. 11, n. 4, p. 407-425, 1999. Citado na página 23.

KAYA, M.; SARHAN, A.; ALHAJJ, R. Multiple sequence alignment with affine gap by using multi-objective genetic algorithm. Computer methods and programs in biomedicine, Elsevier, v. 114, n. 1, p. 38-49, 2014. Citado na página 93.

KENNY, C. Speeding sustainable development: integrating economic, social, and environmental development. Center for Global Development Working Paper, n. 484, 2018. Citado na página 26.

KIENZLER, M.; KOWALKOWSKI, C. Pricing strategy: A review of 22 years of marketing research. Journal of Business Research, Elsevier, v. 78, p. 101-110, 2017. Citado na página 100.

KIKER, G. A. et al. Application of multicriteria decision analysis in environmental decision making. Integrated Environmental Assessment and Management: An International Journal, Wiley Online Library, v. 1, n. 2, p. 95-108, 2005. Citado na página 38.

KILLWORTH, P. D. et al. Estimating the size of personal networks. Social Networks, Elsevier, v. 12, n. 4, p. 289-312, 1990. Citado na página 46.

KIREEVA, I.; O'CONNOR, B. Geographical indications and the trips agreement: What protection is provided to geographical indications in wto members? The Journal of World Intellectual Property, Wiley Online Library, v. 13, n. 2, p. 275-303, 2010. Citado na página 31.

KLÖPFFER, W. The role of setac in the development of lca. The International Journal of Life Cycle Assessment, Springer, v. 11, n. 1, p. 116-122, 2006. Citado na página 27.

KLÖPFFER, W.; CIROTH, A. Is lcc relevant in a sustainability assessment? The International Journal of Life Cycle Assessment, Springer, v. 16, n. 2, p. 99-101, 2011. Citado na página 38.

KÖBRICH, C.; REHMAN, T.; KHAN, M. Typification of farming systems for constructing representative farm models: two illustrations of the application of multi-variate analyses in chile and pakistan. Agricultural systems, Elsevier, v. 76, n. 1, p. 141-157, 2003. Citado na página 76.

KOSTROWICKI, J. Agricultural typology concept and method. Agricultural Systems, Elsevier, v. 2, n. 1, p. 33-45, 1977. Citado na página 78.

KUKKONEN, S.; LAMPINEN, J. An extension of generalized differential evolution for multi-objective optimization with constraints. In: SPRINGER. International Conference on Parallel Problem Solving from Nature. [S.1.], 2004. p. 752-761. Citado na página 93. 
KUMAR, M.; GURIA, C. The elitist non-dominated sorting genetic algorithm with inheritance (i-nsga-ii) and its jumping gene adaptations for multi-objective optimization. Information sciences, Elsevier, v. 382, p. 15-37, 2017. Citado na página 95.

LABUSCHAGNE, C.; BRENT, A. C.; ERCK, R. P. V. Assessing the sustainability performances of industries. Journal of cleaner production, Elsevier, v. 13, n. 4, p. 373-385, 2005. Citado na página 39.

LACOEUILHE, J.; LOUIS, D.; LOMBART, C. Impacts of product, store and retailer perceptions on consumers' relationship to terroir store brand. Journal of Retailing and Consumer Services, Elsevier, v. 39, p. 43-53, 2017. Citado na página 29.

LANDAIS, E. Modelling farm diversity: new approaches to typology building in france. Agricultural systems, Elsevier, v. 58, n. 4, p. 505-527, 1998. Citado 2 vezes nas páginas 77 e 93.

LEBACQ, T.; BARET, P. V.; STILMANT, D. Sustainability indicators for livestock farming. a review. Agronomy for Sustainable Development, Springer, v. 33, n. 2, p. 311-327, 2013. Citado na página 37.

LEE, E.; STAELIN, R. Vertical strategic interaction: Implications for channel pricing strategy. Marketing Science, INFORMS, v. 16, n. 3, p. 185-207, 1997. Citado na página 100.

LEEUWEN, C. V.; SEGUIN, G. The concept of terroir in viticulture. Journal of wine research, Taylor \& Francis, v. 17, n. 1, p. 1-10, 2006. Citado na página 29.

LENGLET, F. Influence of terroir products meaning on consumer's expectations and likings. Food quality and preference, Elsevier, v. 32, p. 264-270, 2014. Citado na página 30 .

LIKOUDIS, Z. et al. Consumers' intention to buy protected designation of origin and protected geographical indication foodstuffs: the case of g reece. International Journal of Consumer Studies, Wiley Online Library, v. 40, n. 3, p. 283-289, 2016. Citado 2 vezes nas páginas 61 e 101.

LIKUDIS, Z. et al. Determination of pesticide residues in olive oils with protected geographical indication or designation of origin. International Journal of Food Science \& Technology, Wiley Online Library, v. 49, n. 2, p. 484-492, 2014. Citado na página 61.

LIN, Y.-C.; PEARSON, T. E.; CAI, L. A. Food as a form of destination identity: A tourism destination brand perspective. Tourism and Hospitality Research, SAGE Publications Sage UK: London, England, v. 11, n. 1, p. 30-48, 2011. Citado na página 28.

LIU, T.; BRUINS, R. J.; HEBERLING, M. T. Factors influencing farmers' adoption of best management practices: A review and synthesis. Sustainability, Multidisciplinary Digital Publishing Institute, v. 10, n. 2, p. 432, 2018. Citado na página 62.

LOPES, C.; LEITÃO, J.; RENGIFO-GALLEGO, J. Place branding: revealing the neglected role of agro food products. International Review on Public and Nonprofit Marketing, Springer, v. 15, n. 4, p. 497-530, 2018. Citado 2 vezes nas páginas 28 e 29. 
LORENZ, B. A.; HARTMANN, M.; SIMONS, J. Impacts from region-of-origin labeling on consumer product perception and purchasing intention-causal relationships in a tpb based model. Food quality and preference, Elsevier, v. 45, p. 149-157, 2015. Citado na página 30.

LOUREIRO, M. L.; MCCLUSKEY, J. J. Assessing consumer response to protected geographical identification labeling. Agribusiness: An International Journal, Wiley Online Library, v. 16, n. 3, p. 309-320, 2000. Citado 3 vezes nas páginas 20, 59 e 75.

LU, H. R.; HANANDEH, A. E.; GILBERT, B. P. A comparative life cycle study of alternative materials for australian multi-storey apartment building frame constructions: Environmental and economic perspective. Journal of cleaner production, Elsevier, v. 166, p. 458-473, 2017. Citado na página 38.

MA, J. et al. Technical efficiency and productivity change of china's iron and steel industry. International Journal of Production Economics, Elsevier, v. 76, n. 3, p. 293-312, 2002. Citado na página 63.

MACDONALD, K. et al. Production and economic responses to intensification of pasture-based dairy production systems. Journal of dairy science, Elsevier, v. 100, n. 8, p. 6602-6619, 2017. Citado na página 37.

MĄDRY, W. et al. An overview of farming system typology methodologies and its use in the study of pasture-based farming system: a review. Spanish Journal of Agricultural Research, 2013 (11 (2)), 316-326., Instituto Nacional de Investigación y Tecnología Agraria y Alimentaria (INIA), 2013. Citado na página 76.

MAO, W.; KOO, W. W. Productivity growth, technological progress, and efficiency change in chinese agriculture after rural economic reforms: a dea approach. China Economic Review, Elsevier, v. 8, n. 2, p. 157-174, 1997. Citado na página 92.

MARGALHO, L. P. et al. Brazilian artisanal cheeses are rich and diverse sources of nonstarter lactic acid bacteria regarding technological, biopreservative, and safety properties - insights through multivariate analysis. Journal of Dairy Science, Elsevier, 2020. Citado na página 33.

MARIANO, M. J.; VILLANO, R.; FLEMING, E. Factors influencing farmers' adoption of modern rice technologies and good management practices in the philippines. Agricultural Systems, Elsevier, v. 110, p. 41-53, 2012. Citado na página 62.

MARIE-VIVIEN, D.; BIÉNABE, E. The multifaceted role of the state in the protection of geographical indications: a worldwide review. World Development, Elsevier, v. 98, p. 1-11, 2017. Citado na página 20.

MARTÍNEZ-GARCÍA, C. G.; DORWARD, P.; REHMAN, T. Factors influencing adoption of improved grassland management by small-scale dairy farmers in central mexico and the implications for future research on smallholder adoption in developing countries. Livestock Science, Elsevier, v. 152, n. 2, p. 228-238, 2013. Citado 3 vezes nas páginas 59, 62 e 75 .

MARTINEZ, S. Local food systems; concepts, impacts, and issues. [S.l.]: Diane Publishing, 2010. Citado 2 vezes nas páginas 29 e 30. 
MCKINNEY, W. et al. Data structures for statistical computing in python. In: AUSTIN, TX. Proceedings of the 9th Python in Science Conference. [S.l.], 2010. v. 445, p. 51-56. Citado 3 vezes nas páginas 65, 80 e 96.

MEADOWCROFT, J. National sustainable development strategies: features, challenges and reflexivity. European Environment, Wiley Online Library, v. 17, n. 3, p. 152-163, 2007. Citado na página 24.

MEDEIROS, M. et al. "com a faca e o queijo nas mãos"? análise da imagem projetada de regiões queijeiras brasileiras. Revista Turismo \& Desenvolvimento (RTED)/Journal of Tourism \& Development, 2017. Citado na página 36.

MEDEIROS, M. d. L.; HORODYSKI, G. S.; PASSADOR, J. L. Food souvenirs in the perception of the tourist: the case of the artisanal minas serro cheese. Revista Brasileira de Pesquisa em Turismo, SciELO Brasil, v. 11, n. 2, p. 347-364, 2017. Citado 5 vezes nas páginas 33, 35, 80, 86 e 96.

MEIJUAN, L.; GUOHONG, C. A review on the research and application of dea [j]. Engineering Science, v. 6, p. 16, 2003. Citado na página 92.

MELEWAR, T.; SKINNER, H. Territorial brand management: Beer, authenticity, and sense of place. Journal of Business Research, Elsevier, 2018. Citado na página 28.

MELLO, J. C. de. Na trilha do inpi: registro de indicação geográfica (ig) e inovação no artesanato brasileiro. Ideias e Inovação-Lato Sensu, v. 2, n. 3, p. 11, 2015. Citado na página 31.

MELO, N. M. et al. Sebrae e empreendedorismo: origem e desenvolvimento. Universidade Federal de São Carlos, 2008. Citado na página 19.

MENAPACE, L.; MOSCHINI, G. C. Strength of protection for geographical indications: promotion incentives and welfare effects. American Journal of Agricultural Economics, Oxford University Press, v. 96, n. 4, p. 1030-1048, 2014. Citado 2 vezes nas páginas 61 e 91.

MENDONÇA, D.; PROCÓPIO, D. P.; CORRÊA, S. R. S. The contribution of geographical indications for brazilian rural development. Research, Society and Development, v. 8, n. 7, p. 41871152, 2019. Citado na página 31.

MENESES, J. N. C. Modos de fazer e a materialidade da cultura "imaterial": o caso do queijo artesanal de minas gerais. Patrimônio e Memória, v. 5, n. 2, p. 19-33, 2007. Citado na página 36.

MILÁN, M.; ARNALTE, E.; CAJA, G. Economic profitability and typology of ripollesa breed sheep farms in spain. Small Ruminant Research, Elsevier, v. 49, n. 1, p. 97-105, 2003. Citado 2 vezes nas páginas 76 e 77.

MILBRATH, L. W. Envisioning a sustainable society. In: New thinking for a new millennium. [S.1.]: Routledge, 2002. p. 199-211. Citado na página 23.

MINTEN, B.; REARDON, T. Food prices, quality, and quality's pricing in supermarkets versus traditional markets in developing countries. Review of Agricultural Economics, Oxford University Press, v. 30, n. 3, p. 480-490, 2008. Citado na página 100. 
MITCHAM, C. The concept of sustainable development: its origins and ambivalence. Technology in society, Elsevier, v. 17, n. 3, p. 311-326, 1995. Citado na página 23.

MITCHELL, S.; OSULLIVAN, M.; DUNNING, I. Pulp: a linear programming toolkit for python. The University of Auckland, Auckland, New Zealand, Citeseer, 2011. Citado 3 vezes nas páginas 65,80 e 96 .

MOIR, H. V. Geographical indications: Eu policy at home and abroad. In: IP Statistics for Decision Makers (IPSDM) conference Sydney, Australia. [S.l.: s.n.], 2016. p. 15-16. Citado 2 vezes nas páginas 61 e 91.

MOLDAN, B.; JANOUŠKOVÁ, S.; HÁK, T. How to understand and measure environmental sustainability: Indicators and targets. Ecological Indicators, Elsevier, v. 17, p. 4-13, 2012. Citado na página 37.

MORAN, W. Terroir-the human factor. Australian and New Zealand Wine Industry Journal, v. 16, n. 2, p. 32-51, 2001. Citado na página 29.

MORRIS, C.; EVANS, N. 'cheese makers are always women': Gendered representations of farm life in the agricultural press. Gender, Place and Culture: A Journal of Feminist Geography, Taylor \& Francis, v. 8, n. 4, p. 375-390, 2001. Citado na página 20.

MORRISON-SAUNDERS, A.; THERIVEL, R. Sustainability integration and assessment. Journal of Environmental Assessment Policy and Management, World Scientific, v. 8, n. 03, p. 281-298, 2006. Citado na página 27.

MOSCHINI, G.; MENAPACE, L.; PICK, D. Geographical indications and the competitive provision of quality in agricultural markets. American Journal of Agricultural Economics, Oxford University Press, v. 90, n. 3, p. 794-812, 2008. Citado 2 vezes nas páginas 20 e 92 .

MOTA, M. G. A experiência do território da serra da canastra: instituições, indicação geográfica e singularidades. Universidade Estadual Paulista (UNESP), 2017. Citado na página 37.

MOULARD, J.; BABIN, B. J.; GRIFFIN, M. How aspects of a wine's place affect consumers' authenticity perceptions and purchase intentions. International Journal of Wine Business Research, Emerald Group Publishing Limited, 2015. Citado na página 30 .

MURPHY, B. Communicating new definitions of terroir to a millennial audience through the medium of fourth space/der begriff terroir-kommunikation an die generation y mittels fourth-space-konzept. In: Kulinarischer Tourismus und Weintourismus. [S.l.]: Springer, 2017. p. 85-93. Citado na página 101.

NACEF, M. et al. Consumers' expectation and liking for cheese: Can familiarity effects resulting from regional differences be highlighted within a country? Food Quality and Preference, Elsevier, v. 72, p. 188-197, 2019. Citado na página 33.

NAKAYAMA, H.; ARAKAWA, M.; YUN, Y. B. Data envelopment analysis in multicriteria decision making. In: Multiple Criteria Optimization: State of the Art Annotated Bibliographic Surveys. [S.1.]: Springer, 2003. p. 333-368. Citado na página 64. 
NESS, B. et al. Categorising tools for sustainability assessment. Ecological economics, Elsevier, v. 60, n. 3, p. 498-508, 2007. Citado 2 vezes nas páginas 25 e 27.

NEUMANN, B. et al. Future coastal population growth and exposure to sea-level rise and coastal flooding-a global assessment. PloS one, Public Library of Science, v. 10, n. 3, p. e0118571, 2015. Citado na página 45.

NEWMAN, M. E. Coauthorship networks and patterns of scientific collaboration. Proceedings of the national academy of sciences, National Acad Sciences, v. 101, n. suppl 1, p. 5200-5205, 2004. Citado na página 46.

NGOKKUEN, C.; GROTE, U. Challenges and opportunities for protecting geographical indications in thailand. Asia-Pacific Development Journal, UN, v. 19, n. 2, p. 93-123, 2013. Citado 2 vezes nas páginas 61 e 91.

NIEDERLE, P. A.; GELAIN, J. Geographical indications in brazilian food markets: quality conventions, institutionalization, and path dependence. Journal of Rural Social Sciences, Southern Rural Sociology Association, v. 28, n. 1, p. 26, 2013. Citado 2 vezes nas páginas 31 e 35.

NILSSON, M.; DALKMANN, H. Decision making and strategic environmental assessment. Journal of Environmental Assessment Policy and Management, World Scientific, v. 3, n. 03, p. 305-327, 2001. Citado na página 26.

NKONYA, E.; SCHROEDER, T.; NORMAN, D. Factors affecting adoption of improved maize seed and fertiliser in northern tanzania. Journal of Agricultural Economics, Wiley Online Library, v. 48, n. 1-3, p. 1-12, 1997. Citado na página 62.

NOGUEIRA, M. C. L.; LUBACHEVSKY, G.; RANKIN, S. A. A study of the volatile composition of minas cheese. LWT-Food Science and Technology, Elsevier, v. 38, n. 5, p. 555-563, 2005. Citado na página 35.

NOTARNICOLA, B. et al. The role of life cycle assessment in supporting sustainable agri-food systems: A review of the challenges. Journal of Cleaner Production, Elsevier, v. 140, p. 399-409, 2017. Citado na página 37.

ODU, G.; CHARLES-OWABA, O. Review of multi-criteria optimization methods-theory and applications. IOSR Journal of Engineering (IOSRJEN), v. 3, n. 10, p. 1-14, 2013. Citado na página 20.

ODUM, H. T.; BROWN, M.; WILLIAMS, S. Handbook of emergy evaluation. Center for environmental policy, Gainesville, 2000. Citado na página 45.

ODUM, H. T.; ODUM, E. C. Energy basis for man and nature. McGraw-Hill Book Company, New York, 1976. Citado na página 45.

OGADA, M. J.; MWABU, G.; MUCHAI, D. Farm technology adoption in kenya: a simultaneous estimation of inorganic fertilizer and improved maize variety adoption decisions. Agricultural and food economics, SpringerOpen, v. 2, n. 1, p. 12, 2014. Citado na página 60.

OHE, Y.; KURIHARA, S. Evaluating the complementary relationship between local brand farm products and rural tourism: Evidence from japan. Tourism Management, Elsevier, v. 35, p. 278-283, 2013. Citado na página 28. 
OLDE, E. M. D. et al. Assessing sustainability at farm-level: Lessons learned from a comparison of tools in practice. Ecological Indicators, Elsevier, v. 66, p. 391-404, 2016. Citado na página 45.

O'ROURKE, D. The science of sustainable supply chains. Science, American Association for the Advancement of Science, v. 344, n. 6188, p. 1124-1127, 2014. Citado na página 27.

PACINI, C. et al. Ecological-economic modelling to support multi-objective policy making: a farming systems approach implemented for tuscany. Agriculture, Ecosystems 85 Environment, Elsevier, v. 102, n. 3, p. 349-364, 2004. Citado na página 93.

PALMIERI, N.; FORLEO, M. B.; SALIMEI, E. Environmental impacts of a dairy cheese chain including whey feeding: an italian case study. Journal of Cleaner Production, Elsevier, v. 140, p. 881-889, 2017. Citado na página 40.

PAPADATOS, A. et al. A nonlinear programming optimization model to maximize net revenue in cheese manufacture. Journal of dairy science, Elsevier, v. 85, n. 11, p. 2768-2785, 2002. Citado na página 40.

PARASECOLI, F. Knowing where it comes from: Labeling traditional foods to compete in a global market. [S.1.]: University of Iowa Press, 2017. Citado na página 31.

PARDOS, L.; RUBIO, M. M.; FANTOVA, E. The diversity of sheep production systems in aragón (spain): characterisation and typification of meat sheep farms. Spanish Journal of Agricultural Research, v. 6, n. 4, p. 497-507, 2008. Citado na página 61.

PARROTT, N.; WILSON, N.; MURDOCH, J. Spatializing quality: regional protection and the alternative geography of food. European Urban and Regional Studies, Sage Publications Sage CA: Thousand Oaks, CA, v. 9, n. 3, p. 241-261, 2002. Citado 2 vezes nas páginas 59 e 75 .

PEDREGOSA, F. et al. Scikit-learn: Machine learning in python. Journal of machine learning research, v. 12, n. Oct, p. 2825-2830, 2011. Citado 3 vezes nas páginas 65, 80 e 96.

PEREIRA, L. S. Water, agriculture and food: challenges and issues. Water Resources Management, Springer, v. 31, n. 10, p. 2985-2999, 2017. Citado na página 20.

PETERS, R. Economic aspects of cheese making as influenced by whey processing options. International Dairy Journal, Elsevier, v. 15, n. 6-9, p. 537-545, 2005. Citado na página 40.

PINTO, H. E. et al. Implicações do selo arte para a competitividade de negócios agroalimentares: o caso dos produtos alimentícios artesanais de origem animal. Research, Society and Development, v. 9, n. 8, p. e374985352-e374985352, 2020. Citado na página 33.

PINTO, J. C.; PAIXÃO, A. E. A. Indicação geográfica: um estudo sobre seus aspectos legais no brasil. Revista INGI-Indicação Geográfica e Inovação, v. 2, n. 2, p. 71-79, 2018. Citado na página 32. 
PITTELKOW, C. M. et al. Productivity limits and potentials of the principles of conservation agriculture. Nature, Nature Publishing Group, v. 517, n. 7534, p. 365, 2015. Citado 2 vezes nas páginas 77 e 92.

PIZZIGALlO, A.; GRANAI, C.; BORSA, S. The joint use of lca and emergy evaluation for the analysis of two italian wine farms. Journal of Environmental Management, Elsevier, v. 86, n. 2, p. 396-406, 2008. Citado na página 45.

POFF, N. L. et al. The ecological limits of hydrologic alteration (eloha): a new framework for developing regional environmental flow standards. Freshwater Biology, Wiley Online Library, v. 55, n. 1, p. 147-170, 2010. Citado na página 26.

POLLARD, C. M. et al. Geographic factors as determinants of food security: a western australian food pricing and quality study. Asia Pacific journal of clinical nutrition, HEC Press, v. 23, n. 4, p. 703, 2014. Citado na página 100.

POPE, J. et al. Reconceptualising sustainability assessment. Environmental impact assessment review, Elsevier, v. 62, p. 205-215, 2017. Citado na página 26.

PRAZERES, A. R.; CARVALHO, F.; RIVAS, J. Cheese whey management: A review. Journal of environmental management, Elsevier, v. 110, p. 48-68, 2012. Citado na página 39.

PRICE, D. d. S. A general theory of bibliometric and other cumulative advantage processes. Journal of the Association for Information Science and Technology, Wiley Online Library, v. 27, n. 5, p. 292-306, 1976. Citado na página 46.

PURVIS, B.; MAO, Y.; ROBINSON, D. Three pillars of sustainability: in search of conceptual origins. Sustainability Science, Springer, v. 14, n. 3, p. 681-695, 2019. Citado na página 23.

QUARRIE, J. Earth Summit'92. The United Nations Conference on Environment and Development, Rio de Janeiro 1992. [S.l.: s.n.], 1992. Citado na página 23.

QUIÑONES-RUIZ, X. F. et al. Why early collective action pays off: evidence from setting protected geographical indications. Renewable agriculture and food systems, Cambridge University Press, v. 32, n. 2, p. 179-192, 2017. Citado na página 60.

RAAN, A. F. V. Fatal attraction: Conceptual and methodological problems in the ranking of universities by bibliometric methods. Scientometrics, Springer, v. 62, n. 1, p. 133-143, 2005. Citado na página 46.

RAJABI-BAHAABADI, M. et al. Multi-objective path finding in stochastic timedependent road networks using non-dominated sorting genetic algorithm. Expert Systems with Applications, Elsevier, v. 42, n. 12, p. 5056-5064, 2015. Citado na página 94.

RALAMBONDRAINY, H. A conceptual version of the k-means algorithm. Pattern Recognition Letters, Elsevier, v. 16, n. 11, p. 1147-1157, 1995. Citado 2 vezes nas páginas 82 e 83.

RAMOS, B. D. et al. An overview of geographical indications in brazil. NISCAIR-CSIR, India, 2012. Citado 2 vezes nas páginas 19 e 30. 
RAPOSA, K. B. et al. Assessing tidal marsh resilience to sea-level rise at broad geographic scales with multi-metric indices. Biological Conservation, Elsevier, v. 204, p. 263-275, 2016. Citado 2 vezes nas páginas 59 e 75.

RAY, T. et al. Infeasibility driven evolutionary algorithm for constrained optimization. In: Constraint-handling in evolutionary optimization. [S.l.]: Springer, 2009. p. 145-165. Citado na página 95.

REED, R. et al. International comparison of sustainable rating tools. Journal of sustainable real estate, American Real Estate Society, v. 1, n. 1, p. 1-22, 2009. Citado na página 24.

RENKO, S. et al. Wine with geographical indication-awareness of croatian consumers. British food journal, Emerald Group Publishing Limited, 2011. Citado na página 102.

RIGHI, E. et al. Capturing farm diversity at regional level to up-scale farm level impact assessment of sustainable development options. Agriculture, ecosystems $\&$ environment, Elsevier, v. 142, n. 1-2, p. 63-74, 2011. Citado na página 76.

ROBÈRT, K.-H. et al. Strategic sustainable development - selection, design and synergies of applied tools. Journal of Cleaner production, Elsevier, v. 10, n. 3, p. 197-214, 2002. Citado na página 24.

ROBERT, K. W.; PARRIS, T. M.; LEISEROWITZ, A. A. What is sustainable development? goals, indicators, values, and practice. Environment: science and policy for sustainable development, Taylor \& Francis, v. 47, n. 3, p. 8-21, 2005. Citado na página 24 .

ROKKA, J.; CANNIFORD, R. Heterotopian selfies: how social media destabilizes brand assemblages. European Journal of Marketing, Emerald Group Publishing Limited, 2016. Citado na página 101.

ROMBACH, M.; RICCHIERI, F.; BITSCH, V. Food recovery and food redistribution in italy. In: International Symposium on Greener Cities for More Efficient Ecosystem Services in a Climate Changing World 1215. [S.l.: s.n.], 2017. p. 301-306. Citado na página 60.

ROSA, M. D. The role of geographical indication in supporting food safety: a not taken for granted nexus. Italian journal of food safety, PAGEPress, v. 4, n. 4, 2015. Citado na página 61.

ROUSSEEUW, P. J. Silhouettes: a graphical aid to the interpretation and validation of cluster analysis. Journal of computational and applied mathematics, North-Holland, v. 20, p. 53-65, 1987. Citado na página 82.

RUIZ, X. F. Q. et al. How are food geographical indications evolving?-an analysis of eu gi amendments. British Food Journal, Emerald Publishing Limited, 2018. Citado na página 30.

SACHS, J. D. From millennium development goals to sustainable development goals. The Lancet, Elsevier, v. 379, n. 9832, p. 2206-2211, 2012. Citado na página 23. 
SALA, S. et al. In quest of reducing the environmental impacts of food production and consumption. Journal of cleaner production, Elsevier, v. 140, p. 387-398, 2017. Citado na página 37.

SALADINI, F. et al. Guidelines for emergy evaluation of first, second and third generation biofuels. Renewable and Sustainable Energy Reviews, Elsevier, v. 66, p. 221-227, 2016. Citado 2 vezes nas páginas 27 e 45.

SANTOS, A. S.; VALENTE, L. R. R. de M.; MEDEIROS, M. F. T. Geographical indications (gis) as a tool to reach the socio-cultural development: A prospection of the brazilian territory. Revista GEINTEC-Gestão, Inovação e Tecnologias, v. 9, n. 1, p. 4769-4785, 2019. Citado na página 31.

SARTORI, S.; WITJES, S.; CAMPOS, L. M. Sustainability performance for brazilian electricity power industry: An assessment integrating social, economic and environmental issues. Energy Policy, Elsevier, v. 111, p. 41-51, 2017. Citado na página 26.

SCHMIT, T.; KAISER, H. Forecasting fluid milk and cheese demands for the next decade. Journal of dairy science, Elsevier, v. 89, n. 12, p. 4924-4936, 2006. Citado na página 91.

SCHRAGE, E. J.; EWING, A. P. The cocoa industry and child labour. Journal of Corporate Citizenship, JSTOR, n. 18, p. 99-112, 2005. Citado na página 20.

SCUDERI, A.; PECORINO, B. Protected designation of origin (pdo) and protected geographical indication (pgi) italian citrus productions. Acta Horticulturae, v. 1065, p. 1911-1917, 2015. Citado na página 101.

SELL, S. K. Industry strategies for intellectual property and trade: the quest for trips, and post-trips strategies. Cardozo J. Int'l \& Comp. L., HeinOnline, v. 10, p. 79, 2002. Citado na página 31.

SHARIFI, A.; MURAYAMA, A. A critical review of seven selected neighborhood sustainability assessment tools. Environmental impact assessment review, Elsevier, v. 38, p. 73-87, 2013. Citado na página 24.

SHIFERAW, B. et al. Adoption of improved wheat varieties and impacts on household food security in ethiopia. Food Policy, Elsevier, v. 44, p. 272-284, 2014. Citado na página 86.

SICHE, R. et al. Convergence of ecological footprint and emergy analysis as a sustainability indicator of countries: Peru as case study. Communications in Nonlinear Science and Numerical Simulation, Elsevier, v. 15, n. 10, p. 3182-3192, 2010. Citado na página 27.

SIDALI, K. L.; KASTENHOLZ, E.; BIANCHI, R. Food tourism, niche markets and products in rural tourism: combining the intimacy model and the experience economy as a rural development strategy. Journal of Sustainable Tourism, Taylor \& Francis, v. 23, n. 8-9, p. 1179-1197, 2015. Citado na página 27.

SILVA, L. C. S. et al. Geographical indications contributions for brazilian agribusiness development. African Journal of Agricultural Research, Academic Journals, v. 8, n. 18, p. 2080-2085, 2013. Citado 2 vezes nas páginas 30 e 31. 
SIMS, R. Food, place and authenticity: local food and the sustainable tourism experience. Journal of sustainable tourism, Taylor \& Francis, v. 17, n. 3, p. 321-336, 2009. Citado na página 27.

SINGH, A.; YADAV, A.; RANA, A. K-means with three different distance metrics. International Journal of Computer Applications, Citeseer, v. 67, n. 10, 2013. Citado na página 78.

SINGH, V.; MISRA, A. et al. Detection of unhealthy region of plant leaves using image processing and genetic algorithm. In: IEEE. 2015 International Conference on Advances in Computer Engineering and Applications. [S.l.], 2015. p. 1028-1032. Citado na página 93.

SMITHERS, G. W. Whey and whey proteins - from 'gutter-to-gold'. International Dairy Journal, Elsevier, v. 18, n. 7, p. 695-704, 2008. Citado na página 39.

SOINI, K.; BIRKELAND, I. Exploring the scientific discourse on cultural sustainability. Geoforum, Elsevier, v. 51, p. 213-223, 2014. Citado na página 23.

SOLANO, C. et al. Relationships between management intensity and structural and social variables in dairy and dual-purpose systems in santa cruz, bolivia. Agricultural systems, Elsevier, v. 65, n. 3, p. 159-177, 2000. Citado na página 38.

SOLTANI, A. et al. Multiple stakeholders in multi-criteria decision-making in the context of municipal solid waste management: a review. Waste Management, Elsevier, v. 35, p. 318-328, 2015. Citado na página 38.

SPANGENBERG, J. H. Sustainability science: a review, an analysis and some empirical lessons. Environmental Conservation, Cambridge University Press, v. 38, n. 3, p. 275-287, 2011. Citado na página 23.

SPIELMANN, N. Brand equity for origin-bounded brands. Journal of Brand Management, Springer, v. 21, n. 3, p. 189-201, 2014. Citado 3 vezes nas páginas 28, 29 e 30 .

SPIELMANN, N.; CHARTERS, S. The dimensions of authenticity in terroir products. International Journal of Wine Business Research, Emerald Group Publishing Limited, 2013. Citado 2 vezes nas páginas 29 e 30.

SPIELMANN, N.; MAGUIRE, J. S.; CHARTERS, S. Product patriotism: How consumption practices make and maintain national identity. Journal of Business Research, Elsevier, 2018. Citado na página 28.

SPIELMANN, N.; WILLIAMS, C. It goes with the territory: Communal leverage as a marketing resource. Journal of Business Research, Elsevier, v. 69, n. 12, p. 5636-5643, 2016. Citado na página 28.

STASI, A. et al. Italian wine demand and differentiation effect of geographical indications. International Journal of Wine Business Research, Emerald Group Publishing Limited, 2011. Citado 2 vezes nas páginas 59 e 75.

STERN, P. C.; DIETZ, T. Public participation in environmental assessment and decision making. [S.1.]: National Academies Press Washington, DC, 2008. Citado na página 26. 
SUBRAMANYAM, K. Bibliometric studies of research collaboration: A review. Information Scientist, Sage Publications Sage CA: Thousand Oaks, CA, v. 6, n. 1, p. 33-38, 1983. Citado na página 46.

SUH, J.; MACPHERSON, A. The impact of geographical indication on the revitalisation of a regional economy: a case study of 'boseong'green tea. Area, Wiley Online Library, v. 39, n. 4, p. 518-527, 2007. Citado 3 vezes nas páginas 59, 75 e 91.

SUN, J.; ZHANG, Q.; TSANG, E. P. De/eda: A new evolutionary algorithm for global optimization. Information Sciences, Elsevier, v. 169, n. 3-4, p. 249-262, 2005. Citado na página 92.

SUN, Z.-g. et al. Geographical indication of traditional specialty in chongqing city and analysis of its intangible cultural heritage [j]. Acta Agriculturae Jiangxi, v. 12, 2011. Citado na página 102.

TALLURI, S.; SARKIS, J. A model for performance monitoring of suppliers. International Journal of Production Research, Taylor \& Francis, v. 40, n. 16, p. 4257-4269, 2002. Citado na página 63.

TAVERNIER, E. M.; TOLOMEO, V. Farm typology and sustainable agriculture: does size matter? Journal of sustainable agriculture, Taylor \& Francis, v. 24, n. 2, p. 33-46, 2004. Citado 2 vezes nas páginas 76 e 78.

TEDDLIE, C.; YU, F. Mixed methods sampling: A typology with examples. Journal of mixed methods research, Sage publications, v. 1, n. 1, p. 77-100, 2007. Citado na página 37.

TENG, C.-Y.; LIN, Y.-R.; ADAMIC, L. A. Recipe recommendation using ingredient networks. In: ACM. Proceedings of the 3rd Annual ACM Web Science Conference. [S.l.], 2012. p. 298-307. Citado na página 46.

TREGEAR, A. et al. Regional foods and rural development: the role of product qualification. Journal of Rural studies, Elsevier, v. 23, n. 1, p. 12-22, 2007. Citado na página 27.

TREGEAR, A.; GIRAUD, G. et al. Geographical indications, consumers and citizens. Labels of origin for food: local development, global recognition, CABI Oxfordshire, p. 63-74, 2011. Citado na página 21.

TREGEAR, A.; KUZNESOF, S.; MOXEY, A. Policy initiatives for regional foods: some insights from consumer research. Food policy, Elsevier, v. 23, n. 5, p. 383-394, 1998. Citado 2 vezes nas páginas 35 e 38.

TRICHOPOULOU, A.; SOUKARA, S.; VASILOPOULOU, E. Traditional foods: a science and society perspective. Trends in Food Science 86 Technology, Elsevier, v. 18, n. 8, p. 420-427, 2007. Citado na página 27.

UHL, J. N.; BROWN, H. L. Consumer perception of experimental retail food price changes. The journal of consumer affairs, JSTOR, p. 174-185, 1971. Citado na página 100 . 
ULGIATI, S.; ODUM, H. T.; BASTIANONI, S. Emergy use, environmental loading and sustainability an emergy analysis of italy. Ecological modelling, Elsevier, v. 73, n. 3-4, p. 215-268, 1994. Citado na página 45.

ULLRICH, H. Trips: adequate protection, inadequate trade, adequate competition policy. Pac. Rim L. \& Pol'y J., HeinOnline, v. 4, p. 153, 1995. Citado na página 31.

VALENTE, T. W. Network models of the diffusion of innovations. Cresskill New Jersey Hampton Press 1995., 1995. Citado na página 46.

VALIDI, S.; BHATTACHARYA, A.; BYRNE, P. A case analysis of a sustainable food supply chain distribution system - a multi-objective approach. International Journal of Production Economics, Elsevier, v. 152, p. 71-87, 2014. Citado na página 93.

VANDECANDELAERE, E. et al. Geographical indication as a tool for sustainable food systems: importance of a territorial approach. Voluntary standards for sustainable food systems: challenges and opportunities. FAO, Rome, Italy, p. 93-104, 2013. Citado 2 vezes nas páginas 61 e 91 .

VANDECANDELAERE, E. et al. Strengthening sustainable food systems through geographical indications. [S.1.]: FAO, 2018. Citado 2 vezes nas páginas 61 e 92.

VATS, N. K. Geographical indication-the factors of rural development and strengthening economy. NISCAIR-CSIR, India, 2016. Citado 2 vezes nas páginas 40 e 61 .

VELDHUIZEN, D. A. V.; LAMONT, G. B. On measuring multiobjective evolutionary algorithm performance. In: IEEE. Proceedings of the 2000 Congress on Evolutionary Computation. CEC00 (Cat. No. 00TH8512). [S.l.], 2000. v. 1, p. 204-211. Citado na página 94.

VITA, G. D. et al. Agricultural Economics Review, v. 14, n. 389-2016-23498, p. 46-58, 2013. Citado na página 60.

WAGSTAFF, K. et al. Constrained k-means clustering with background knowledge. In: Icml. [S.l.: s.n.], 2001. v. 1, p. 577-584. Citado na página 78.

WALT, S. V. D.; COLBERT, S. C.; VAROQUAUX, G. The numpy array: a structure for efficient numerical computation. Computing in Science $\&$ Engineering, IEEE Computer Society, v. 13, n. 2, p. 22, 2011. Citado 3 vezes nas páginas 65, 80 e 96.

WANG, D. T.-C.; OCHOA, L. F.; HARRISON, G. P. Modified ga and data envelopment analysis for multistage distribution network expansion planning under uncertainty. IEEE Transactions on Power Systems, IEEE, v. 26, n. 2, p. 897-904, 2010. Citado na página 92.

WANG, X.; LI, D. A dynamic product quality evaluation based pricing model for perishable food supply chains. Omega, Elsevier, v. 40, n. 6, p. 906-917, 2012. Citado na página 100.

WEIDEMA, B. P. The integration of economic and social aspects in life cycle impact assessment. The International Journal of Life Cycle Assessment, Springer, v. 11, n. 1, p. 89-96, 2006. Citado na página 27. 
WHITING, K.; CARMONA, L. G.; SOUSA, T. A review of the use of exergy to evaluate the sustainability of fossil fuels and non-fuel mineral depletion. Renewable and Sustainable Energy Reviews, Elsevier, v. 76, p. 202-211, 2017. Citado na página 45.

WHITTAKER, G. et al. A hybrid genetic algorithm for multiobjective problems with activity analysis-based local search. European Journal of Operational Research, Elsevier, v. 193, n. 1, p. 195-203, 2009. Citado na página 92.

WILKINSON, J.; CERDAN, C.; DORIGON, C. Geographical indications and "origin" products in brazil-the interplay of institutions and networks. World Development, Elsevier, v. 98, p. 82-92, 2017. Citado 5 vezes nas páginas 19, 31, 32, 35 e 36.

WILSON, J. E. Terroir: The role of geology, climate and culture in the making of French wines. [S.l.]: Univ of California Press, 1998. Citado na página 29.

WOOD, H. W. The united nations world charter for nature: The developing nations' initiative to establish protections for the environment. Ecology Law Quarterly, JSTOR, v. 12, n. 4, p. 977-996, 1985. Citado na página 23.

WOODHOUSE, P.; HOWLETT, D.; RIGBY, D. A framework for research on sustainability indicators for agriculture and rural livelihoods. Centre for Agricultural Food and Resource Economics, University of Manchester, 2000. Citado na página 20.

XIAOBING, W.; KIREEVA, I. Protection of geographical indications in china: conflicts, causes and solutions. The Journal of World Intellectual Property, Wiley Online Library, v. 10, n. 2, p. 79-96, 2007. Citado 2 vezes nas páginas 19 e 91.

XU, T.; FLAPPER, J.; KRAMER, K. J. Characterization of energy use and performance of global cheese processing. Energy, Elsevier, v. 34, n. 11, p. 1993-2000, 2009. Citado na página 40.

XUE, F.; SANDERSON, A. C.; GRAVES, R. J. Pareto-based multi-objective differential evolution. In: IEEE. The 2003 Congress on Evolutionary Computation, 2003. CEC'03. [S.1.], 2003. v. 2, p. 862-869. Citado 2 vezes nas páginas 95 e 98.

YAMAGUCHI, C. K. et al. Geographical indication in the process of creating knowledge to develop new competences. African Journal of Business Management, Academic Journals, v. 9, n. 9, p. 412-424, 2015. Citado na página 31.

YIGITCANLAR, T.; DUR, F. Developing a sustainability assessment model: The sustainable infrastructure, land-use, environment and transport model. Sustainability, Molecular Diversity Preservation International, v. 2, n. 1, p. 321-340, 2010. Citado na página 39.

ZAMAGNI, A.; PESONEN, H.-L.; SWARR, T. From lca to life cycle sustainability assessment: concept, practice and future directions. The international journal of life cycle assessment, Springer, v. 18, n. 9, p. 1637-1641, 2013. Citado na página 26.

ZANDER, K.; STOLZ, H.; HAMM, U. Promising ethical arguments for product differentiation in the organic food sector. a mixed methods research approach. Appetite, Elsevier, v. 62, p. 133-142, 2013. Citado na página 28. 
ZHANG, R.; CHIONG, R. Solving the energy-efficient job shop scheduling problem: A multi-objective genetic algorithm with enhanced local search for minimizing the total weighted tardiness and total energy consumption. Journal of Cleaner Production, Elsevier, v. 112, p. 3361-3375, 2016. Citado 2 vezes nas páginas 93 e 94.

ZHANG, R.; TAO, J. A nonlinear fuzzy neural network modeling approach using an improved genetic algorithm. IEEE Transactions on Industrial Electronics, IEEE, v. 65, n. 7, p. 5882-5892, 2017. Citado na página 92.

ZHANG, Z.; WANG, X.; LU, J. Multi-objective immune genetic algorithm solving nonlinear interval-valued programming. Engineering Applications of Artificial Intelligence, Elsevier, v. 67, p. 235-245, 2018. Citado na página 92.

ZHENG, Y. et al. Multicomposition analysis and pattern recognition of chinese geographical indication product: vinegar. European Food Research and Technology, Springer, v. 238, n. 2, p. 337-344, 2014. Citado na página 60.

ZITZLER, E.; DEB, K.; THIELE, L. Comparison of multiobjective evolutionary algorithms: Empirical results. Evolutionary computation, MIT Press, v. 8, n. 2, p. 173-195, 2000. Citado na página 93.

ZITZLER, E.; LAUMANNS, M.; THIELE, L. Spea2: Improving the strength pareto evolutionary algorithm. TIK-report, Eidgenössische Technische Hochschule Zürich (ETH), Institut für Technische ..., v. 103, 2001. Citado na página 94. 